\title{
Variance Risk Premium Components and International Stock Return Predictability
}

Londono, Juan M. and Nancy R. Xu

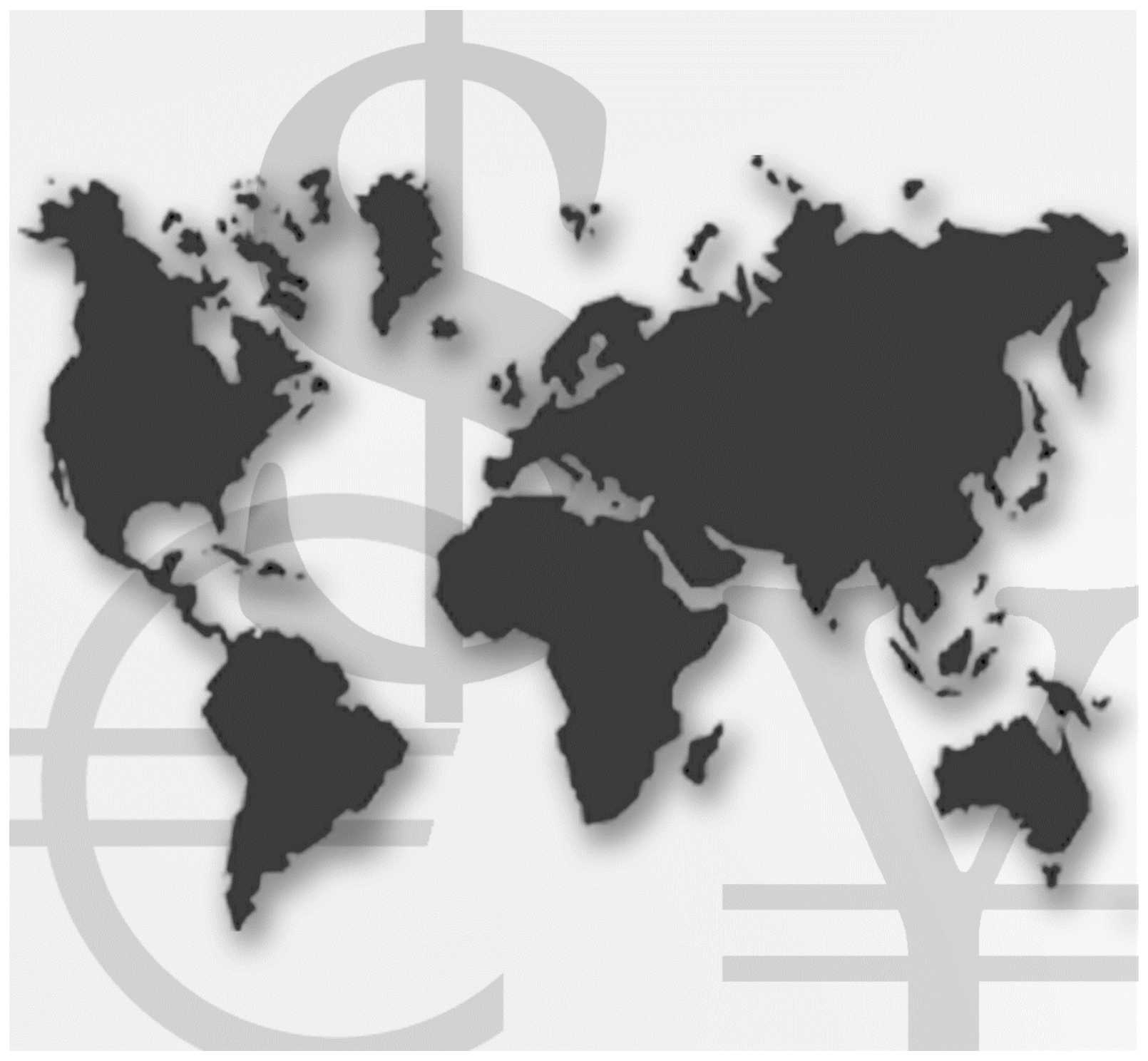

\section{International Finance Discussion Papers}

Board of Governors of the Federal Reserve System

Number 1247

April 2019 
Board of Governors of the Federal Reserve System

International Finance Discussion Papers

Number 1247

April 2019

\title{
Variance Risk Premium Components and International Stock Return Predictability
}

\author{
Juan M. Londono and Nancy R. Xu
}

Notes: International Finance Discussion Papers (IFDPs) are preliminary materials circulated to stimulate discussion and critical comment. References to IFDPs (other than an acknowledgment that the writer has had access to unpublished material) should be cleared with the author or authors. Recent IFDPs are available on the web at https://www.federalreserve.gov/econres/ifdp/. This paper can be downloaded without charge from the Social Science Research Network electronic library at https://www.ssrn.com. 


\title{
Variance Risk Premium Components and International Stock Return Predictability
}

\author{
Juan M. Londono ${ }^{\mathrm{a}}$ and Nancy R. Xu ${ }^{\mathrm{b}}$
}

\begin{abstract}
In this paper, we document and explain the distinct behaviors of U.S. downside and upside variance risk premiums (DVP and UVP, respectively) and their international stock return predictability patterns. DVP, the compensation for bearing downside variance risk, is positive, highly correlated with the total variance premium, and countercyclical, whereas UVP is, on average, borderline positive and procyclical with large negative spikes around episodes of market turmoil. We then provide robust evidence that decomposing VP into its downside and upside components significantly improves domestic and international stock return predictability. DVP is a robust predictor at four to six months and exhibits a hump-shaped pattern, whereas UVP performs the best at very short horizons. These stylized facts highlight the importance of acknowledging asymmetry in equity risk premiums. Hence, in the second part of the paper, we rationalize the economic sources of DVP and UVP in an international dynamic asset pricing model featuring asymmetric and time-varying risk aversion and economic uncertainty in a partially integrated world economy. We show that DVP is mostly driven by the upside movements of risk aversion, whereas UVP loads significantly and negatively on downside economic uncertainty. Moreover, we find that DVP (UVP) transmits to international markets mostly through financial integration (real economic integration).
\end{abstract}

Keywords: Variance risk premium, downside variance risk premium, international stock markets, asymmetric state variables, stock return predictability

JEL classifications: F36, G12, G13, G15

${ }^{a}$ Federal Reserve Board; ${ }^{b}$ Boston College, Carroll School of Management. We would like to thank Terry Pan (discussant) and seminar/conference participants at Boston College (Carroll), Boston Macro Juniors Workshop (MIT), 2018 Econometric Society European winter meeting, 2018 China International Risk Forum, and 2019 Midwest Finance Association annual meeting. This version is scheduled to be presented at the upcoming Eastern Finance Association annual meeting (Miami). First circulated version: November 17, 2018. All errors are our own. 


\section{Introduction}

Since the global financial crisis, there has been renewed interest in understanding how asset returns comove across countries. While the recent literature aims to document and rationalize various global risk variables (see, e.g., Miranda-Agrippino and Rey (2015) and $\mathrm{Xu}(2017 \mathrm{a})$ ), the present research focuses on their asymmetric aspect and highlights distinct asset pricing implications of their asymmetric components. In particular, the U.S. variance risk premium (henceforth $\mathrm{VP}$ ) is a suitable proxy of a global risk variable to study for the following reasons. VP captures the compensation demanded by investors for bearing variance risk in the U.S. stock market and, given the high-frequency nature of option prices, can be easily measured. Moreover, VP exhibits robust predictive power for domestic and international stock returns (see, e.g., Bollerslev, Tauchen, and Zhou (2009), Bekaert and Hoerova (2014), Bollerslev, Marrone, Xu, and Zhou (2014), and Londono (2015)), which suggests that VP is informative about equity risk premiums. Importantly, it is economically intuitive to decompose VP into its downside and upside components, which we refer to as "downside" and "upside" variance risk premiums (henceforth DVP and UVP). DVP and UVP capture asymmetric investors' attitudes toward variance risks emanating from the left and right tail of the return distribution, respectively. Yet, there is scanty research on the estimation, dynamics, and economic interpretation of the VP components (with a few notable exceptions like Kilic and Shaliastovich (2018) and Feunou, Jahan-Parvar, and Okou (2017)).

In this paper, we establish new stylized facts on the dynamics of DVP and UVP and document their international stock return predictability patterns. We then propose an international no-arbitrage dynamic asset pricing model with a closed-form solution to rationalize these facts. Together with our empirical estimates, our framework is able to identify plausible economic sources of DVP and UVP, and it allows us to infer information about the latent term structures of equity risk premium loadings on state variables and about the transmission of these U.S. risk variables to international stock markets.

To obtain the asymmetric components of U.S. VP, we first explore a wide range of alternative measures for DVP and UVP. The downside and upside components of the VP are estimated conditioning on whether the one-month-ahead stock price is below (bad states) or above (good states) the current stock price, respectively. In particular, we approximate the risk-neutral expectation of the downside (upside) stock return variance using puts (calls) on the S\&P 500 index at different strikes and maturities. We approximate the physical expectation of the downside (upside) stock return variation as the best in-sample forecast of the downside (upside) realized semivariance using various information sets. Semivariances are calculated using intradaily prices for the S\&P 500 index. Our sample spans from January 1990 to March 2018.

We document stylized facts of VP, DVP, and UVP from four aspects: magnitude, 
cyclicality, relativity, and persistence. We find that the total VP and its downside component are, on average, positive and significant. Moreover, VP and DVP are highly correlated and countercyclical, with large positive spikes around key episodes of market stress and economic turmoil. In contrast, UVP, although on average positive, is borderline significant and often negative. UVP exhibits a much more transitory and procyclical behavior with large negative spikes that coincide with some of the large positive DVP spikes. These different dynamics suggest that, during normal periods, investors dislike downside variance risk (fluctuations in variances due to the left tail of the return distribution) and disregard upside variance risk (fluctuations in variances due to the right tail of the return distribution); however, during episodes of economic turmoil, investors dislike downside variance risk more than in normal periods while revealing preferences for being exposed to upside variance risk.

We then test empirically whether acknowledging asymmetry in the VP improves its domestic and international stock return predictability. To assess model improvement, we consider both country-level and panel regression frameworks for the predictive power of VP and its components and control for other well-known return predictors. We calculate excess returns for 22 countries' headline stock indexes in U.S. dollars. We establish four new empirical facts. First, decomposing the VP into its downside and upside components results in higher predictability for domestic and international stock returns than using the total VP, with the improvements being the strongest at horizons of less than six months. Second, DVP and UVP exhibit different international return predictability patterns. The predictive power of DVP follows a hump-shaped pattern and is maximized at horizons between four and six months, while the predictive power of UVP follows a decreasing pattern. Third, the downside component of VP explains most of the predictability at mid-term horizons, whereas the upside component explains most of the predictability only at very short horizons (less than four months). Fourth, the individual and joint predictive power of DVP and UVP is additional to that of the U.S. dividend yield and term spread, especially for horizons of less than six months.

In the second part of the paper, we solve an international no-arbitrage dynamic asset pricing model and provide a unified framework to explain our empirical findings. The goals of the model are, first, to identify the economic determinants of the asymmetric VP components and, second, to infer latent information about equity risk premiums and understand the transmission of asymmetric risks to international stock markets. The model has two key features. On the one hand, the disturbance of U.S. risk premium state variables (economic uncertainty and risk aversion) is modeled with heteroskedastic and asymmetric gamma shocks, as in Bekaert, Engstrom, and Xu (2017). This modeling choice allows us to introduce realistic shock assumptions while generating a parsimonious affine-class model solution. On the other hand, the world economy is assumed to be partially integrated through common (U.S.) kernel and fundamental state variables with 
different integration coefficients across state variables and across countries. This modeling choice induces cross-country variation in the common predictors' predictability patterns, which sheds light on the transmission mechanism of U.S. predictors (DVP and UVP).

First, to provide economic interpretations for DVP and UVP, we design a General Methods of Moments (GMM) system to match model-implied and empirical VP components and estimate the loadings of the VP components on the U.S. economy's premium state variables. We find that DVP loads mostly on the upside movements in risk aversion, a price-of-risk state variable, which explains around $41 \%$ of the total variation in DVP; in comparison, only $7 \%$ of the variation in UVP is explained by this state variable. Through the lens of our model, a one standard deviation (SD) increase in risk aversion can increase DVP by $8.5 \sim 10$ (monthly percentage squared), with a higher increase corresponding to periods with larger realized economic growth fluctuations. DVP also appears to increase when upside economic uncertainty is expected to drop and/or downside economic uncertainty is expected to increase. In contrast, UVP is significantly more sensitive to economic uncertainty, an amount-of-risk state variable. The relation between UVP and economic uncertainty is highly nonlinear and depends on the observed current economic conditions. For instance, when the current economic growth fluctuation is at its historical average, a one SD increase in the downside economic uncertainty dampens UVP by around 2 (monthly percentage squared), while, when the current economic growth fluctuation is around its 99th percentile (like during the Lehman Brothers aftermath), a one SD increase in downside economic uncertainty is followed by a 29 (percentage squared) drop in UVP - a drop that is almost 8 times the sample's standard deviation of UVP (3.77).

Hence, confronting the empirical facts with our model suggests that, during normal periods, investors dislike variance, irrespective of whether it comes from left- or right-tail returns, which is consistent with conventional wisdom. When risk aversion increases, investors are willing to pay more to hedge against future downside variance risk, resulting in higher (more positive) DVP. In episodes where both risk aversion and, particularly, downside uncertainty are expected to increase, large positive DVP and negative UVP spikes are highly likely to co-occur. In our model, in these episodes, investors start differentiating downside from upside variance risk and thus price them differently. Investors then maintain or even increase their preference to hedge downside variance risk but would like to be paid to hold a hedging position against variance risk emanating from the right tail of the return distribution. During our sample period, such key episodes are the Asian Crisis in 1997, the Lehman Brothers aftermath in 2008, the European Debt Crisis in 2011, and during the third Greece bailout in 2015. However, it is noteworthy that large spikes in DVP can appear without being accompanied by negative UVP; these are typically periods where risk aversion increases while no major economic shocks are realized - e.g., $9 / 11$ in 2001 - which is consistent with our model. 
Second, we provide insights on the model-implied term structures of equity risk premium loadings on each state variable by matching model-implied and empirical estimates of domestic and international predictability patterns. We find that the hump-shaped predictability pattern of DVP is explained by the fact that international equity risk premiums load positively and significantly on the U.S. risk aversion state variable, with loadings peaking at four- to six-month horizons as well. The decreasing predictability pattern of UVP is explained by equity risk premium loadings on the U.S. downside economic uncertainty. Our model is suitable to study the transmission channels of U.S. risk variables to international stock markets by exploiting both the cross-horizon and cross-country predictability patterns. We find that international transmission channels are in line with the different economic interpretations of DVP and UVP. In particular, financial integration, proxied by each country's credit-to-GDP ratio, is more important in transmitting the pricing information carried by DVP, while real economic integration, proxied by each country's trade-to-GDP ratio, is a more important transmission channel of UVP.

The remainder of the paper is organized as follows. Section 2 reviews the relevant literature and discusses our main contributions. Section 3 constructs upside and downside VP components and examines their time series behaviors. Section 4 documents the distinct international stock return predictability patterns of U.S. DVP and UVP. Section 5 proposes and solves an international dynamic asset pricing model to rationalize our main empirical findings. Section 6 concludes.

\section{Related Literature and Contributions}

Our paper is related to the growing literature documenting the variance risk premium and its predictive power for asset returns. This literature initially focused on understanding the predictive power of U.S. VP for domestic stock returns. Bollerslev, Tauchen, and Zhou (2009) and Drechsler and Yaron (2010), among others, find empirical evidence that U.S. VP is a useful predictor of U.S. stock returns. Several papers have documented the predictive power of U.S. VP for other domestic assets' returns (see, for instance, Zhou (2010)). Interestingly, Londono and Zhou (2017) find evidence that U.S. VP also has predictive power for the appreciation rate of several currencies against the U.S. dollar. Other papers have explored the relation between VP and international equity risk premiums. For instance, Londono (2015) and Bollerslev, Marrone, Xu, and Zhou (2014) document that U.S. VP and a global average VP have predictive power for international stock returns (denominated in local currencies). The evidence on international stock return predictability might provide direct empirical suggestions on priced global risk premium determinants. While most international evidence is found using country-level variables, we focus on a perspective of a U.S. investor in both the theoretical and empirical parts of this paper. Our results can immediately be related to the use of the U.S. pricing kernel 
as a proxy for the world pricing kernel in some reduced-form international asset pricing models and, more generally, to the role of U.S. risk variables in influencing international financial markets.

In addition, the recent literature has highlighted potentially different compensations for bearing stock return variations associated with either positive or negative market returns. These different compensations reveal another form of asymmetry or non-linearity that can help explain the (joint) dynamics of higher-order asset moments. Kilic and Shaliastovich (2018), Held, Kapraun, Omachel, and Thimme (2018), and Feunou, JahanParvar, and Okou (2017) propose various ways to decompose the VP into its downside (negative returns or bad states) and upside (positive returns or good states) components. We contribute to this literature by examining a wide range of models to obtain the physical expectation of downside and upside variances and, thus, to calculate the VP under different market environments. Our contribution shows that considering different tail predictors improves the forecast of expected realized semivariances. We also provide new evidence that decomposing VP into its downside and upside components yields higher predictability for international stock returns than using the total VP. The international predictability of the VP components is, to the best of our knowledge, new to the literature.

Our paper also contributes to the recent literature on the economic interpretation of VP. While the literature has established fairly robust empirical evidence that VP should be informative about the dynamics of domestic and international risk premiums, there is little agreement on the economic interpretations of VP or its components. For instance, Bollerslev, Tauchen, and Zhou (2009) interpret VP in a general equilibrium model with recursive preferences and time-varying variance of variance of consumption (fundamental uncertainty). An international extension of this model is used in Londono (2015) and Bollerslev, Marrone, Xu, and Zhou (2014) to understand the predictive power of U.S. and global VP for international stock returns. A recent study by Bekaert, Engstrom, and $\mathrm{Xu}(2017)$ formally justifies the close relation between VP and risk aversion in a noarbitrage dynamic asset pricing model with time-varying risk aversion and uncertainty that consistently prices a wide range of domestic risky assets. Bekaert, Engstrom, and Xu (2017) establishes that risk aversion explains almost $90 \%$ of U.S. VP. In this paper, we expand this literature by rationalizing and potentially differentiating economic sources of the downside and upside VP components given relevant economic implications from a parsimonious (international) asset pricing model and the data. Beyond a domestic setting, we also contribute to this literature by providing a fundamental explanation for the transmission of global risk variables to country-specific equity risk premiums that is consistent with the economic interpretation of the VP components. 


\section{VP and Its Downside and Upside Components}

In this section, we explore measures of the upside and downside components of the variance risk premium. We first set the notation and define the total VP and its components, and then we introduce the data and compare the time series properties for the alternative VP measures.

\subsection{Definitions}

Following the notation in Bollerslev, Tauchen, and Zhou (2009), the total one-monthahead VP is defined as the difference between the risk-neutral $(Q)$ and the physical $(P)$ expectations of the total variance of one-month-ahead stock returns,

$$
V P_{t, t+1}=V_{t}^{Q}\left(r_{t+1}\right)-V_{t}^{P}\left(r_{t+1}\right)
$$

where $r_{t+1}$ denotes the stock return for the month - that is, between periods $t$ and $t+1$. We can decompose VP into its upside and downside components, which we label UVP and DVP, respectively. These components allow us to disentangle the compensations for bearing upside and downside variance risks. The general expression for the decomposition is as follows (see also Feunou, Jahan-Parvar, and Okou (2017), Kilic and Shaliastovich (2018), and Held, Kapraun, Omachel, and Thimme (2018)):

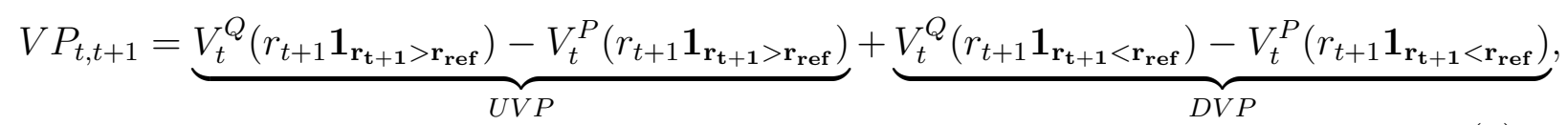

where $\mathbf{1}_{\mathbf{r}_{\mathbf{t}+\mathbf{1}}>\mathbf{r}_{\mathbf{r e f}}}\left(\mathbf{1}_{\mathbf{r}_{\mathbf{t}+\mathbf{1}}<\mathbf{r}_{\mathbf{r e f}}}\right)$ is a dummy that takes the value of 1 when the one-monthahead return is above (below) a reference level $r_{\text {ref }}$. Following the convention in the literature (see Feunou, Jahan-Parvar, and Okou (2017), Kilic and Shaliastovich (2018), and Baele, Driessen, Ebert, Londono, and Spalt (2018)), we define downside (upside) stock return variances conditional on the stock price at maturity being below (above) the current stock price $\left(r_{\text {ref }}=0\right)$.

To calculate the VP and its components, we estimate the risk-neutral and physical variables in Equation (2) separately. The risk-neutral variables can be extracted from option prices using what is usually known as the model-free methodology (see BrittenJones and Neuberger (2000)). Specifically, following Andersen and Bondarenko (2009), we approximate the risk-neutral components of UVP and DVP as the option-implied downside and upside variances, respectively, as follows:

$$
i v_{t, t+1}^{D}=\left(\int_{0}^{S_{t}} \frac{2\left(1+\log \left(S_{t} / K\right)\right.}{K^{2}} P(t+1, K) d K\right)^{2}
$$




$$
i v_{t, t+1}^{U}=\left(\int_{S_{t}}^{\infty} \frac{2\left(1-\log \left(K / S_{t}\right)\right.}{K^{2}} C(t+1, K) d K\right)^{2},
$$

where $S_{t}$ is the current stock index price and $P(K)(C(K))$ is the price of a put (call) with strike $K$ and a one-month maturity. Intuitively, the option-implied downside (upside) variance is identified by put (call) options that pay off when returns are negative (positive).

We approximate the physical components of UVP and DVP in Equation (2) as the expected value of one-month-ahead upside and downside realized semivariances, respectively. We calculate these realized semivariances following Barndorff-Nielsen, Kinnebrock, and Shephard (2010) as follows:

$$
\begin{aligned}
& r v_{t+1}^{D}=\sum_{\tau=1}^{N} r_{\tau}^{2} \mathbf{1}_{\mathbf{r}_{\tau}<\mathbf{0}}, \\
& r v_{t+1}^{U}=\sum_{\tau=1}^{N} r_{\tau}^{2} \mathbf{1}_{\mathbf{r}_{\tau}>\mathbf{0}},
\end{aligned}
$$

where $r_{\tau}$ represents the instantaneous return, which is calculated using stock prices sampled at high frequencies (every 5 or 15 minutes), and $N$ is the total number of highfrequency return observations within the month. We estimate the expected value of semivariances using the following linear regression setting:

$$
E_{t}\left(r v_{t+1}^{i}\right)=\hat{\alpha}^{i}+\hat{\gamma}^{\mathbf{i}} \mathbf{X}_{\mathbf{t}}^{\mathbf{i}}
$$

where $i=D$ (downside) or $U$ (upside), and $\mathbf{X}_{\mathbf{t}}^{\mathbf{i}}$ is a chosen set of predictors available at time $t$. In Section 3.2 , we explore alternative specifications for one-month-ahead expected realized semivariances to determine our benchmark DVP and UVP measures.

\subsection{VP measures}

To calculate the downside and upside components of U.S. VP, we use daily prices for options on the S\&P 500 index at different strikes and maturities and intradaily prices for the index for a sample between January 1990 and March 2018. Option prices are obtained from OptionMetrics and intradaily S\&P 500 prices (i.e., prices sampled every 15 minutes) are obtained from TICKDATA.

\subsubsection{Option-implied variances}

Figure 11 shows the time series for the option-implied variance and its upside and downside components. The dynamics of option-implied variances confirm the stylized facts documented in the existing literature (see Kilic and Shaliastovich (2018)). In par- 
ticular, the downside implied variance accounts for a larger portion of the total optionimplied variance than its upside component $\left(i v_{t}^{D} / i v_{t}=68.7 \%\right.$ on average). Overall, the total implied variance and its components are highly correlated (correlation coefficients of 0.96 and 0.99 for the upside and downside implied variance, respectively), and tend to spike around crises, including the Long-Term Capital Management fund crisis in the late 1990s, the corporate scandals in the early 2000s, the collapse of Lehman Brothers during the global financial crisis, and around key episodes related to the euro-area crisis. However, our more recent sample shows a few episodes in which total implied variance spikes are mostly driven by its downside component, such as the Chinese stock market turbulence in the second half of 2015 and the episode of increasing global trade tensions, interest rate hikes, and inflationary pressures in early 2018.

\subsubsection{Physical variances}

While the literature has thoroughly explored and compared various models for predicting the total realized variance (see, e.g., Bekaert and Hoerova (2014) for a thorough discussion), there is limited research on predicting the downside and upside realized semivariances, which is at the core of the present research.

In Table 1, we explore various specifications for the one-month-ahead expected realized semivariances using the regression framework in Equation (5). We examine seven different specifications. The specification in column (1) assumes that realized semivariances follow a Martingale process, as in the total VP measure in Bollerslev, Tauchen, and Zhou (2009) and the VP components in Kilic and Shaliastovich (2018); that is,

$$
E_{t}\left(r v_{t+1}^{i}\right)=r v_{t}^{i}
$$

In columns (2) to (7), we consider a wide set of predictors to forecast one-month ahead realized semivariances, including realized variance and semivariances calculated at various horizons and option-implied variances.

As can be seen in column (2) of Table 1, simple AR(1) forecasts of downside and upside realized semivariances yield considerable gains in adjusted $R^{2} \mathrm{~s}$ with respect to the Martingale specification in column (1) (0.38 versus 0.27 and 0.46 versus 0.31 for downside and upside semivariance, respectively). The predictability of the model does not improve further once we include the total variance to the $\mathrm{AR}(1)$ specification (column (3)). Moreover, the specification in column (3) is subject to multicolinearity given the high correlation between the total realized variance and semivariances, especially the downside semivariance.

A heterogeneous autoregressive (HAR) framework of realized semivariances (column (4)), using measures of realized semivariances calculated over the last five days (or weekly, $r v_{t-5 d, t}^{i}$ ) and the last day (or daily, $r v_{t-1 d, t}^{i}$ ) of each month, improves the BIC for both 
downside and upside semivariances but not adjusted $R^{2} \mathrm{~s}$. In particular, for the downside semivariance, realized semivariances calculated over the last week or day of the month are significant and positive predictors, and their predictability is additional to that of the realized downside semivariance calculated over the entire month. For the upside semivariance, only the semivariance calculated over the last day turns out to be a significant predictor. We allow only for downside (upside) realized semivariances to predict onemonth-ahead downside (upside) realized variances because the estimation results for the model in column (2) show that semivariances are more useful for predicting semivariance than the total realized variance. This finding provides suggestive evidence that asymmetry in the physical variances might be due to different tail-specific information that evolves at different frequencies (daily, weekly, and monthly). This HAR framework for realized semivariances extends Corsi (2009), which focuses on the total realized variance forecasting $]^{1}$

According to column (5), option-implied downside and upside variances are informative of their respective one-month-ahead semivariances. BIC for specification (6) drops with respect to that for specification (5) for both upside and downside realized semivariance. However, most predictor variables in this specification become (borderline) insignificant, which is, in part, because of the high correlation among the predictors, especially between the option-implied total variance and the option-implied downside variance $($ correlation $=0.91) .^{2}$

We also add the total option-implied variance as a predictor to check whether upside (downside) implied variance might inform next month's downside (upside) realized semivariances; intuitively, when investors expect more volatility in the market, they can buy both call and put options (e.g., long straddle). According to column (7), we find that the total option-implied variance improves the downside realized semivariance model, but not the upside realized semivariance model. Hereafter, we select model (7) as the chosen model for obtaining daily estimates of the expectation of the downside physical variance and model (6) for obtaining daily estimates of the expectation of upside physical variance. We use their end-of-month values as monthly measures for the physical variables in Equation (2) in the remainder of the paper. Our paper is, to the best of our knowledge, the first one to document that the set of predictors of the total realized variance and its

\footnotetext{
1 Feunou, Jahan-Parvar, and Okou (2017) also consider the HAR framework to approximate the expectation of downside and upside semivariances. However, they do not report the coefficients associated with the HAR components or the fit of the model, and they conclude that the results for the HAR specification are qualitatively similar to those for the Martingale specification. We explore a wider range of models.

${ }^{2}$ We are able to replicate the predictability patterns of the option-implied variance and HAR realized variances for the total realized variance in Bekaert and Hoerova (2014). Bekaert and Hoerova (2014) use a HAR framework combined with option-implied variances when predicting realized stock return variances and show that their model dominates the original Corsi HAR framework; however, neither Corsi (2009) nor Bekaert and Hoerova (2014) disentangle upside and downside realized variances as we do here.
} 
upside and downside semivariances can be different from each other.

\subsubsection{Stylized facts of VP components}

In Table 2, we report summary statistics for the estimates of option-implied and expected upside and downside variances $\left(i v_{t, t+1}^{i}\right.$ and $E_{t}\left(r v_{t+1}^{i}\right)$, where $\left.i \in\{D, U\}\right)$ across the seven realized semivariance models as shown in Table 1. The chosen models are indicated in bold. We also report summary statistics for the difference between optionimplied and expected variance, which corresponds to our estimate of the upside and downside variance risk premiums $\left(v p_{t, t+1}^{i}\right)$. Figure 2 depicts the time variation in the selected measures of DVP and UVP.

We discuss several stylized facts for the components of the VP. First, on the magnitudes, for all downside VP measures, the option-implied downside variance is, on average, higher than the expected downside realized variance, yielding a positive DVP with an average of 13.63 squared percent in the chosen model. It is noteworthy that the average DVP varies little across measures, which indicates consistency in its measurement. Moreover, average DVP is significant and positive at any standard confidence level. The positive nature of our DVP measures is in line with the findings in Kilic and Shaliastovich (2018), Feunou, Jahan-Parvar, and Okou (2017), and Held, Kapraun, Omachel, and Thimme (2018). DVP is more prone to large positive spikes than to negative spikes and reaches a maximum of up to 101.10 squared percent in our sample for the chosen model. Although the option-implied upside variance is also, on average, higher than any of the expected realized upside variances, averages of UVPs are considerably smaller than those of DVPs across the various models, ranging from 0.51 for specification (3) to 0.64 for specification (6). Average UVP is significantly positive at the $5 \%$ significance level for the chosen model in column (6) ${ }^{3}$ In contrast to DVP, UVP is more prone to large negative spikes; it reaches a level as low as -40.84 squared percent, which is almost 13 times its standard deviation, according to the UVP estimates from the chosen model (6).

Hence, our results show different assessments about the nature of UVP with respect to the existing literature. In particular, the positive nature of our UVP measure stands somewhat in contrast to the results in Kilic and Shaliastovich (2018) and Feunou, JahanParvar, and Okou (2017), who find that UVP is, on average, negative and significant. However, in line with these papers, average UVP exhibits a borderline magnitude compared with the significantly positive average DVP and can have large negative values. Our findings for the dynamics of UVP can be interpreted as follows. Investors dislike or disregard the risk emanating from the upside tail volatility during most periods but reveal preferences for being exposed to upside variance risk during certain episodes.

\footnotetext{
${ }^{3}$ Average UVP is significantly positive at the $5 \%$ significance level for models $(5)-(7)$ but borderline significant at the $10 \%$ significance level for models (1) and (4).
} 
The second stylized fact is about the relative importance of DVP and UVP in explaining the total VP (which is constructed as the sum of the selected DVP and UVP estimates). We find that DVP comoves closer to the total VP than UVP, as observed in Figure 2. Panel A of Table 3 confirms this fact by showing that the correlation between VP and DVP in the chosen model is 0.954 Therefore, our evidence suggests that most of the total variance risk premium is actually compensation for downside variance risk.

Third, we find that DVP is countercyclical, whereas UVP is weakly procyclical. Statistically, DVP is positively correlated with the monthly NBER recession indicator (correlation $=0.423, \mathrm{p}$-value $=0.000)$ and negatively correlated with monthly U.S. industrial production growth (correlation $=-0.118$, p-value $=0.033$ ) ; both correlation statistics render a countercyclical DVP. In contrast, UVP is insignificantly correlated with the monthly NBER indicator but weakly correlated with growth (correlation $=0.101$, pvalue $=0.069)$, suggesting a procyclical process. According to Figure 2, DVP is almost always positive and displays large (positive) spikes around crises, as previously documented in the literature for U.S. total VP (see, e.g., Bollerslev, Gibson, and Zhou (2011), Corradi, Distaso, and Mele (2013), and Bekaert and Hoerova (2014)). In contrast, UVP is often negative. In particular, UVP displays large negative spikes that tend to coincide with the positive DVP spikes - for instance, around the Asian crisis in 1997, after the collapse of Lehman Brothers, and during the Greek bailout. Thus, our preliminary evidence rejects constant hedging demands. Episodes of market or economic turmoil tend to trigger increasing demands in hedging against downside risk, as illustrated by the positive spikes in DVP, and an increase in the desire to be exposed to upside risk, as suggested by the negative UVP spikes. However, it is noteworthy that DVP and UVP do not always decouple during episodes of extreme large DVP spikes, for example during the escalated inflationary fears in early 2018.

Finally, a fourth stylized fact is that UVP is much more transitory than DVP. At the monthly frequency, the AR(1) coefficient of our DVP measure is 0.78 , whereas that of our UVP measure is only 0.22 . Our DVP and UVP measures are statistically uncorrelated, as suggested by the evidence in Table 3. Hence, it is plausible that our measures of VP components capture different aspects of the total VP, and we interpret them as compensations for bearing variance risks emanating from different tails of the market return distribution.

\footnotetext{
${ }^{4}$ Panels B and $\mathrm{C}$ of Table 3 show correlations across alternative DVP and UVP measures, respectively. Both the DVP and UVP measures are highly correlated, with correlations ranging from 0.74 to 0.99 for DVP and from 0.74 to 0.99 for UVP. Correlations across measures are, on average, lower for model (1), the measure that assumes a random walk for expected semivariances.
} 


\section{VP Components and International Stock Return Predictability}

In this section, we establish distinct international stock return predictability patterns of UVP and DVP. We study a balanced sample of 22 countries covering North America, Asia, and Europe for a sample period from April 1991 to March 2018 ( $\mathrm{T}=324$ months). We construct log monthly country stock returns using the total return index of the country's stock market index including dividends (source: DataStream). Stock returns are denominated in U.S. dollars (USD), and excess returns are calculated by subtracting the zero-coupon yield of U.S. Treasury bonds (source: Federal Reserve Board).

\subsection{Empirical framework}

The country-level predictability regression has the following general framework, where the predictive horizon " $h$ " is in units of months:

$$
h^{-1} r_{i, t, t+h}=a_{i, h}+b_{i, h, D} v p_{t, t+1}^{D}+b_{i, h, U} v p_{t, t+1}^{U}+\boldsymbol{c}_{\boldsymbol{i}, \boldsymbol{h}} \boldsymbol{Z}_{\boldsymbol{t}}+\epsilon_{i, t+h},
$$

where $r_{i, t, t+h}$ denotes the $h$-month-ahead log excess returns for country $i, v p_{t, t+1}^{D}\left(v p_{t, t+1}^{U}\right)$ is the estimate of the downside (upside) variance risk premium (see Section 3.2), and $\boldsymbol{Z}_{\boldsymbol{t}}$ includes excess return predictors established in the literature; specifically, in this paper, we consider the term spread and the dividend yield as the control variables. The pooled version of our regression framework is as follows:

$$
h^{-1} r_{i, t, t+h}=a_{h}+b_{h, D} v p_{t, t+1}^{D}+b_{h, U} v p_{t, t+1}^{U}+c_{\boldsymbol{h}} \boldsymbol{Z}_{\boldsymbol{t}}+\epsilon_{i, t+h} .
$$

In total, we analyze four models. Model (1) is a bivariate predictive regression with DVP and UVP estimated at the country level $\left(\boldsymbol{c}_{\boldsymbol{i}, \boldsymbol{h}}=0\right)$, and model (2) is the pooled version of model (1). In models (3) and (4), we examine the predictability of DVP and UVP after controlling for the term spread and the dividend yield at the country and pooled levels, respectively.

\subsection{Results}

We first explore a null model, which is a univariate predictive model with the total $\mathrm{VP}$ as the predictor. The null model is then a restricted version of the models introduced in Section 4.1 under the restriction that DVP and UVP have exactly the same predictive coefficients and, therefore, the same predictability patterns. Table 4 reports the predictive coefficients of the total VP for all countries in our sample at the $1-, 3-, 6-$, and $12-$ month horizons, and the full-horizon predictability pattern is shown in Figure 3 . Our 
results for the U.S. are consistent with those in the domestic return predictability literature (see, e.g., Bollerslev, Tauchen, and Zhou (2009) and Drechsler and Yaron (2010)). In particular, U.S. VP has a hump-shaped domestic predictability pattern with its highest predictive power at the six-month horizon $\left(R^{2}=2.6 \%\right)$. We also provide evidence that this hump-shaped U.S. VP predictability pattern holds for almost all countries in our country sample with small variations across countries, which is similar to recent evidence in Bollerslev, Marrone, Xu, and Zhou (2014). U.S. VP is a significant and positive predictor of stock returns for all countries in our sample with the exception of Belgium, the Netherlands, Ireland, Portugal, and Switzerland. For Switzerland, the coefficient associated with VP is negative and significant at the one-month horizon. Our results are not immediately comparable to those in Bollerslev, Marrone, Xu, and Zhou (2014), who document a positive and borderline significant coefficient associated with VP for all countries in their sample, including Switzerland. This difference arises mainly because their country-level evidence uses country-specific VPs and returns both denominated in local currencies, whereas we consider the international stock return predictability of a U.S. predictor (i.e., VP) from the perspective of a U.S. investor. Together with their results, our findings suggest that changes in U.S. VP might also predict changes in exchange rates, as documented by Londono and Zhou (2017). Exploring the effect of VP and its components for exchange rates is, however, not the focus of our paper.

We then test whether DVP and UVP exhibit the same international predictability patterns as implicitly assumed by the null model. In Table 5, we compare the bivariate predictive regression (model (1)) against the null model using the AIC, the BIC, and the adjusted $R^{2}$. Irrespective of the fit measure considered, model (1), which allows for different DVP and UVP predictive coefficients, significantly outperforms the null model for all countries and all horizons considered. The outperformance of a model in which the components of VP are considered separately is one of the core empirical results of this paper.

Figures 4 and 5 show the estimates of the predictive coefficients associated with DVP and UVP, respectively. At the country level, the salient hump-shaped pattern of the predictive coefficients of DVP (see Figure 4) is similar to that of the predictive coefficients of the total VP (see Figure 3). However, as shown in Figure 5, the estimated coefficients of UVP peak at the one-month horizon, a finding that, to the best of our knowledge, is new to the literature. Our findings then suggest that the two asymmetric components of VP might capture different economic and pricing information.

In Figure 6, we conduct a variance decomposition analysis for the bivariate framework (model (1)). The blue region depicts the portion of the total $R^{2}$ that is explained by DVP, leaving the white region to be the part explained by UVP. Between DVP and UVP, DVP contributes more to total $R^{2} \mathrm{~s}$, as the blue region typically becomes wider at most horizons greater than one month, whereas UVP appears to be more important 
at very short horizons for the majority of countries. In the case of U.S. stock returns, DVP contributes to the mid- and long-horizon predictability, while UVP contributes more to the one- to six-month predictive horizons. Interestingly, while the $R^{2}$ of the null model reaches its peak typically at the six-month horizon for almost all countries, the performance of model (1) has a bimodal pattern. Therefore, our evidence so far suggests that decomposing VP into its downside and upside components introduces more flexibility in capturing short- and mid-horizon predictability patterns, where the improvement at the very short horizon is due to UVP and at longer horizons due to DVP.

To better summarize the country-level information, we estimate a pooled bivariate predictive model (model (2)). Table 6 presents the main results that are consistent with the country-level results. Specifically, the coefficient associated with DVP follows a humpshaped pattern and has the largest coefficient at the six-month horizon $\left(0.2676^{* * *}\right)$, while the coefficient associated with UVP follows a decreasing pattern. Moreover, the variance decomposition analysis confirms that UVP is a dominant predictor relative to DVP only for horizons of less than six months.

We now assess whether the predictive power of UVP and DVP is additional to that of some traditional stock return predictors. In model (3) as reported in Table 7, we include the U.S. term spread and the dividend yield to the bivariate predictive model (model (1)). Figures 7 and 8 compare the predictive coefficient estimates of DVP and UVP in model (3) with those obtained in model (1). The predictability patterns of both DVP and UVP remain statistically indifferent, which indicates their potentially unique contributions in model (3). According to Figure 9, adding those traditional predictors increases the adjusted $R^{2}$ for all countries in our sample, especially for long horizons. As can be seen from the green region in the figure, which denotes the part that is explained by the VP components, their contributions typically concentrate at shorter horizons. We document a robust international stock return predictability of the U.S. dividend yield at long horizons across all countries, which is consistent with the existing literature (see, e.g. Fama and French (1988) and Golez and Koudijs (2018)). Furthermore, Figure 10 shows the variance decomposition for the four variables in model (3). We find that, for most countries, while UVP accounts for most of the explained variance at very short horizons, DVP plays a more important role at medium-term horizons.

Finally, we estimate the pooled multivariate predictive model, model (4), to aggregate findings at the global level, and we find consistent results. In particular, according to Table 8, UVP (DVP) exhibits the leading variance decomposition share at very short (medium) horizons, while the dividend yield is a long-horizon predictor. We also test model (4) against model (2), which is a nested model, and are able to reject the null hypothesis that they are equal. 


\section{Economic Interpretations}

In this section, we propose an international dynamic no-arbitrage asset pricing model to rationalize the economic sources of the asymmetric components of U.S. VP and how these components relate to international equity risk premiums. The model realistically features asymmetries in U.S. premium state variables related to risk aversion and fundamental/economic uncertainty. We confront the model solution with the stylized facts established in Section 3 on the distinct behaviors of DVP and UVP to identify the different economic sources of the two VP components. We also infer information about the term structure of international equity risk premium loadings on the model's state variables to understand the international stock return predictability patterns established in Section 4, and we provide an explanation for the international integration channels driving the transmission of the risk factors carried by DVP and UVP across countries.

We introduce the model in Section 5.1 and provide the model's implications to understand the distinct time-series behaviors and predictability patterns of DVP and UVP in Section 5.2. Section 5.3 presents the empirical strategies and discusses the main estimation results.

\subsection{The model}

Given our focus on documenting non-linear VP and equity risk premium properties, our theoretical model builds on two key ingredients to induce asymmetries in the dynamics of international asset prices. On the one hand, we allow for asymmetric, non-Gaussian, and heteroskedastic state variable shocks. On the other hand, we consider a partially integrated global economy in which countries have different exposures to different tail events (upside and downside) in U.S. state variables.

\subsubsection{Asymmetries in U.S. preferences and fundamentals}

Assume that the representative U.S. investor has a period utility function over consumption $C_{t}$ and a reference level $Q_{t}$ in the type of HARA class,

$$
U\left(C_{t}\right)=\frac{\left(C_{t} / Q_{t}\right)^{1-\gamma}}{1-\gamma},
$$

where $Q_{t}$ drives the time variation in the relative risk aversion, $R R A_{t}$,

$$
R R A_{t}=-\frac{C_{t} U^{\prime \prime}\left(C_{t}\right)}{U^{\prime}\left(C_{t}\right)}=\gamma Q_{t}
$$

and $\gamma$ is the utility kernel parameter. Note that $Q_{t}$ is $\frac{C_{t}}{C_{t}-H_{t}}$ in Campbell and Cochrane (1999), where $H_{t}$ is the external habit level. The logarithm of the stochastic discount 
factor $(\mathrm{SDF})$ can be derived as follows:

$$
m_{t+1}=\ln (\beta)+\ln \left[\frac{U^{\prime}\left(C_{t+1}\right)}{U^{\prime}\left(C_{t}\right)}\right]=\ln (\beta)-\gamma \Delta c_{t+1}+\gamma \Delta q_{t+1},
$$

where $\beta$ is a constant time preference parameter, $\Delta c_{t+1} \equiv \ln \left[C_{t+1} / C_{t}\right]$ is the log change in consumption growth, and $\Delta q_{t+1}$ captures the log change in the relative risk aversion.

We define stochastic processes for the two key kernel state variables: $C_{t}$, which captures the real and fundamental source of kernel shocks, and $Q_{t}$, the non-fundamental source. The log consumption growth has the following process:

$$
\Delta c_{t+1}=c_{0}+\rho_{c p} c p_{t}+\rho_{c n} c n_{t}+\delta_{c p} \omega_{c p, t+1}-\delta_{c n} \omega_{c n, t+1}
$$

where the conditional mean is sensitive to the expected economic upside and downside uncertainties, $c p_{t}$ and $c n_{t}$, respectively. Following Bekaert and Engstrom (2017) and Xu (2017a), the disturbance of the log consumption growth is decomposed into the following two independent centered gamma shocks:

$$
\begin{aligned}
& \omega_{c n, t+1}=\Gamma\left(c n_{t}, 1\right)-c n_{t} \\
& \omega_{c p, t+1}=\Gamma\left(c p_{t}, 1\right)-c p_{t} .
\end{aligned}
$$

$\omega_{c n, t+1}$, the real downside shock, governs the left-tail dynamics of the growth distribution, while $\omega_{c p, t+1}$, the upside shock, governs the right-tail dynamics. State variables $c n_{t}$ and $c p_{t}$ are shape parameters of the gamma shocks that determine all higher moments of the total innovation. For example, given the moment generating function (MGF) of independent gamma shocks, the conditional variance of $\Delta c_{t+1}$ is $V_{t}\left(\Delta c_{t+1}\right)=\delta_{c p}^{2} c p_{t}+\delta_{c n}^{2} c n_{t}$ and the conditional unscaled skewness is $S k_{t}\left(\Delta c_{t+1}\right)=2 \delta_{c p}^{3} c p_{t}-2 \delta_{c n}^{3} c n_{t}$. The dynamics of the downside and upside real uncertainties follow parsimonious $\mathrm{AR}(1)$ processes:

$$
\begin{aligned}
& c n_{t+1}=c n_{0}+\rho_{c n c n} c n_{t}+\delta_{c n c n} \omega_{c n, t+1} \\
& c p_{t+1}=c p_{0}+\rho_{c p c p} c p_{t}+\delta_{c p c p} \omega_{c p, t+1}
\end{aligned}
$$

Given the dynamic process specifications, $c n_{t}$ can be interpreted as the "bad" volatility, as left-tail real economic shock realizations $\left(\omega_{c n, t}>0\right)$ increase downside uncertainty $c n_{t}$ (assuming $\delta_{c n c n}$ is strictly positive), which implies a higher chance of obtaining low economic growth in the future. In contrast, $c p_{t}$ can be interpreted as the "good" volatility because a higher $c p_{t}$ indicates a higher chance of obtaining large growth in the future.

The risk aversion state variable $q_{t}=\ln \left(Q_{t}\right)$ evolves over time with a state-dependent persistent conditional mean and a disturbance that is exposed to both real fundamental 
shocks (as defined above) and non-fundamental shocks, as follows:

$$
\begin{aligned}
q_{t+1} & =q_{0}+\rho_{q} q_{t}+\rho_{q c p} c p_{t}+\rho_{q c n} c n_{t}+\rho_{q q p} q p_{t}+\rho_{q q n} q n_{t} \\
& +\delta_{q c p} \omega_{c p, t+1}+\delta_{q c n} \omega_{c n, t+1}+\delta_{q q p} \omega_{q p, t+1}-\delta_{q q n} \omega_{q n, t+1}
\end{aligned}
$$

where $q p_{t}\left(q n_{t}\right)$ is the variation in the upside (downside) tail of risk aversion and $\omega_{q p, t+1}$ $\left(\omega_{q n, t+1}\right)$ is the pure upside (downside) risk aversion shock. By definition, pure risk aversion shocks are orthogonal to fundamental shocks.

The conditional mean of $q_{t+1}$ is driven by past states of both economic fundamentals and risk aversion. This reduced-form conditional mean process can be justified by some recent studies. In particular, risk aversion has been shown to be countercyclical according to direct lab evidence in Cohn, Engelmann, Fehr, and Maréchal (2015). Moreover, risk aversion is likely to be persistent and autoregressive, as documented in Malmendier and Nagel (2011). Finally, instead of directly measuring risk aversion, Bekaert, Engstrom, and $\mathrm{Xu}(2017)$ use a structural asset pricing model to estimate the time-varying relative risk aversion of the representative agent in an endowment economy that is consistent with the pricing of multiple risky assets and exploits a wide information set of asset and risk variables in the U.S.. They find that after controlling for macroeconomic and cash flow uncertainties, risk aversion exhibits an autoregressive and countercyclical conditional mean. Our innovation with respect to Bekaert, Engstrom, and $\mathrm{Xu}(2017)$ is that the conditional mean of $q_{t+1}$ is also sensitive to the past higher-order moments of risk aversion, which allows for the variation in risk aversion to predict the level of future risk aversion. For example, a "stable" downside movement in risk aversion (i.e., low left-tail variability, or low $q n_{t}$ ) might indicate a low future risk aversion level (i.e., negative $\rho_{q q n}$ ).

The two pure risk aversion shocks, $\omega_{q p, t+1}$ and $\omega_{q n, t+1}$ in Equation (17), follow an isomorphic assumption:

$$
\begin{aligned}
\omega_{q n, t+1} & =\Gamma\left(q n_{t}, 1\right)-q n_{t}, \\
\omega_{q p, t+1} & =\Gamma\left(q p_{t}, 1\right)-q p_{t}, \\
q n_{t+1} & =q n_{0}+\rho_{q n q n} q n_{t}+\delta_{q n q n} \omega_{q n, t+1}, \\
q p_{t+1} & =q p_{0}+\rho_{q p q p} q p_{t}+\delta_{q p q p} \omega_{q p, t+1} .
\end{aligned}
$$

Having fundamental shocks endogenously span the time variation in risk aversion is in the spirit of Campbell and Cochrane (1999), and building in a non-fundamental nonGaussian source to explain the time variation in risk aversion is first formally discussed by Bekaert, Engstrom, and $\mathrm{Xu}(2017)$. We further separate the pure risk aversion (nonfundamental) disturbance into left- and right-tail shocks to realistically capture different tail behaviors of risk aversion, therefore introducing another source of asymmetry into the world economy through the common discount rate channel. In addition, we impose 
a general form for both shocks to be conservative given the lack of existing empirical suggestions.

We assume that the U.S. aggregate dividend claim has an isomorphic growth dynamics, similar to that of the real consumption growth,

$$
\begin{aligned}
\Delta d_{t+1} & =d_{0}+\rho_{d c p} c p_{t}+\rho_{d c n} c n_{t} \\
& +\delta_{d c p} \omega_{c p, t+1}+\delta_{d c n} \omega_{c n, t+1}+\delta_{d d p} \omega_{d p, t+1}-\delta_{d d n} \omega_{d n, t+1}
\end{aligned}
$$

where the upside $\left(\omega_{d p, t+1}\right)$ and downside $\left(\omega_{d n, t+1}\right)$ cash flow shocks are centered homoskedastic gamma shocks for the purpose of simplicity $\left.\right|^{5}$

Hence, we summarize the state variables in the domestic market in a linear matrix representation as follows:

$$
Y_{t+1}=\mu+A Y_{t}+\Sigma \omega_{t+1}
$$

where $\boldsymbol{Y}_{\boldsymbol{t}+\mathbf{1}}\left(7\right.$-by-1) contains $\left\{c_{t+1}, q_{t+1}, d_{t+1}, c n_{t+1}, c p_{t+1}, q n_{t+1}, q p_{t+1}\right\}$ and $\boldsymbol{\omega}_{\boldsymbol{t}+\mathbf{1}}$ (6-by-1) contains six independent centered gamma shocks $\left\{\omega_{c n, t+1}, \omega_{c p, t+1}, \omega_{q n, t+1}, \omega_{q p, t+1}, \omega_{d n, t+1}, \omega_{d p, t+1}\right\}$; $\boldsymbol{\Sigma}$ is a 7 -by-6 matrix. The shock assumption of $\boldsymbol{\omega}_{\boldsymbol{t}+\mathbf{1}}$ can be generalized into $\boldsymbol{\omega}_{t+\mathbf{1}} \sim$ $\Gamma\left(\boldsymbol{\Omega} \boldsymbol{Y}_{\boldsymbol{t}}+\boldsymbol{e}, 1\right)-\left(\boldsymbol{\Omega} \boldsymbol{Y}_{\boldsymbol{t}}+\boldsymbol{e}\right)$, where $\boldsymbol{\Omega}$ is a 6 -by-7 matrix and $\boldsymbol{e}$ a 6-by-1 matrix to capture constant shape parameters.

\subsubsection{Foreign exposure to common U.S. factors}

We model the international counterparts analogously. Thus, we assume that country $i$ has a representative investor who has a period utility function as follows:

$$
U\left(C_{t}^{i}\right)=\frac{\left(C_{t}^{i} / Q_{t}^{i}\right)^{1-\gamma}}{1-\gamma}
$$

where $C_{t}^{i}$ is the consumption level and $Q_{t}^{i}$ drives the time variation in $R R A_{t}$. We assume that the consumption level and the RRA level follow a power product with a U.S. component and an idiosyncratic component that are log-linearly weighted by constant parameters,

$$
\begin{aligned}
& C_{t}^{i}=\left(C_{t}^{U S}\right)^{\alpha_{1}^{i}}\left(C_{t}^{i, f}\right)^{1-\alpha_{1}^{i}} \\
& Q_{t}^{i}=\left(Q_{t}^{U S}\right)^{\alpha_{2}^{i}}\left(Q_{t}^{i, f}\right)^{1-\alpha_{2}^{i}}
\end{aligned}
$$

\footnotetext{
${ }^{5}$ Assuming heteroskedastic shocks do not change the model solution and implications for the dynamics of VP because "pure" cash flow shocks (not the part of cash flow shocks explained by macroeconomic fundamentals) are not compensated when generating VP, as they do not enter the kernel.
} 
where $C_{t}^{U S}\left(Q_{t}^{U S}\right)$ is $C_{t}\left(Q_{t}\right)$ in Section 5.1.1 and $C_{t}^{i, f}$ and $Q_{t}^{i, f}$ denote country-specific counterparts. $\alpha_{1}^{i}$ is not necessarily equal to $\alpha_{2}^{i}{ }^{6}$ Changes in consumption, $\Delta c_{t+1}^{i} \equiv$ $\ln \left(C_{t+1}^{i} / C_{t}^{i}\right)$, are equal to $\alpha_{1}^{i} \Delta c_{t+1}^{U S}+\left(1-\alpha_{1}^{i}\right) \Delta c_{t+1}^{i, f}$; similarly, $\Delta q_{t+1}^{i} \equiv \ln \left(Q_{t+1}^{i} / Q_{t}^{i}\right)=$ $\alpha_{2}^{i} \Delta q_{t+1}^{U S}+\left(1-\alpha_{2}^{i}\right) \Delta q_{t+1}^{i, f}$. Because habit is external, country $i$ investor's intertemporal marginal rate of substitution is given by $M_{t+1}^{i}=\beta^{i} \frac{U^{\prime}\left(C_{t+1}^{i}\right)}{U^{\prime}\left(C_{t}^{i}\right)}=\beta^{i} \frac{\left(C_{t+1}^{i} / Q_{t+1}^{i}\right)^{-\gamma}}{\left(C_{t}^{i} / Q_{t}^{i}\right)^{-\gamma}}$. The logarithm of the foreign country's SDF thus follows,

$$
m_{t+1}^{i}=\ln \left(\beta^{i}\right)-\gamma \alpha_{1}^{i} \Delta c_{t+1}^{U S}-\gamma\left(1-\alpha_{1}^{i}\right) \Delta c_{t+1}^{i, f}+\gamma \alpha_{2}^{i} \Delta q_{t+1}^{U S}+\gamma\left(1-\alpha_{2}^{i}\right) \Delta q_{t+1}^{i, f},
$$

which, intuitively, contains a U.S. component and an idiosyncratic component. Importantly, $\alpha^{i}$ s can be interpreted as integration coefficients, as they characterize the exposure of country $i$ to the common shocks, which, in this case, are proxied by U.S. shocks.

For the dynamic processes of country $i$ 's consumption, risk aversion, and cash flow (dividend), we assume that state variables follow a similar affine structure that contains a common U.S. component and an idiosyncratic component:

$$
\begin{aligned}
& Y_{t+1}^{i}=B^{U S} Y_{t+1}^{U S}+\left(1-B^{U S}\right) Y_{t+1}^{i, f} \\
& Y_{t+1}^{i, f}=\mu^{i, f}+A^{i, f} Y_{t}^{i, f}+\Sigma^{i, f} \omega_{t+1}^{i, f}
\end{aligned}
$$

where $\boldsymbol{B}^{\boldsymbol{U} \boldsymbol{S}}, \boldsymbol{\mu}^{\boldsymbol{i}, \boldsymbol{f}}$, and $\boldsymbol{A}^{\boldsymbol{i}, \boldsymbol{f}}$ are constant matrices (or vectors) and $\omega_{t+1}^{i, f}$ denotes a vector of gamma shocks in the idiosyncratic counterparts. We do not need to explicitly impose assumptions on the idiosyncratic shocks to understand our main empirical findings for the dynamics of the U.S. VP components and their international predictability patterns through the lens of the model.

\subsection{The model solution}

We first derive the model solution for U.S. VP and then the solution for the international equity risk premiums.

The U.S. model. Given the Euler equation with the no-arbitrage assumption and the MGF of the sum of gamma shocks, this model fits into the affine class. Thus, the model solution for the risk free rate, equity risk premium, and higher-order moments of equity returns can be shown to be (approximately) linear to $\boldsymbol{Y}_{\boldsymbol{t}}^{\boldsymbol{U} \boldsymbol{S}}$ and $\boldsymbol{Y}_{\boldsymbol{t}}^{\boldsymbol{i , f}}$ (see proof in a similar international setting in $\mathrm{Xu}(2017 \mathrm{a}))$.

To be consistent, the log U.S. pricing kernel can be rewritten as follows,

$$
m_{t+1}=m_{0}+\boldsymbol{m}_{\mathbf{1}} \boldsymbol{Y}_{\boldsymbol{t}}+\boldsymbol{m}_{\mathbf{2}} \boldsymbol{\Sigma} \boldsymbol{\omega}_{\boldsymbol{t}+\mathbf{1}}
$$

\footnotetext{
${ }^{6}$ The curvature parameter $\gamma$ can also be generalized to be country-specific, which will be reflected in the model solution as an additional source of heterogeneity across countries.
} 
where $\boldsymbol{Y}_{\boldsymbol{t}}$ (7-by-1), $\boldsymbol{\omega}_{\boldsymbol{t}+\mathbf{1}}$ (6-by-1), and $\boldsymbol{\Sigma}$ (7-by-6) are introduced in Equation (23), and $\boldsymbol{m}_{\mathbf{2}}$ (1-by-7) is a vector of kernel loadings on shocks. Given the assumptions on the utility function and the dynamics of the state variables defined in Section 5.1.1, the U.S. pricing kernel receives four shocks: two real macro shocks capturing asymmetric amounts of risk, $\left\{\omega_{c n, t+1}, \omega_{c p, t+1}\right\}$, and two non-fundamental risk aversion shocks capturing asymmetric tail behaviors of risk aversion, $\left\{\omega_{q n, t+1}, \omega_{q p, t+1}\right\}$. By design, these four shocks are orthogonal to each other.

The price-dividend ratio can be solved in an approximate affine framework and log market returns also have a linear expression with constant return sensitivities to these shocks, $]^{7}$

$$
r_{t+1}=\xi_{0}+\boldsymbol{\xi}_{1} \boldsymbol{Y}_{t}+\boldsymbol{\xi}_{2} \Sigma \boldsymbol{\omega}_{t+1}
$$

Then, the U.S. equity risk premium in this model is given by

$$
E_{t}\left(r_{t+1}\right)-r f_{t}=\left\{\boldsymbol{\xi}_{\mathbf{2}} \boldsymbol{\Sigma}+\ln \left[\mathbf{1}-\left(\boldsymbol{m}_{\mathbf{2}}+\boldsymbol{\xi}_{\mathbf{2}}\right) \boldsymbol{\Sigma}\right]-\ln \left(\mathbf{1}-\boldsymbol{m}_{\mathbf{2}} \boldsymbol{\Sigma}\right)\right\}\left(\boldsymbol{\Omega} \boldsymbol{Y}_{\boldsymbol{t}}+\boldsymbol{e}\right),
$$

where the relevant state variables in $\boldsymbol{Y}_{\boldsymbol{t}}$ that drive the time variation in the U.S. equity risk premium are time-varying second moments of kernel shocks; they are $\left\{c n_{t}, c p_{t}, q n_{t}, q p_{t}\right\}$. To gain intuition, a Gaussian affine approximation of the equity risk premium above is $-\left(\boldsymbol{m}_{2} \boldsymbol{\Sigma} \circ \boldsymbol{\xi}_{2} \boldsymbol{\Sigma}\right)\left(\boldsymbol{\Omega} \boldsymbol{Y}_{\boldsymbol{t}}+\boldsymbol{e}\right)$ (or exactly $-\operatorname{Cov}_{t}\left(m_{t+1}, r_{t+1}\right)$ ), where "o" indicates elementby-element matrix multiplication 8 Only return exposures to kernel shocks are compensated in this economy, rendering the four key premium state variables above. Equity risk premium loadings can also be suggested. For example, the traditional asset pricing literature suggests that investors demand higher risk compensation given higher risk aversion; in our expression, the coefficient of the right-tail of risk aversion $q p_{t}$ in the equity risk premium is indeed positive because $m_{2}(q p)>0$ (i.e., higher risk aversion driving up the marginal utility) and $\xi_{2}(q p)<0$ (i.e., through both the interest rate and the compensation channels).

The model-implied U.S. VP can be derived as follows:

$$
\begin{aligned}
V_{t}^{Q}\left(r_{t+1}\right)-V_{t}^{P}\left(r_{t+1}\right) & =\left(\boldsymbol{\xi}_{\mathbf{2}} \boldsymbol{\Sigma}\right)^{\circ 2}\left[\left(\mathbf{1}-\boldsymbol{m}_{\mathbf{2}} \boldsymbol{\Sigma}\right)^{\circ-2}-\mathbf{1}\right]\left(\boldsymbol{\Omega} \boldsymbol{Y}_{\boldsymbol{t}}+\boldsymbol{e}\right) \\
& \equiv D V P+U V P .
\end{aligned}
$$

Here are some insights from the model solution. Given the sandwich form and the strictly positive nature of second moments, it is crucial to understand the sign of $\left[\left(\mathbf{1}-\boldsymbol{m}_{\mathbf{2}} \boldsymbol{\Sigma}\right)^{\circ-2}-\mathbf{1}\right]$ (1-by-6) with respect to each relevant premium state variable; i.e., $\left\{c n_{t}, c p_{t}, q n_{t}, q p_{t}\right\}$.

\footnotetext{
${ }^{7}$ In the rest of the paper, we ignore the approximation error in the derivation. See detailed discussions in Bekaert, Engstrom, and $\mathrm{Xu}(2017)$ or $\mathrm{Xu}(2017 \mathrm{a})$.

${ }^{8}$ For example, $\left[x_{1}, x_{2}\right] \circ\left[x_{3}, x_{4}\right]=\left[x_{1} x_{3}, x_{2} x_{4}\right],\left[x_{1}, x_{2}\right]^{\circ 2}=\left[x_{1}^{2}, x_{2}^{2}\right],\left[x_{1}, x_{2}\right]^{\circ-2}=\left[x_{1}^{-2}, x_{2}^{-2}\right]$.
} 
Given the habit formation assumption, the pricing kernel generally increases with log changes in risk aversion and decreases with log changes in consumption. Therefore, $m_{t+1}$ likely loads positively on both the right-tail (upside) risk aversion shock $\left(\omega_{q p}\right)$ and the left-tail (downside) real shock $\left(\omega_{c n}\right)$. Both shocks are likely to spike up in a bad environment. With positive $m$ loadings, $\left(\frac{1}{1-m_{2} \sigma}\right)^{2}$ is strictly greater than 1 , rendering a strictly positive VP component that compensates for variance risk associated with a bad environment. Similarly, the other two shocks, the upside real shock $\omega_{c p}$ and left-tail swings in risk aversion $\omega_{q n}$, likely have negative kernel loadings. Thus, the closed-form solution has the potential to disentangle economic sources of the VP components that capture compensations for bearing upside and downside risks.

It is noteworthy that there is little literature on identifying different economic interpretations of VP and its components. Our framework, albeit in reduced form, provides preliminary insights on the interpretation of the VP components in equilibrium. We propose and estimate a GMM system framework to identify the relative importance of these determinants in VP and its components in Section 5.3.2.

The international equity risk premiums. Country $i$ 's equity risk premium has the following solution,

$$
\begin{aligned}
& E_{t}\left(r_{t+1}^{i}\right)-r f_{t}^{i}= \\
& \left\{\boldsymbol{\xi}_{\mathbf{2}}^{i, \boldsymbol{U}} \boldsymbol{\Sigma}^{\boldsymbol{U} \boldsymbol{S}}+\ln \left[\mathbf{1}-\left(\boldsymbol{m}_{\mathbf{2}}^{i, \boldsymbol{U} \boldsymbol{S}}+\boldsymbol{\xi}_{\mathbf{2}}^{i, \boldsymbol{U} \boldsymbol{S}}\right) \boldsymbol{\Sigma}^{\boldsymbol{U S}}\right]-\ln \left(\mathbf{1}-\boldsymbol{m}_{\mathbf{2}}^{i, \boldsymbol{U}} \boldsymbol{\Sigma}^{\boldsymbol{U} \boldsymbol{S}}\right)\right\}\left(\boldsymbol{\Omega}^{\boldsymbol{U} \boldsymbol{S}} \boldsymbol{Y}_{\boldsymbol{t}}^{\boldsymbol{U} \boldsymbol{S}}+\boldsymbol{e}^{\boldsymbol{U} \boldsymbol{S}}\right) \\
& + \text { Idiosyncratic component, }
\end{aligned}
$$

where $\boldsymbol{\xi}_{\mathbf{2}}^{i, U S}$ denotes the sensitivity of country $i$ 's log market returns to U.S. (common) shocks that transmit to the rest of the world through both the discount rate and the cash flow channels; $\boldsymbol{m}_{\mathbf{2}}^{\boldsymbol{i}, \boldsymbol{U} \boldsymbol{S}}$ denotes the sensitivity of country $i$ 's log pricing kernel to U.S. shocks. $\boldsymbol{\Sigma}, \boldsymbol{\Omega}, \boldsymbol{Y}_{\boldsymbol{t}}$, and $\boldsymbol{e}$ are denoted with "US" as well to indicate that they are obtained from Equation (23) of the U.S. state variables.

There are three immediate implications from Equation (34). First, the foreign equity risk premium can be decomposed into a global part and an idiosyncratic part. Global shocks are conditionally priced because they enter both local kernels and cash flow processes through certain integration channels. Second, in this model, besides different country-specific macro and kernel second moments, different degrees of global market integration play an important role in the cross-country variation in international equity risk premiums, while global premium state variables determine the time variation. Third, the global state variables, $\left\{c p^{U S}, c n^{U S}, q p^{U S}, q n^{U S}\right\}$, also drive the time variation in U.S. VP and its components. Therefore, the model solution suggests common economic determinants of U.S. VP and country-level excess returns, which results in the commonality in the international stock return predictability patterns. 


\subsection{Estimation strategy}

The theoretical model solution implies some structure to reconcile the new empirical stylized facts established in Sections 3 and 4 . Our estimation strategy aims to (1) identify the economic sources of DVP and UVP and (2) explain their distinct predictability patterns. To achieve these two goals, we propose a three-step estimation approach. In a first step, explained in Section 5.3.1, we extract the four U.S. premium determinants. In a second step, in Section 5.3.2, we identify DVP and UVP loadings on the four U.S. premium determinants. In a third step, in Section 5.3.3, we estimate the term structure of international equity risk premium loadings on the four U.S. premium determinants.

\subsubsection{Estimation results of U.S. premium determinants}

We first extract the upside and downside real economic uncertainties using an approximate MLE methodology for filtering non-Gaussian state variables as designed in Bates (2006). Given the empirical focus of the paper and data availability at the monthly frequency, we extract the real fundamental shocks and uncertainties from the industrial production growth (source: FRED), which is denoted as $\theta_{t}$ (see other papers using monthly industrial production growth to proxy for the real macroeconomic environment-e.g., Jurado, Ludvigson, and Ng (2015) and Bekaert, Engstrom, and Xu (2017)). We use the longest sample available (from January 1947 to March 2018) in the estimation.

Table 9 presents the estimation results for the estimates of the real economic uncertainties. Panel A provides evidence that the left tail of the real growth rate (after controlling for the conditional mean) is significantly more non-Gaussian than the right tail because the left-tail shape parameter $(\theta n)$ has a mean $\left(10.3362^{* * *}\right)$ that is much smaller than the mean of $\theta p$ (500) $!^{9}$ In addition, the left-tail shape parameter (downside uncertainty state variable) has a lower persistence level at the monthly frequency $\left(0.9525^{* * *}<1\right)$, suggesting that downside uncertainty reverts toward its long-run mean faster and is more transitory than the upside uncertainty (whose time series process cannot be rejected by a random walk test). Panel B provides evidence on moment matching, and Panel $\mathrm{C}$ provides a cyclicality test. On the one hand, we show that the downside uncertainty state variable $\left(\theta n_{t}\right)$ comoves positively with the NBER recession indicator $\left(\rho=0.6012^{* * *}\right)$, rendering a countercyclical process. On the other hand, we document acyclical upside uncertainty $\left(\theta p_{t}\right)$ given the long sample period.

Figure 11 shows the time variation in real growth rate $\theta_{t}$, its conditional mean (top), the upside uncertainty state variable $\theta p_{t}$ (middle), and the downside uncertainty state variable $\theta n_{t}$ (bottom). Major spikes in our estimate of $\theta n_{t}$ coincide exactly with the NBER recession periods, which illustrates its strong countercyclical pattern. The magni-

\footnotetext{
${ }^{9}$ For a gamma-distributed random variable, as the shape parameter increases, the distribution becomes more like (but not identical to) a normal distribution.
} 
tude (and scale) of $\theta n_{t}$ is smaller than that of $\theta p_{t}$, suggesting, again, that the downside growth shock is more non-Gaussian.

To extract pure risk aversion shocks $\omega_{q p}$ and $\omega_{q n}$, we use $q_{t}$ estimates from Bekaert, Engstrom, and $\mathrm{Xu}$ (2017), who also work with a variant of the external habit formation model. Therefore, their $q_{t}$ measure is comparable to our measure in terms of economic magnitudes. Panel A of Table 10 provides the estimation results for the risk aversion system (Equations (17) to (21)). The left-tail variation of the pure risk aversion shock has little time variation, which can also be seen from the bottom plot of Figure 12. This finding indicates that it is less likely to see extreme fluctuations in the left tail of risk aversion. In contrast, the right tail of risk aversion exhibits substantive time variation with a moderate persistence coefficient $\left(0.6352^{* * *}\right)$. The level of $q p_{t}$ (around $14.5891^{* * *}$ ) is significantly smaller than that of $q n_{t}$ (around $612.3177^{* * *}$ ), which can also be observed from the second and third plots of Figure 12. This finding indicates that the right tail of risk aversion captures most of the non-Gaussian properties of the total risk aversion and suggests an obvious asymmetry in this premium state variable. In addition, the conditional mean of risk aversion is persistent and countercyclical given significant and positive coefficient estimates of $\rho_{q q}$ and $\rho_{q \theta n}$. Panel B of Table 10 provides the moment matching results, and Panel $\mathrm{C}$ shows that the right-tail (left-tail) variability of the pure risk aversion part is significantly countercyclical (procyclical). In other words, there is a higher chance of observing extreme high risk aversion realizations during recessions, and there is a higher chance of observing extreme high risk appetite realizations during normal periods.

In Figure 13 , we calculate and plot the conditional variance decomposition of the four shocks that drive the disturbance of total risk aversion: two fundamental shocks and two non-fundamental shocks. We find that the pure right-tail risk aversion shock $\left(\omega_{q p}\right)$, which captures the extreme right-tail fluctuations in risk aversion, accounts for around $70 \%$ of the total conditional variance in the full sample. Then, in line with the literature, risk aversion is also quite sensitive to the economic environment. Interestingly, the percentage explained by the pure risk aversion shock is seen reaching a peak value (even at 100\%) right around periods when the economy just entered a recession or stress period, which is clear from the top plot of Figure 13 . In contrast, according to the bottom plot of Figure 13, the percentage explained by the economic downside shock (the other major source of countercyclicality in risk aversion) appears to peak later in a recession. This finding provides suggestive evidence that total risk aversion becomes less "moody" during the peak of the crisis and immediately after the crisi. 


\subsubsection{Economic interpretations of DVP and UVP}

To identify the economic sources of DVP and UVP, we use a GMM system to estimate the loadings of downside and upside VPs on the four second-moment state variables as implied by the theoretical model. We also allow for the loadings to be time varying. First, we denote the empirical benchmarks estimates of the one-month-ahead variance premiums in Section 3 as $\widetilde{v p_{t}^{D}}$ and $\widetilde{v p_{t}^{U}} 10$ Then, for each iteration, we compute the model-implied downside and upside VP counterparts:

$$
\begin{aligned}
& {\widehat{v p^{D}}}_{t}=w_{\theta p, t}^{D} \widehat{\theta p}_{t}+w_{\theta n, t}^{D} \widehat{\theta n}_{t}+w_{q p, t}^{D} \widehat{q p}_{t}+w_{q n, t}^{D} \widehat{q n}_{t} \\
& {\widehat{v p^{U}}}_{t}=w_{\theta p, t}^{U} \widehat{\theta p}_{t}+w_{\theta n, t}^{U} \widehat{\theta n}_{t}+w_{q p, t}^{U} \widehat{q p}_{t}+w_{q n, t}^{U} \widehat{q n}_{t},
\end{aligned}
$$

where the time-varying coefficients are linearly spanned by a common economic indicator,

$$
\begin{aligned}
& w_{x, t}^{D}=w_{x, 0}^{D}+w_{x, 1}^{D} z_{t}, \\
& w_{x, t}^{U}=w_{x, 0}^{U}+w_{x, 1}^{U} z_{t}, \forall x \in\{\theta p, \theta n, q p, q n\} .
\end{aligned}
$$

We use $u_{\theta, t}^{2}$ (the squared innovation to real economic growth) as the proxy for $z_{t}$ to capture environments with different shock realizations that potentially introduce nonlinearity. Thus, there are 16 unknown parameters in this GMM system,

$\boldsymbol{w}=\left\{w_{\theta p, 0}^{D}, w_{\theta n, 0}^{D}, w_{q p, 0}^{D}, w_{q n, 0}^{D}, w_{\theta p, 0}^{U}, w_{\theta n, 0}^{U}, w_{q p, 0}^{U}, w_{q n, 0}^{U}, w_{\theta p, 1}^{D}, w_{\theta n, 1}^{D}, w_{q p, 1}^{D}, w_{q n, 1}^{D}, w_{\theta p, 1}^{U}, w_{\theta n, 1}^{U}, w_{q p, 1}^{U}, w_{q n, 1}^{U}\right\}$

The raw moment conditions of interest include mean (2 moments), variance (2), scaled skewness (2), scaled kurtosis (2), covariance (1), and share of DVP in VP (1) and are denoted as follows:

\footnotetext{
${ }^{10}$ The notation of VP in the empirical part of the paper is $v p_{t, t+1}$, the one-month-ahead variance risk premium. For simplicity, " $t+1$ " is dropped so that the only subscript indicates the information set at $t$.
} 


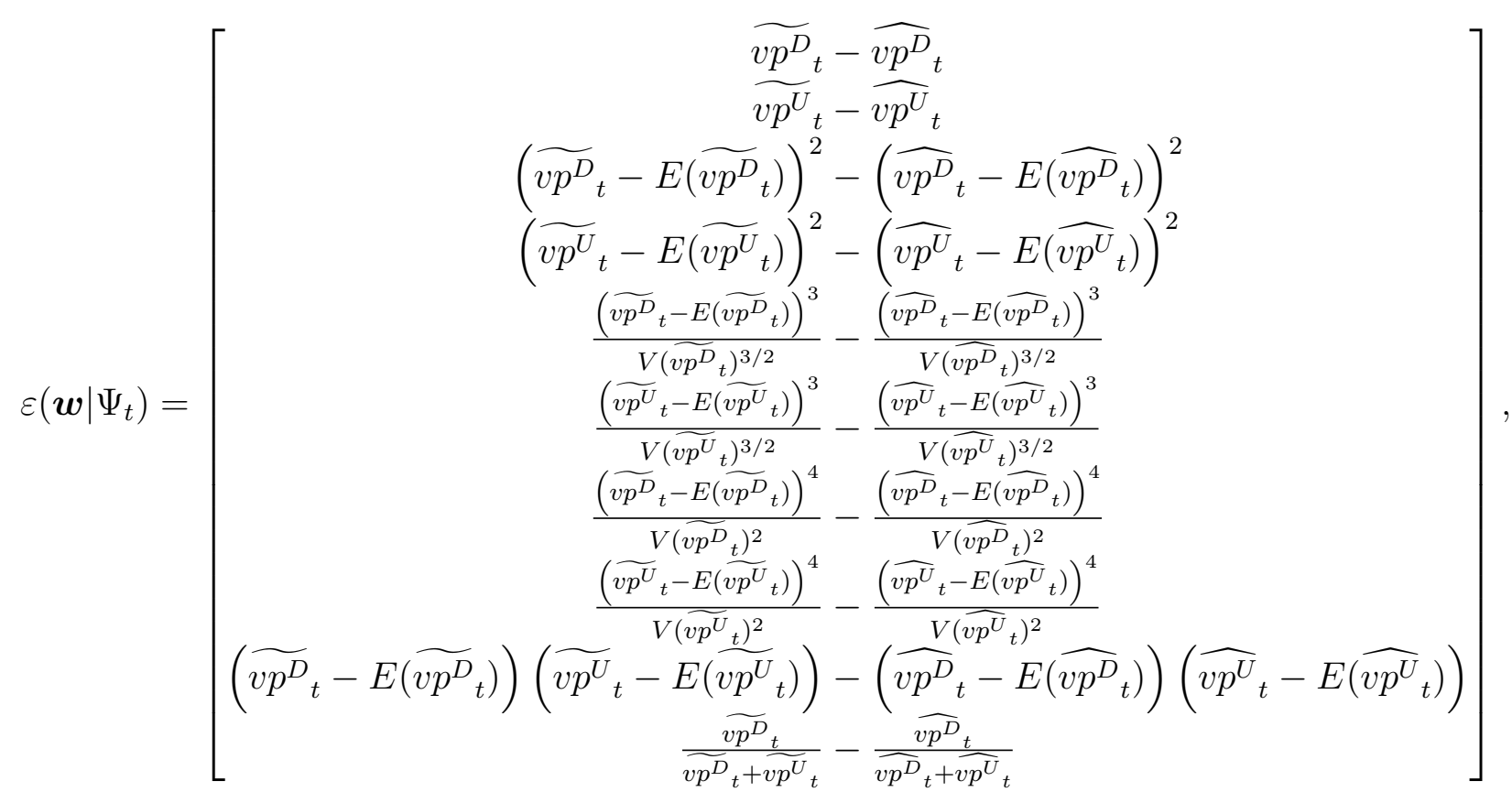

where $\Psi_{t}$ represents the information set, which includes the parameters in $\left\{\widehat{\theta p}_{t}, \widehat{\theta n}_{t}, \widehat{q p}_{t}, \widehat{q n}_{t}\right.$, ${\widehat{v p^{D}}}_{t}$ and ${\widehat{v p^{U}}}_{t}\}$, and model-implied VP components $\left({\widehat{v p^{D}}}_{t}\right.$ and ${\widehat{v p^{U}}}_{t})$ contain $\boldsymbol{w}$. Each raw moment condition is then tensor-multiplied with a set of instruments $\left\{1, \widehat{\theta p}_{t}, \widehat{\theta n}_{t}, \widehat{q p}_{t}, \widehat{q n}_{t}, \theta_{t-1}\right.$, $\left.q_{t-1}, u_{\theta, t}, u_{q, t}\right\}$. The GMM system has 90 moments and 16 unknowns and is estimated using iterative GMM. The standard Hansen's $J$ overidentification test follows.

Table 11 presents the moment matching results of the GMM system. Panel A shows that all moments are significantly close to the empirical benchmark. Some moments are worth revisiting. For instance, it is the DVP that dominates total VP on average, with DVP exhibiting higher time variation and being significantly right skewed. Our modelimplied DVP is also highly correlated with its empirical counterpart, with a coefficient of 0.56 (see Figure 14), and the correlation is 0.47 for matching the total VP (see Figure 15). The matching of UVP is relatively weak, although we are able to match the statistical properties of UVP and some major drops during the 2008 and 2012 economic turmoil. Finally, we fail to reject Hansen's J test, which means that these over-identification restrictions/moments are valid.

We then explore the relative importance of the identified economic determinants in explaining the distinct behaviors of DVP and UVP. The results are summarized in Table 12 , which is a core table to understand the economic determinants of the VP components. According to Panel A of Table 12, we find that DVP loads strongly and positively on extreme right-tail movements of risk aversion, $q p$. The variance decomposition (henceforth VARC) results suggest that $q p$ explains more of the time variation in DVP (41\%) than the other state variables. In addition, the positive mapping is stronger during en- 
vironments with high observed real uncertainty realizationsgiven that the coefficient on the time-varying instrument is significant and positive $\left(159.573^{* * *}\right)$. This finding indicates that investors are willing to pay more to buy protection against bad volatility risk (downside uncertainty) when risk aversion is higher and conditionally more right skewed, and, in particular, when they have observed extreme high uncertainty realizations in the last period.

Panel B of Table 12 calculates the loadings of VPs on each of the four state variables at various values of $z_{t}$. Because $z_{t}$ (proxied by $u_{\theta}^{2}$ ) is an extremely right-skewed variable and is always greater than 0 , we consider the mean and three extreme right-tail values. To help interpret the magnitude, we re-scale the state variables. On the one hand, for DVP, a one standard deviation (SD) increase in the right-tail movement in risk aversion is associated with the highest marginal increases (>8.54 monthly percentage squared) in DVP, compared with a one SD change in other state variables. The marginal increase of the $q p$ effect goes up as investors observe higher real realized variance in the economy (i.e., from 8.54 to 9.77) with a monotonic relation. DVP also increases when downside economic uncertainty is higher and/or when upside economic uncertainty is lower. We find that a one SD increase in the countercyclical downside uncertainty could cause DVP to increase by 4 to 6 (monthly percentage squared) during the majority (90\%) of the time, while a one SD decrease in the procyclical upside uncertainty could increase DVP consistently by 3 to 4 during all periods.

On the other hand, UVP is more sensitive to realized and expected economic uncertainty. In particular, the time-varying component of $\theta n$ accounts for most of the variation in UVP (coefficient $=-9009.524^{* * *}, \mathrm{VARC}=106.16 \%$ ), according to the second half of Panel A of Table 12. UVP strongly negatively loads on downside economic uncertainty $\theta n$ during all $z_{t}$ values. We learn from Figure 11 that $\theta n$ is countercyclical and relatively more transitory, which is consistent with the empirical fact established earlier that UVP is more transitory than DVP, displays occasional negative spikes, and is procyclical. The loading of UVP on $\theta n$ is more negative under environments with high real uncertainty realizations in a very non-linear fashion, according to Panel B. In particular, a one SD increase in downside uncertainty results in mild drops in UVP of 1.8 while realized economic variance is at its historical average, but might cause extremely large drops in UVP of around 29 when realized economic variance also peaks. To make sense of the magnitude, the historical standard deviation of UVP is only 3.77 (monthly percentage squared).

Together with the empirical facts from Section 3, based on the estimation of our model, we interpret the behavior of UVP as follows. During bad economic environments with high downside macroeconomic uncertainty, we see extreme negative and positive stock return realizations. Increases in the buying pressure of call options are not enough compared to the increases in stock return upside realized variance, which renders a nega- 
tive UVP. A negative UVP implies that investors are less interested in "hedging" against the volatility risk coming from the right tail of the stock return distribution during these periods, and would like to be paid to hold such a hedging position. The negative relation between downside macroeconomic uncertainty and UVP is stronger as the observed macro uncertainty increases, thus capturing a non-linear effect. However, the fact that UVP is positive, on average (see Table 2), albeit small, means that investors dislike both good and bad volatility in "normal times."

\subsubsection{International predictability patterns}

We now confront our model solution with the international predictability patterns documented in Section 4 to infer the loadings of our model's state variables on the term structures of international equity risk premiums. Our results also shed light on the relative importance of international integration channels in explaining the cross-country differences in the predictability patterns of U.S. risk variables and how these channels relate to the economic interpretations of DVP and UVP in Section 5.3.2.

Our theoretical model suggests that international equity risk premiums can be written as a linear combination of real uncertainty and risk aversion state variables, according to Section 5.2 ;

$$
\widehat{E R P}_{h, t}^{i}=v_{\theta p, h, t}^{i} \widehat{\theta p}_{t}+v_{\theta n, h, t}^{i} \widehat{\theta n}_{t}+v_{q p, h, t}^{i} \widehat{q p}_{t}+v_{q n, h, t}^{i} \widehat{q n}_{t}+\text { Idiosyncratic component }
$$

where $\widehat{E R P}_{h, t}^{i}$ is the $h$-month equity risk premium candidate for country $i$ at time $t$. The four empirical proxies for the state variables, $\widehat{\theta p}_{t}, \widehat{\theta n}_{t}, \widehat{q p}_{t}$, and $\widehat{q n}_{t}$, are as estimated and discussed in Section 5.3.1. The coefficients in Equation (40) are assumed to follow the processes

$$
\begin{aligned}
& v_{\theta p, h, t}^{i}=v_{\theta p, h, 0}+\boldsymbol{v}_{\boldsymbol{\theta} \boldsymbol{p}, \boldsymbol{h}, \mathbf{1}}{ }^{\prime} \boldsymbol{x}^{\boldsymbol{i}}+v_{\theta p, h, 2} z_{t}, \\
& v_{\theta n, h, t}^{i}=v_{\theta n, h, 0}+\boldsymbol{v}_{\boldsymbol{\theta} \boldsymbol{n , \boldsymbol { h } , \mathbf { 1 }}}{ }^{\prime} \boldsymbol{x}^{\boldsymbol{i}}+v_{\theta n, h, 2} z_{t},
\end{aligned}
$$

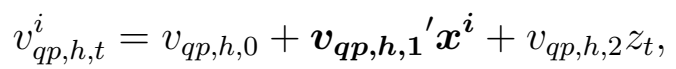

$$
\begin{aligned}
& v_{q n, h, t}^{i}=v_{q n, h, 0}+\boldsymbol{v}_{\boldsymbol{q n}, \boldsymbol{h}, \mathbf{1}}{ }^{\prime} \boldsymbol{x}^{i}+v_{q n, h, 2} z_{t},
\end{aligned}
$$

where $\boldsymbol{x}^{i}$ is a chosen set of country-specific variables that are informative about financial development (proxied by each country's standardized credit-to-GDP ratio; source: World Bank) and economic integration (proxied by the standardized trade-to-GDP ratio; source: World Bank); $z_{t}$ is proxied by $u_{\theta, t}^{2}$, as reasoned before. Thus, there are 16 unknown parameters:

$\boldsymbol{v}=\left\{v_{\theta p, h, 0}, v_{\theta n, h, 0}, v_{q p, h, 0}, v_{q n, h, 0}, \boldsymbol{v}_{\boldsymbol{\theta p}, \boldsymbol{h}, \mathbf{1}}, \boldsymbol{v}_{\boldsymbol{\theta} \boldsymbol{n}, \boldsymbol{h}, \mathbf{1}}, \boldsymbol{v}_{\boldsymbol{q p}, \boldsymbol{h}, \mathbf{1}}, \boldsymbol{v}_{\boldsymbol{q n}, \boldsymbol{h}, \mathbf{1}}, v_{\theta p, h, 2}, v_{\theta n, h, 2}, v_{q p, h, 2}, v_{q n, h, 2}\right\}$ 
The model-implied predictive coefficients of DVP are thus given by

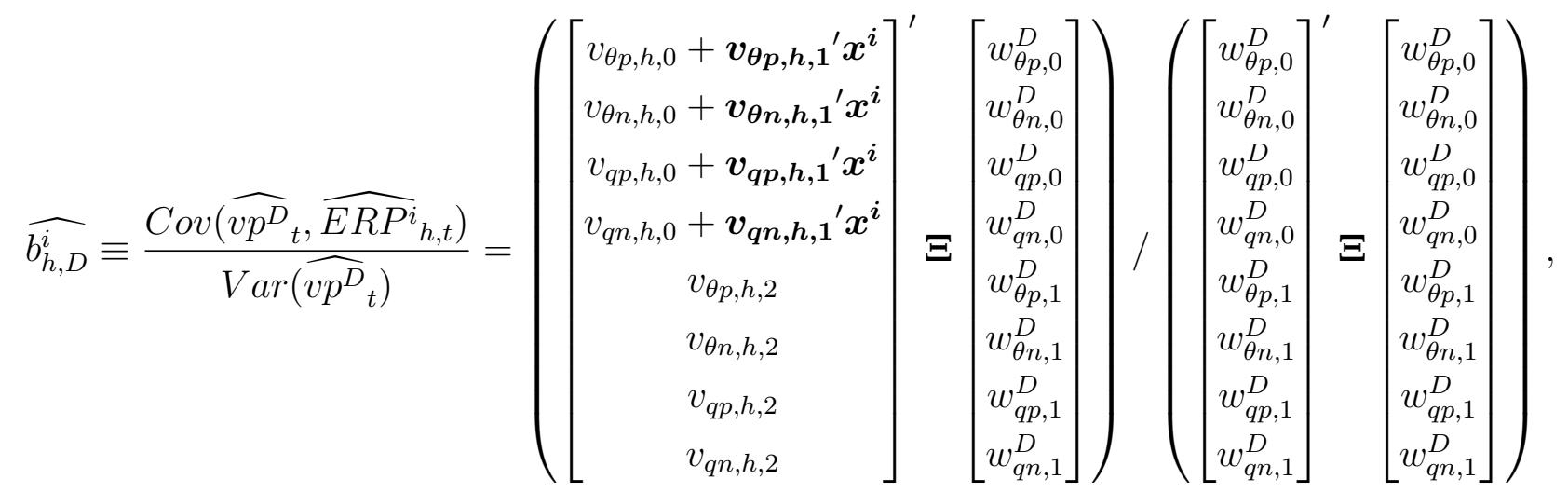

where $\boldsymbol{\Xi}$ is the covariance-variance matrix of $\left[\theta p_{t}, \theta n_{t}, q p_{t}, q n_{t}, \theta p_{t} z_{t}, \theta n_{t} z_{t}, q p_{t} z_{t}, q n_{t} z_{t}\right]$. A similar calculation applies to the UVP predictive coefficients $\widehat{b_{h, U}^{i}}$ at the $h$-month horizon for country $i$.

For each horizon $h$, the estimation is conducted by minimizing the sum of squared standardized residuals for $22 \widehat{b_{h, D}^{i}}, 22 \widehat{b_{h, U}^{i}}$, and the U.S. equity risk premium. Therefore, the estimation results reconcile both DVP and UVP predictive patterns for all countries and for the U.S. equity risk premium (given that there is no idiosyncratic component for the U.S.). Table 13 and Table 14 demonstrate the predictive coefficient matching for the U.S. and for the panel of countries, respectively. Model-implied predictive coefficients are statistically close to the empirical benchmarks.

Table 15 demonstrates the economic significance of each of the four sources $(\theta p, \theta n$, $q p, q n)$ in the magnitude of the predictive coefficients at all horizons for an "average country." An average country is defined as having an average level of financial and economic integration. Because we standardize these integration channels, we denote this hypothetical country as $(0,0)$ in the calibration. To assess the economic significance of each source, for each horizon, we conduct a "jackknife"-type exercise. Specifically, we delete one source at a time (both the constant and time-varying components in the equity risk premium loadings of that source) and recalculate the implied predictive coefficient. In the table, we report the relative change after deleting each source at a time. The more negative the relative change is, the more significant the source is in explaining the predictive patterns. In Panel A, for the predictive patterns of DVP, column " $q p$ " is associated with the most significant negative changes (i.e., decreases in the positive predictive coefficient of DVP, as highlighted). Most importantly, according to the second to last row, if we focus on the horizons with the highest $R^{2} \mathrm{~s}$ as documented in Section 4 around four to six months, the average drop in the estimated coefficient is -4.99 , which is the most negative among all other variables. These findings can be interpreted as follows. In the empirical part of the paper, we document that DVP exhibits a robust 
hump-shaped predictive pattern for all countries. When confronted with the model, we find that this predictability pattern is mostly explained by the fact that international equity risk premium's loading on global risk aversion - particularly its extreme right-tail movements - is positive. This shape is further confirmed by Figure 16, wherein we show the ERP loadings on the standardized state variables. In that figure, the solid line with hollow squares in the third set of plots exhibits a hump shape that is consistent with the evidence in Table 15 .

In the second part of Table 15 on the relative change in UVP predictive pattern for an average country, we show that deleting the downside uncertainty source results in the largest drop in the UVP predictive coefficient magnitude. From the results in Section 5.3.2, we learn that time variation in UVP (and its negative transitory spikes) is likely to be associated with extreme real and expected economic uncertainty: when economic uncertainty is high today, we observe that investors differentiate the volatility coming from the right tail of the underlying asset return distribution and prefer exposure to upside volatility. Thus, investors would like to be paid to be exposed to future upside volatility. From the results in this section, we find that it is, indeed, the equity risk premium loadings on downside uncertainty that exhibit a term structure and thus account for a significant part of the UVP predictive pattern (i.e., positive and decaying; one- to three-month predictor).

To reconcile the positive and decaying predictive pattern of UVP and the positive and hump-shaped predictive pattern of DVP, the equity risk premium could load significantly negatively on the downside economic uncertainty $\theta n$ at short horizons, according to the second set of plots in Figure 16 (see the red solid line with hollow squares). However, as the horizon increases to nine months and above (including the annual frequency), the equity risk premium loading on the downside uncertainty rises to the positive region, contributing positively to a countercyclical risk premium at mid-to-long horizons. It is noteworthy that most of the asset pricing paradigms derive that the equity risk premium should be strongly countercyclical; however, there is scanty empirical research or suggestions on the term structure of the cyclicality of the equity risk premium 11 Our approach aims to reconcile both the predictability literature and the theoretical asset pricing lit-

\footnotetext{
${ }^{11}$ Merton et al. (1973) implies that the relation between risk and return should be positive as "investors should be compensated for taking risk", which is intuitively advocated by the mainstream representativeagent asset pricing theories since. However, recent empirical analysis suggests that this relation only seems to be clear for long horizons (see, for instance, Bandi and Perron (2008), Jacquier and Okou (2013)). For shorter horizons, however, the relation is not as conclusive: Brandt and Kang (2004), for instance, document a negative relation between realized market risk and returns using GARCH-class models, while Ghysels, Santa-Clara, and Valkanov (2005) and Ludvigson and Ng (2007) find a positive relation, and Baillie and DeGennaro (1990) and Bollerslev and Zhou (2006) document mixed results. In consumption-based asset pricing literature, only a few papers examine and provide empirical evidence of a possible procyclical equity risk premium. For instance, Duffee $(2005)$ and $\mathrm{Xu}(2017 \mathrm{~b})$ directly examine the comovement between stock returns and consumption growth, which represents the time-varying amount of risk in the equity risk premium in such models, and find it to be procyclical.
} 
erature, and finds that, at mid-long horizons, there is indeed a positive relation between economic uncertainty and equity risk premium, whereas for shorter horizons, the relation is more puzzling. To the contrary, the equity risk premium loadings on risk aversion (as discussed above) are consistently and always positive and land at a reasonable value. For example, according to Figure 17, at the mid-long horizons, a one SD increase in risk aversion $(q p)$ increases an average-country equity risk premium by $2.5 \%$, which is almost twice the effect of a one SD increase in downside economic uncertainty $(\theta n)$; to put it into context, the 2008 financial crisis could correspond to over 6 SDs from the average risk aversion and downside economic uncertainty (which are both highly right-skewed).

We now move from the average country and explore the heterogeneity in the term structure of equity risk premiums. In our setting, cross-country heterogeneity is driven by each country's financial and economic integration levels. In Table 16, we recalculate the relative change in the predictive coefficient when deleting one economic source at a time. A country with a trade-to-GDP (credit-to-GDP) ratio that is one SD above the average is denoted by $(1,0)((0,1))$. The main finding is that, for a country with a higher financial integration level, risk aversion becomes a more significant economic source of the predictive power of DVP on country returns $(9.66>1.94)$. For a country with a higher real integration level, economic uncertainty becomes more important in explaining the predictive power of UVP (1.29>0.71). Opposite effects can be found and justified in Panel $\mathrm{B}$ when we calibrate two countries with weaker international integration levels $((-1,0)$ and $(0,1))$. Thus, the relation between international financial and economic integration and the predictive power of UVP and DVP is consistent with the economic interpretations of the components of VP.

\section{Conclusion}

In this paper, we document new stylized facts on the behaviors and international stock return predictability patterns of U.S. downside and upside variance risk premiums. Our research also sheds light on the economic interpretation of asymmetric risk compensations and their transmission to international stock markets.

We find that DVP and UVP exhibit distinct time series behaviors. DVP, the compensation for bearing the risk of downside variance, is, on average, positive and significant, and it explains most of the time variation of the total variance risk premium, while UVP, the compensation related to the variance of the right tail of the stock return distribution, is borderline positive and often negative. Moreover, DVP is strongly countercyclical, while UVP is weakly procyclical and displays large negative spikes around episodes of crisis. We also document that DVP and UVP contain differential information to explain the time variation of future stock returns. On the one hand, the international stock return predictability pattern of DVP peaks at $4 \sim 6$ months and exhibits a hump-shaped 
behavior, in line with the existing literature for the domestic predictability of total VP and DVP. On the other hand, UVP is a useful predictor of international stock returns at the very-short horizon, a finding that is new to both the domestic and international predictability literature. Importantly, we find that the predictive model with asymmetric components of the VP dominates that with only the total VP, with the improvement being strongest at horizons of less than six months. The predictability patterns of DVP and UVP are robust after controlling for a set of standard U.S. predictors.

To explain the different dynamics of DVP and UVP and their international predictability patterns, we propose and solve an international dynamic no-arbitrage asset pricing model. Given the focus on asymmetry in asset prices and on the international transmission of risk factors, the model features (1) time-varying and asymmetric risk aversion and real economic uncertainty and (2) an imperfectly integrated world economy. We use a GMM framework to estimate the relative weights of asymmetric risk premium state variables in jointly determining the time series dynamics of DVP and UVP in closed form. We find that $41 \%$ of the variation in DVP is driven by risk aversion, especially by the right-tail component of risk aversion. Thus, when risk aversion increases, investors demand higher compensation for bearing downside variance risk, inducing a higher DVP. In contrast, UVP is mostly explained by downside economic uncertainty. In particular, when the economy experiences large uncertainty today and investors, therefore, expect more downside uncertainty in the future, they prefer to be exposed to volatility coming from the right tail of the return distributions, which implies a negative UVP around crises. Then, we explain the domestic and international predictability patterns given the model solution for international equity risk premiums. On the one hand, we find that risk aversion is the key economic source in the predictability of DVP, exhibiting a hump-shaped pattern in the term structure of its relative importance in equity risk premiums. On the other hand, downside economic uncertainty is more informative about the predictability of UVP. Interestingly, our results reveal that the contribution of downside economic uncertainty in explaining equity risk premiums can be negative at very short horizons. However, as the horizon increases to above nine months, the contribution of uncertainty to equity risk premiums becomes positive, as suggested in traditional asset pricing paradigms. Our theoretical framework also allows us to explain the transmission mechanism of DVP and UVP to international stock markets. We find that financial integration is relatively more important at explaining the transmission of DVP, the VP component that is mainly driven by risk aversion, while real economic integration better explains the transmission of UVP, the component of VP mainly explained by real economic uncertainty. 


\section{References}

Andersen, T. G., Bondarenko, O., 2009. Dissecting the market pricing of return volatility. Working paper .

Baele, L., Driessen, J., Ebert, S., Londono, J. M., Spalt, O., 2018. Cumulative prospect theory, option returns, and the variance premium. The Review of Financial Studies, forthcoming .

Baillie, R. T., DeGennaro, R. P., 1990. Stock returns and volatility. Journal of financial and Quantitative Analysis 25, 203-214.

Bandi, F. M., Perron, B., 2008. Long-run risk-return trade-offs. Journal of Econometrics $143,349-374$.

Barndorff-Nielsen, O., Kinnebrock, S., Shephard, N., 2010. Volatility and time series econometrics: Essays in honor of robert f. engle, chapter measuring downside riskrealised semivariance.

Bates, D. S., 2006. Maximum likelihood estimation of latent affine processes. The Review of Financial Studies 19, 909-965.

Bekaert, G., Engstrom, E., 2017. Asset return dynamics under habits and bad environmentgood environment fundamentals. Journal of Political Economy 125, 713-760.

Bekaert, G., Engstrom, E., Xu, N., 2017. The time variation in risk appetite and uncertainty .

Bekaert, G., Hoerova, M., 2014. The vix, the variance premium and stock market volatility. Journal of Econometrics 183, 181-192.

Bollerslev, T., Gibson, M., Zhou, H., 2011. Dynamic estimation of volatility risk premia and investor risk aversion from option-implied and realized volatilities. Journal of Econometrics 160, 235-245.

Bollerslev, T., Marrone, J., Xu, L., Zhou, H., 2014. Stock return predictability and variance risk premia: statistical inference and international evidence. Journal of Financial and Quantitative Analysis 49, 633-661.

Bollerslev, T., Tauchen, G., Zhou, H., 2009. Expected stock returns and variance risk premia. The Review of Financial Studies 22, 4463-4492.

Bollerslev, T., Zhou, H., 2006. Volatility puzzles: a simple framework for gauging returnvolatility regressions. Journal of Econometrics 131, 123-150. 
Brandt, M. W., Kang, Q., 2004. On the relationship between the conditional mean and volatility of stock returns: A latent var approach. Journal of Financial Economics 72, $217-257$.

Britten-Jones, M., Neuberger, A., 2000. Option prices, implied price processes, and stochastic volatility. The Journal of Finance 55, 839-866.

Campbell, J. Y., Cochrane, J. H., 1999. By force of habit: A consumption-based explanation of aggregate stock market behavior. Journal of political Economy 107, 205-251.

Cohn, A., Engelmann, J., Fehr, E., Maréchal, M. A., 2015. Evidence for countercyclical risk aversion: an experiment with financial professionals. American Economic Review 105, 860-85.

Corradi, V., Distaso, W., Mele, A., 2013. Macroeconomic determinants of stock market volatility and volatility risk premiums. Journal of Monetary Economics 60, 203-220.

Corsi, F., 2009. A simple approximate long-memory model of realized volatility. Journal of Financial Econometrics 7, 174-196.

Drechsler, I., Yaron, A., 2010. What's vol got to do with it. The Review of Financial Studies 24, 1-45.

Duffee, G. R., 2005. Time variation in the covariance between stock returns and consumption growth. The Journal of Finance 60, 1673-1712.

Fama, E. F., French, K. R., 1988. Dividend yields and expected stock returns. Journal of financial economics 22, 3-25.

Feunou, B., Jahan-Parvar, M. R., Okou, C., 2017. Downside variance risk premium. Journal of Financial Econometrics 16, 341-383.

Ghysels, E., Santa-Clara, P., Valkanov, R., 2005. There is a risk-return trade-off after all. Journal of Financial Economics 76, 509-548.

Golez, B., Koudijs, P., 2018. Four centuries of return predictability. Journal of Financial Economics 127, 248-263.

Held, M., Kapraun, J., Omachel, M., Thimme, J., 2018. Up-and downside variance risk premia in global equity markets .

Jacquier, E., Okou, C., 2013. Disentangling continuous volatility from jumps in long-run risk-return relationships. Journal of Financial Econometrics 12, 544-583.

Jurado, K., Ludvigson, S. C., Ng, S., 2015. Measuring uncertainty. American Economic Review 105, 1177-1216. 
Kilic, M., Shaliastovich, I., 2018. Good and bad variance premia and expected returns. Management Science .

Londono, J. M., 2015. The variance risk premium around the world .

Londono, J. M., Zhou, H., 2017. Variance risk premiums and the forward premium puzzle. Journal of Financial Economics 124, 415-440.

Ludvigson, S. C., Ng, S., 2007. The empirical risk-return relation: A factor analysis approach. Journal of Financial Economics 83, 171-222.

Malmendier, U., Nagel, S., 2011. Depression babies: do macroeconomic experiences affect risk taking? The Quarterly Journal of Economics 126, 373-416.

Merton, R. C., et al., 1973. An intertemporal capital asset pricing model. Econometrica $41,867-887$.

Miranda-Agrippino, S., Rey, H., 2015. World asset markets and the global financial cycle. Tech. rep., National Bureau of Economic Research.

Xu, N., 2017a. Global risk aversion and international return comovements .

Xu, N., 2017b. Procyclicality of the comovement between dividend growth and consumption growth.

Zhou, H., 2010. Variance risk premia, asset predictability puzzles, and macroeconomic uncertainty . 
Table 1: Expected downside and upside realized semivariances

This table shows the coefficients associated with the predictors of one-month-ahead downside and upside realized semivariances, in panels A and B, respectively. The specification in column (1) assumes that realized semivariances follow a Martingale $\left(E\left(r v_{t+1}^{i}\right)=r v_{t}^{i}\right.$, for $i=D, U$ (downside or upside)). For the specifications in columns (2) to (7), we estimate the following regression setting:

$$
E_{t}\left(r v_{t+1}^{i}\right)=\hat{\alpha^{i}}+\hat{\gamma^{\mathbf{i}}} \mathbf{X}_{\mathbf{t}}^{\mathbf{i}}
$$

We consider the following predictors in matrix $\mathbf{X}$ : the total realized variance calculated over the last month $\left(r v_{t}\right)$ and its downside an upside components $\left(r v_{t}^{i}\right)$; realized semivariances calculated using either the last five days $\left(r v_{t-5 d, t}^{i}\right)$ or the last day of the month $\left(r v_{t-1 d, t}^{i}\right)$; and the option-implied variance $\left(i v_{t, t+1}\right)$ and its downside and upside components $\left(i v_{t, t+1}^{i}\right)$. We report, in parentheses, heteroskedasticity and autocorrelation consistent (HAC) standard deviations. ${ }^{* * *}\left({ }^{* *},{ }^{*}\right)$ represent significance at the $1 \%$ $(5 \%, 10 \%)$ confidence level. We also report the following two measures for the relative fit of each model: the adjusted $R^{2}$ and the Bayesian information criterion (BIC).

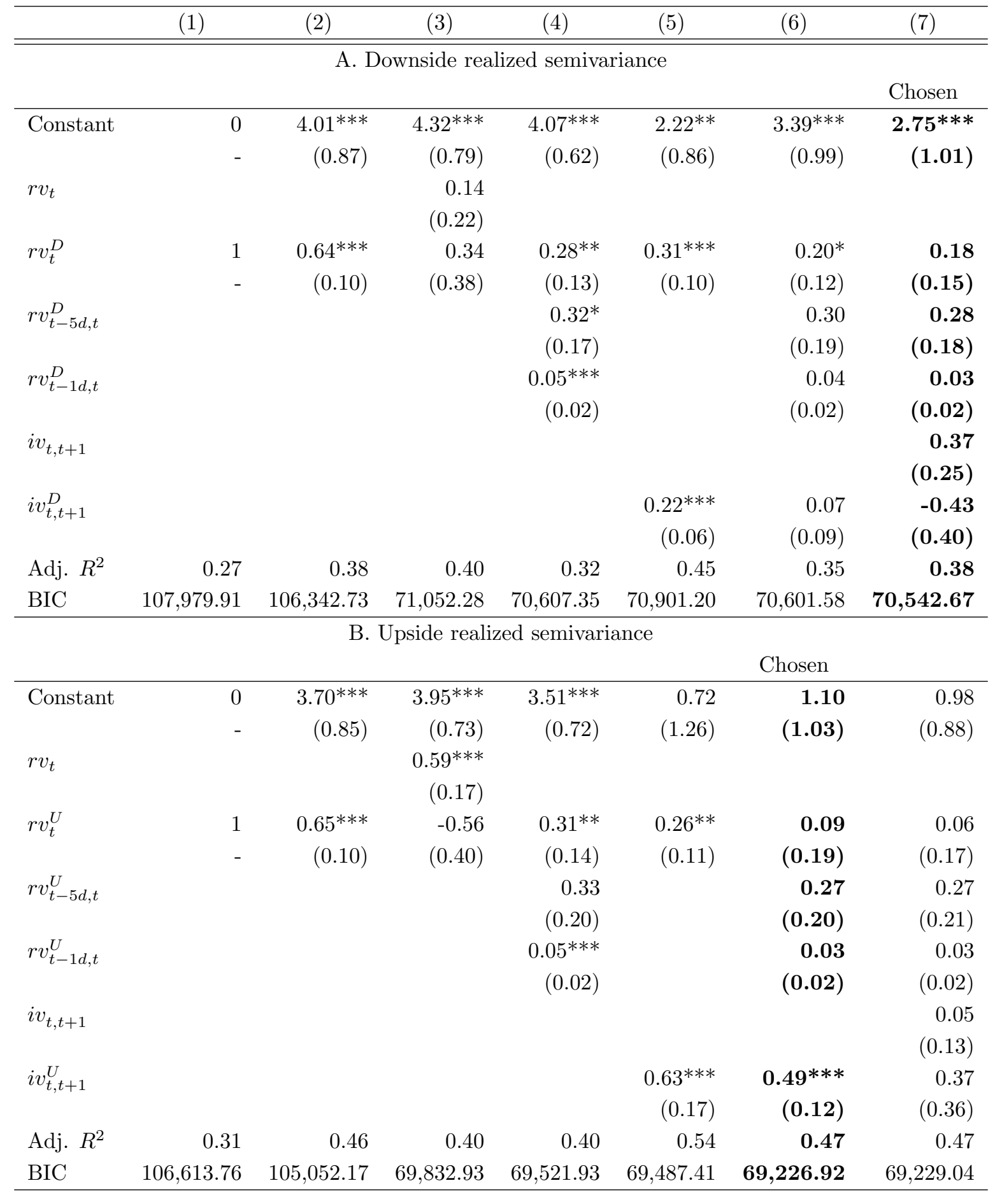


Table 2: Summary statistics for variance premium variables

This table reports time series averages for the risk-neutral and the physical expectation of the variance as well as the corresponding variance premiums (VPs). All measures are in units of monthly variancei.e., in annual percentage squared divided by 12 . For the VPs, we also report standard deviations and minimum and maximum values. We report summary statistics for the alternative VP measures calculated using the expected realized semivariances for each of the specifications in Table 1. Time series are monthly (end-of-the-month data), and the sample runs from January 1990 to March 2018.

\begin{tabular}{lrrrrrrr}
\hline & $(1)$ & $(2)$ & $(3)$ & $(4)$ & $(5)$ & \multicolumn{1}{c}{$(6)$} & \multicolumn{1}{c}{$(7)$} \\
\hline \hline \multicolumn{7}{c}{ A. DVP } \\
& 24.46 & 24.46 & 24.46 & 24.46 & 24.46 & 24.46 & $\mathbf{2 4 . 4 6}$ \\
\hline$i v_{t, t+1}^{D}$ & 11.05 & 11.05 & 11.08 & 10.81 & 11.02 & 10.80 & $\mathbf{1 0 . 8 0}$ \\
$E_{t}\left(r v_{t+1}^{D}\right)$ & 13.40 & 13.40 & 13.37 & 13.65 & 13.43 & 13.66 & $\mathbf{1 3 . 6 5}$ \\
$v p_{t, t+1}^{D}$ & 11.45 & 14.14 & 14.54 & 14.32 & 13.38 & 14.00 & $\mathbf{1 3 . 8 7}$ \\
$S D\left(v p_{t, t+1}^{D}\right)$ & -20.18 & -1.27 & -1.57 & -1.55 & 0.55 & -0.86 & $\mathbf{- 1 . 2 8}$ \\
$\operatorname{Min}\left(v p_{t, t+1}^{D}\right)$ & -1.25 & 93.28 & 96.81 & 89.34 & 94.42 & 95.23 & $\mathbf{1 0 1 . 1 0}$ \\
$\operatorname{Max}\left(v p_{t, t+1}^{D}\right)$ & 81.25 & & & & & & \\
\hline
\end{tabular}

\section{B. UVP}

\begin{tabular}{lrrrrrrr} 
& & & & & Chosen \\
\hline$i v_{t, t+1}^{U}$ & 11.26 & 11.26 & 11.26 & 11.26 & 11.26 & $\mathbf{1 1 . 2 6}$ & 11.26 \\
$E_{t}\left(r v_{t+1}^{U}\right)$ & 10.67 & 10.66 & 10.74 & 10.66 & 10.63 & $\mathbf{1 0 . 6 2}$ & 10.62 \\
$v p_{t, t+1}^{U}$ & 0.61 & 0.61 & 0.53 & 0.60 & 0.63 & $\mathbf{0 . 6 5}$ & 0.64 \\
$S D\left(v p_{t, t+1}^{U}\right)$ & 9.86 & 6.33 & 6.23 & 6.45 & 2.48 & $\mathbf{3 . 7 8}$ & 3.72 \\
$\operatorname{Min}\left(v p_{t, t+1}^{U}\right)$ & -138.25 & -65.12 & -67.14 & -66.95 & -28.53 & $\mathbf{- 4 0 . 8 4}$ & -39.90 \\
$\operatorname{Max}\left(v p_{t, t+1}^{U}\right)$ & 23.27 & 27.48 & 19.37 & 22.63 & 10.31 & $\mathbf{1 0 . 2 8}$ & 11.42 \\
\hline
\end{tabular}




\section{Table 3: Correlations}

This table reports correlations using total, downside, and upside variance premiums for the VP measures calculated using the expected realized semivariances for each of the specifications in Table 1. The last column, "chosen," considers the VP measures calculated using specification (7) for DVP and specification (6) for UVP. ${ }^{* * *}\left({ }^{* *},{ }^{*}\right)$ represent significance at the $1 \%(5 \%, 10 \%)$ confidence level and are calculated using standard errors bootstrapped 10,000 times. Time series are monthly (end-of-the-month data), and the sample runs from January 1990 to March 2018.

\begin{tabular}{lrrrrrrrr}
\hline & $(1)$ & \multicolumn{1}{c}{$(2)$} & \multicolumn{1}{c}{$(3)$} & \multicolumn{1}{c}{$(4)$} & \multicolumn{1}{c}{$(5)$} & \multicolumn{1}{c}{$(6)$} & \multicolumn{1}{c}{$(7)$} & Chosen \\
\hline \hline \multicolumn{7}{c}{ A. Correlations within models } \\
\hline Correl(VP,DVP) & $0.85^{* * *}$ & $0.95^{* * *}$ & $0.94^{* * *}$ & $0.93^{* * *}$ & $0.98^{* * *}$ & $0.97^{* * *}$ & $0.97^{* * *}$ & $0.95^{* * *}$ \\
Correl(VP,UVP) & $0.78^{* * *}$ & $0.69^{* * *}$ & $0.63^{* * *}$ & $0.57^{* * *}$ & 0.32 & $0.30^{*}$ & 0.23 & $0.35^{*}$ \\
Correl(UVP,DVP) & $0.33^{* * *}$ & $0.41^{* *}$ & $0.34^{*}$ & 0.22 & 0.14 & 0.04 & -0.03 & 0.11 \\
\hline
\end{tabular}

B. Correlations across models; DVP

\begin{tabular}{|c|c|c|c|c|c|c|c|c|}
\hline (1) & 1.00 & & & & & & & \\
\hline (2) & $0.88^{* * *}$ & 1.00 & & & & & & \\
\hline (3) & $0.87^{* * *}$ & $1.00^{* * *}$ & 1.00 & & & & & \\
\hline (4) & $0.77^{* * *}$ & $0.96^{* * *}$ & $0.97^{* * *}$ & 1.00 & & & & \\
\hline (5) & $0.77^{* * *}$ & $0.98^{* * *}$ & $0.98^{* * *}$ & $0.98^{* * *}$ & 1.00 & & & \\
\hline (6) & $0.74^{* * *}$ & $0.96^{* * *}$ & $0.96^{* * *}$ & $1.00^{* * *}$ & $0.98^{* * *}$ & 1.00 & & \\
\hline (7) & $0.75^{* * *}$ & $0.96^{* * *}$ & $0.96^{* * *}$ & $0.99^{* * *}$ & $0.98^{* * *}$ & $0.99^{* * *}$ & 1.00 & \\
\hline Chosen & $0.74^{* * *}$ & $0.96^{* * *}$ & $0.96^{* * *}$ & $1.00^{* * *}$ & $0.98^{* * *}$ & $1.00^{* * *}$ & $0.99^{* * *}$ & 1.00 \\
\hline \multicolumn{9}{|c|}{ C. Correlations across models; UVP } \\
\hline VP1 & 1.00 & & & & & & & \\
\hline VP2 & $0.82^{* * *}$ & 1.00 & & & & & & \\
\hline VP3 & $0.77^{* * *}$ & $0.94^{* * *}$ & 1.00 & & & & & \\
\hline VP4 & $0.77^{* * *}$ & $0.89^{* * *}$ & $0.87^{* * *}$ & 1.00 & & & & \\
\hline VP5 & $0.89^{* * *}$ & $0.99^{* * *}$ & $0.93^{* * *}$ & $0.89^{* * *}$ & 1.00 & & & \\
\hline VP6 & $0.76^{* * *}$ & $0.77^{* * *}$ & $0.77^{* * *}$ & $0.97^{* * *}$ & $0.79^{* * *}$ & 1.00 & & \\
\hline VP7 & $0.74^{* * *}$ & $0.77^{* * *}$ & $0.78^{* * *}$ & $0.97^{* * *}$ & $0.79^{* * *}$ & $0.99^{* * *}$ & 1.00 & \\
\hline Chosen & $0.89^{* * *}$ & $0.99^{* * *}$ & $0.93^{* * *}$ & $0.89^{* * *}$ & $1.00^{* * *}$ & $0.79^{* * *}$ & $0.79^{* * *}$ & 1.00 \\
\hline
\end{tabular}


Table 4: The null model: country-level regression with total variance risk premium

This table reports the country-level univariate predictability regression coefficient estimates where the predictor is the total variance risk premium. The regression setting is the following:

$$
h^{-1} r_{i, t, t+h}=a_{i, h}+b_{i, h}\left(v p_{t, t+1}^{D}+v p_{t, t+1}^{U}\right)+\epsilon_{i, t, t+h},
$$

where $r_{i, t, t+h}$ denotes the $h$-month-ahead log excess returns for country $i$. The table reports the results at various horizons of interest (in units of months). The estimates and their Newey-West standard errors (in parentheses) are reported along with the adjusted $R^{2} .{ }^{* * *}\left({ }^{* *},{ }^{*}\right)$ represent significance at the $1 \%$ $(5 \%, 10 \%)$ confidence level.

\begin{tabular}{|c|c|c|c|c|c|c|c|c|}
\hline & $\mathrm{h}=1$ & & $\mathrm{~h}=3$ & & $\mathrm{~h}=6$ & & $\mathrm{~h}=12$ & \\
\hline Country & Est (SE) & $R^{2}$ & Est (SE) & $\mathrm{R} 2$ & Est (SE) & $R^{2}$ & Est (SE) & $R^{2}$ \\
\hline Australia & $\begin{array}{l}0.3757 \\
(0.2727)\end{array}$ & $0.59 \%$ & $\begin{array}{l}0.4792^{* * *} \\
(0.1601)\end{array}$ & $2.73 \%$ & $\begin{array}{l}0.5159^{* * *} \\
(0.1174)\end{array}$ & $5.76 \%$ & $\begin{array}{l}0.3129 * * * \\
(0.0821)\end{array}$ & $4.48 \%$ \\
\hline Austria & $\begin{array}{l}-0.1748 \\
(0.3212)\end{array}$ & $0.09 \%$ & $\begin{array}{l}0.1649 \\
(0.2090)\end{array}$ & $0.19 \%$ & $\begin{array}{l}0.3282^{* *} \\
(0.1603)\end{array}$ & $1.31 \%$ & $\begin{array}{l}0.0745 \\
(0.1130)\end{array}$ & $0.14 \%$ \\
\hline Belgium & $\begin{array}{l}-0.2155 \\
(0.2542)\end{array}$ & $0.22 \%$ & $\begin{array}{l}0.0369 \\
(0.1627)\end{array}$ & $0.02 \%$ & $\begin{array}{l}0.0855 \\
(0.1242)\end{array}$ & $0.15 \%$ & $\begin{array}{l}-0.0312 \\
(0.0895)\end{array}$ & $0.04 \%$ \\
\hline Canada & $\begin{array}{l}0.2216 \\
(0.2552)\end{array}$ & $0.23 \%$ & $\begin{array}{l}0.4187^{* * *} \\
(0.1608)\end{array}$ & $2.08 \%$ & $\begin{array}{l}0.458^{* * *} \\
(0.1170)\end{array}$ & $4.63 \%$ & $\begin{array}{l}0.2779^{* * *} \\
(0.0818)\end{array}$ & $3.59 \%$ \\
\hline Denmark & $\begin{array}{l}-0.0622 \\
(0.2583)\end{array}$ & $0.02 \%$ & $\begin{array}{l}0.2416 \\
(0.1576)\end{array}$ & $0.73 \%$ & $\begin{array}{l}0.2893^{* *} \\
(0.1201)\end{array}$ & $1.80 \%$ & $\begin{array}{l}0.1391 \\
(0.0847)\end{array}$ & $0.86 \%$ \\
\hline Finland & $\begin{array}{l}0.3036 \\
(0.3661)\end{array}$ & $0.21 \%$ & $\begin{array}{l}0.3825^{*} \\
(0.2295)\end{array}$ & $0.86 \%$ & $\begin{array}{l}0.3779^{* *} \\
(0.1694)\end{array}$ & $1.55 \%$ & $\begin{array}{l}0.1760 \\
(0.1269)\end{array}$ & $0.62 \%$ \\
\hline France & $\begin{array}{c}-0.0019 \\
(0.2679)\end{array}$ & $0.00 \%$ & $\begin{array}{l}0.2355 \\
(0.1544)\end{array}$ & $0.72 \%$ & $\begin{array}{l}0.2808^{* *} \\
(0.1132)\end{array}$ & $1.91 \%$ & $\begin{array}{l}0.1508^{*} \\
(0.0817)\end{array}$ & $1.09 \%$ \\
\hline Germany & $\begin{array}{l}-0.0760 \\
(0.2970)\end{array}$ & $0.02 \%$ & $\begin{array}{l}0.1749 \\
(0.1719)\end{array}$ & $0.32 \%$ & $\begin{array}{l}0.2198^{*} \\
(0.1255)\end{array}$ & $0.96 \%$ & $\begin{array}{l}0.0609 \\
(0.0891)\end{array}$ & $0.15 \%$ \\
\hline Hong Kong & $\begin{array}{l}0.1582 \\
(0.3296)\end{array}$ & $0.07 \%$ & $\begin{array}{l}0.2223 \\
(0.1980)\end{array}$ & $0.39 \%$ & $\begin{array}{l}0.2562^{*} \\
(0.1375)\end{array}$ & $1.09 \%$ & $\begin{array}{l}0.1324 \\
(0.1002)\end{array}$ & $0.56 \%$ \\
\hline Ireland & $\begin{array}{l}-0.1292 \\
(0.2756)\end{array}$ & $0.07 \%$ & $\begin{array}{l}0.1149 \\
(0.1775)\end{array}$ & $0.13 \%$ & $\begin{array}{l}0.1402 \\
(0.1414)\end{array}$ & $0.31 \%$ & $\begin{array}{l}-0.1020 \\
(0.1054)\end{array}$ & $0.30 \%$ \\
\hline Italy & $\begin{array}{l}0.0841 \\
(0.3314)\end{array}$ & $0.02 \%$ & $\begin{array}{l}0.2654 \\
(0.1847)\end{array}$ & $0.64 \%$ & $\begin{array}{l}0.3012^{* *} \\
(0.1383)\end{array}$ & $1.48 \%$ & $\begin{array}{l}0.0874 \\
(0.0985)\end{array}$ & $0.25 \%$ \\
\hline Japan & $\begin{array}{l}-0.1642 \\
(0.2564)\end{array}$ & $0.13 \%$ & $\begin{array}{l}0.1705 \\
(0.1562)\end{array}$ & $0.37 \%$ & $\begin{array}{l}0.3545^{* * *} \\
(0.1165)\end{array}$ & $2.85 \%$ & $\begin{array}{l}0.2783^{* * *} \\
(0.0852)\end{array}$ & $3.33 \%$ \\
\hline Netherlands & $\begin{array}{l}-0.2470 \\
(0.2754)\end{array}$ & $0.25 \%$ & $\begin{array}{l}0.0765 \\
(0.1653)\end{array}$ & $0.07 \%$ & $\begin{array}{l}0.1070 \\
(0.1243)\end{array}$ & $0.23 \%$ & $\begin{array}{l}-0.0076 \\
(0.0898)\end{array}$ & $0.00 \%$ \\
\hline New Zeland & $\begin{array}{l}-0.1484 \\
(0.2812)\end{array}$ & $0.09 \%$ & $\begin{array}{l}0.1738 \\
(0.1589)\end{array}$ & $0.37 \%$ & $\begin{array}{l}0.2926^{* *} \\
(0.1224)\end{array}$ & $1.78 \%$ & $\begin{array}{l}0.1485 \\
(0.0928)\end{array}$ & $0.82 \%$ \\
\hline Norway & $\begin{array}{l}0.0120 \\
(0.3307)\end{array}$ & $0.00 \%$ & $\begin{array}{l}0.2245 \\
(0.2087)\end{array}$ & $0.36 \%$ & $\begin{array}{l}0.2822^{*} \\
(0.1554)\end{array}$ & $1.03 \%$ & $\begin{array}{l}0.1636 \\
(0.1091)\end{array}$ & $0.72 \%$ \\
\hline
\end{tabular}

(next page) 
(table continued)

\begin{tabular}{lllllllll}
\hline \hline & $\mathrm{h}=1$ & & $\mathrm{~h}=3$ & & $\mathrm{~h}=6$ & & $\mathrm{~h}=12$ & \\
\hline Country & Est (SE) & $R^{2}$ & Est (SE) & $R^{2}$ & Est (SE) & $R^{2}$ & Est (SE) & $R^{2}$ \\
\hline Portugal & -0.0044 & $0.00 \%$ & 0.1611 & $0.23 \%$ & 0.1188 & $0.22 \%$ & -0.0591 & $0.11 \%$ \\
& $(0.2998)$ & & $(0.1860)$ & & $(0.1419)$ & & $(0.1024)$ & \\
Singapore & 0.3085 & $0.31 \%$ & $0.5312^{* * *}$ & $2.36 \%$ & $0.571^{* * *}$ & $4.98 \%$ & $0.4526^{* * *}$ & $5.90 \%$ \\
& $(0.3106)$ & & $(0.1914)$ & & $(0.1403)$ & & $(0.1027)$ & \\
Spain & 0.2528 & $0.20 \%$ & $0.3621^{* *}$ & $1.26 \%$ & $0.2547^{*}$ & $1.17 \%$ & 0.0110 & $0.00 \%$ \\
& $(0.3133)$ & & $(0.1792)$ & & $(0.1317)$ & & $(0.0947)$ & \\
Sweden & 0.3639 & $0.40 \%$ & $0.5686^{* * *}$ & $2.78 \%$ & $0.5868^{* * *}$ & $4.98 \%$ & $0.379^{* * *}$ & $3.87 \%$ \\
& $(0.3209)$ & & $(0.1884)$ & & $(0.1442)$ & & $(0.1073)$ & \\
Switzerland & $-0.3776^{*}$ & $0.92 \%$ & -0.0581 & $0.06 \%$ & 0.0314 & $0.03 \%$ & -0.0414 & $0.12 \%$ \\
& $(0.2186)$ & & $(0.1294)$ & & $(0.0952)$ & & $(0.0692)$ & \\
U.K. & 0.0164 & $0.00 \%$ & 0.1916 & $0.69 \%$ & $0.2271^{* *}$ & $1.66 \%$ & 0.1042 & $0.66 \%$ \\
& $(0.2119)$ & & $(0.1285)$ & & $(0.0983)$ & & $(0.0727)$ & \\
U.S. & 0.0907 & $0.07 \%$ & $0.2292^{* *}$ & $1.33 \%$ & $0.2413^{* * *}$ & $2.57 \%$ & $0.1196^{*}$ & $1.12 \%$ \\
& $(0.1889)$ & & $(0.1106)$ & & $(0.0835)$ & & $(0.0638)$ & \\
\hline
\end{tabular}


Table 5: Model (1), country-level multivariate regression results with DVP and UVP: Model comparisons against the null

This table reports the country-level multivariate predictability regression results where the predictors are downside and upside variance risk premiums. Model (1) is a special case of Equation (7) (Section 4),

$$
h^{-1} r_{i, t, t+h}=a_{i, h}+b_{i, h, D} v p_{t, t+1}^{D}+b_{i, h, U} v p_{t, t+1}^{U}+\epsilon_{i, t, t+h} .
$$

Panel A provides AICs, Panel B BICs, and Panel C Adjusted $R^{2}$ s. Bold values indicate that Model (1) outperforms the null model (see Table 4) according to each fit measure. In the last row of each panel, we calculate the percentage of countries for which Model (1) outperforms the null model. The country-level coefficient estimates for this model are shown in Figures 4 and 5 (downside and upside, respectively).

\begin{tabular}{|c|c|c|c|c|c|c|c|c|}
\hline \multicolumn{9}{|c|}{ A. AIC } \\
\hline & $\mathrm{h}=1$ & & $\mathrm{~h}=3$ & & $\mathrm{~h}=6$ & & $\mathrm{~h}=12$ & \\
\hline Country & AIC (Null) & AIC (M1) & AIC (Null) & AIC (M1) & AIC (Null) & AIC (M1) & AIC (Null) & $\mathrm{AIC}(\mathrm{M} 1)$ \\
\hline Australia & 3672.15 & 3667.45 & 3307.26 & 3305.03 & 3077.26 & 3077.09 & 2792.57 & 2790.42 \\
\hline Austria & 3777.77 & 3771.41 & 3478.22 & 3476.28 & 3275.54 & 3275.44 & 2992.14 & 2991.39 \\
\hline Belgium & 3626.78 & 3619.52 & 3317.33 & 3315.35 & 3113.26 & 3112.93 & 2847.00 & 2846.51 \\
\hline Canada & 3629.13 & 3620.47 & 3310.05 & 3305.75 & 3074.92 & 3073.75 & 2790.50 & 2790.50 \\
\hline Finland & 3862.27 & 3858.11 & 3538.25 & 3536.31 & 3310.48 & 3310.28 & 3064.77 & 3064.70 \\
\hline France & 3660.65 & 3657.00 & 3283.91 & 3279.51 & 3054.04 & 3052.47 & 2789.73 & 2789.73 \\
\hline Germany & 3727.08 & 3724.53 & 3352.65 & 3350.56 & 3119.99 & 3119.39 & 2843.82 & 2843.63 \\
\hline Hong Kong & 3794.42 & 3794.27 & 3443.58 & 3443.57 & 3177.94 & 3177.84 & 2917.10 & 2915.54 \\
\hline Ireland & 3678.90 & 3670.86 & 3373.31 & 3369.42 & 3195.54 & 3195.23 & 2948.74 & 2948.66 \\
\hline Italy & 3797.95 & 3795.62 & 3398.86 & 3395.57 & 3181.75 & 3179.73 & 2906.75 & 2906.74 \\
\hline Netherlands & 3678.35 & 3676.96 & 3327.68 & 3326.67 & 3113.82 & 3113.08 & 2848.90 & 2848.61 \\
\hline New Zeland & 3691.99 & 3690.14 & 3302.21 & 3301.14 & 3103.84 & 3103.84 & 2869.62 & 2866.96 \\
\hline Norway & 3796.71 & 3787.75 & 3477.40 & 3475.41 & 3255.53 & 3255.39 & 2970.14 & 2969.84 \\
\hline Portugal & 3733.15 & 3731.74 & 3403.51 & 3401.97 & 3197.92 & 3197.72 & 2930.99 & 2930.67 \\
\hline Singapore & 3756.08 & 3754.65 & 3421.65 & 3421.32 & 3190.57 & 3190.48 & 2932.47 & 2930.76 \\
\hline Spain & 3761.78 & 3760.55 & 3379.39 & 3376.98 & 3150.27 & 3148.51 & 2881.81 & 2881.45 \\
\hline Sweden & 3777.17 & 3775.67 & 3411.66 & 3410.80 & 3208.09 & 3208.04 & 2960.16 & 2959.07 \\
\hline Switzerland & 3529.31 & 3527.04 & 3170.67 & 3167.14 & 2944.31 & 2941.30 & 2686.02 & 2686.02 \\
\hline U.K. & 3509.23 & 3503.23 & 3166.09 & 3160.29 & 2964.28 & 2961.79 & 2716.60 & 2716.60 \\
\hline U.S. & 3434.83 & 3428.25 & 3069.66 & 3062.49 & 2860.82 & 2858.62 & 2635.25 & 2635.25 \\
\hline$\%$ of $\mathrm{M}(1)$ Outperforms & $100 \%$ & & $100 \%$ & & $100 \%$ & & $100 \%$ & \\
\hline
\end{tabular}


(table continues)

\begin{tabular}{|c|c|c|c|c|c|c|c|c|}
\hline \multicolumn{9}{|c|}{ B. BIC } \\
\hline & $\mathrm{h}=1$ & & $\mathrm{~h}=3$ & & $\mathrm{~h}=6$ & & $\mathrm{~h}=12$ & \\
\hline Country & BIC (Null) & BIC (M1) & BIC (Null) & BIC (M1) & BIC (Null) & BIC (M1) & BIC (Null) & $\mathrm{BIC}(\mathrm{M} 1)$ \\
\hline Australia & 3679.71 & 3675.00 & 3314.80 & 3312.57 & 3084.78 & 3084.62 & 2800.06 & 2797.90 \\
\hline Austria & 3785.32 & 3778.97 & 3485.76 & 3483.82 & 3283.06 & 3282.96 & 2999.62 & 2998.88 \\
\hline Belgium & 3634.33 & 3627.07 & 3324.87 & 3322.89 & 3120.79 & 3120.45 & 2854.49 & 2854.00 \\
\hline Canada & 3636.69 & 3628.02 & 3317.59 & 3313.30 & 3082.45 & 3081.28 & 2797.99 & 2797.99 \\
\hline Denmark & 3644.60 & 3641.52 & 3304.45 & 3303.84 & 3099.40 & 3099.36 & 2819.88 & 2819.12 \\
\hline Finland & 3869.83 & 3865.67 & 3545.79 & 3543.85 & 3318.00 & 3317.80 & 3072.25 & 3072.19 \\
\hline France & 3668.21 & 3664.55 & 3291.45 & 3287.06 & 3061.56 & 3059.99 & 2797.22 & 2797.21 \\
\hline Germany & 3734.64 & 3732.09 & 3360.20 & 3358.11 & 3127.52 & 3126.91 & 2851.31 & 2851.11 \\
\hline Hong Kong & 3801.98 & 3801.82 & 3451.12 & 3451.12 & 3185.46 & 3185.36 & 2924.59 & 2923.03 \\
\hline Ireland & 3686.46 & 3678.41 & 3380.86 & 3376.97 & 3203.06 & 3202.76 & 2956.22 & 2956.15 \\
\hline Italy & 3805.51 & 3803.18 & 3406.40 & 3403.12 & 3189.27 & 3187.25 & 2914.23 & 2914.23 \\
\hline Japan & 3639.69 & 3638.40 & 3298.86 & 3298.02 & 3079.96 & 3079.83 & 2823.23 & 2821.74 \\
\hline Netherlands & 3685.90 & 3684.51 & 3335.22 & 3334.21 & 3121.35 & 3120.60 & 2856.38 & 2856.10 \\
\hline New Zeland & 3699.54 & 3697.70 & 3309.76 & 3308.68 & 3111.37 & 3111.37 & 2877.10 & 2874.44 \\
\hline Norway & 3804.27 & 3795.31 & 3484.94 & 3482.96 & 3263.06 & 3262.91 & 2977.63 & 2977.32 \\
\hline Portugal & 3740.71 & 3739.29 & 3411.05 & 3409.51 & 3205.44 & 3205.24 & 2938.48 & 2938.16 \\
\hline Singapore & 3763.63 & 3762.20 & 3429.20 & 3428.86 & 3198.10 & 3198.00 & 2939.96 & 2938.25 \\
\hline Spain & 3769.33 & 3768.11 & 3386.94 & 3384.52 & 3157.80 & 3156.03 & 2889.29 & 2888.94 \\
\hline Sweden & 3784.72 & 3783.23 & 3419.20 & 3418.35 & 3215.61 & 3215.56 & 2967.65 & 2966.56 \\
\hline Switzerland & 3536.87 & 3534.59 & 3178.21 & 3174.68 & 2951.83 & 2948.82 & 2693.51 & 2693.50 \\
\hline U.K. & 3516.78 & 3510.78 & 3173.64 & $\mathbf{3 1 6 7 . 8 4}$ & 2971.80 & 2969.32 & 2724.08 & 2724.08 \\
\hline U.S. & 3442.38 & 3435.80 & 3077.20 & 3070.03 & 2868.34 & 2866.14 & 2642.74 & 2642.73 \\
\hline$\%$ of $\mathrm{M}(1)$ Outperforms & $100 \%$ & & $100 \%$ & & $100 \%$ & & $100 \%$ & \\
\hline \multicolumn{9}{|c|}{ C. Adjusted $R^{2}$} \\
\hline & $\mathrm{h}=1$ & & $\mathrm{~h}=3$ & & $\mathrm{~h}=6$ & & $\mathrm{~h}=12$ & \\
\hline Country & $R^{2}$ (Null) & $\mathrm{R} 2(\mathrm{M} 1)$ & R2 (Null) & $\mathrm{R} 2(\mathrm{M} 1)$ & R2 (Null) & $\mathrm{R} 2(\mathrm{M} 1)$ & R2 (Null) & $\mathrm{R} 2$ (M1) \\
\hline Australia & $0.59 \%$ & $2.03 \%$ & $2.73 \%$ & $3.40 \%$ & $5.76 \%$ & $5.81 \%$ & $4.48 \%$ & $5.14 \%$ \\
\hline Austria & $0.09 \%$ & $2.04 \%$ & $0.19 \%$ & $0.80 \%$ & $1.31 \%$ & $1.34 \%$ & $0.14 \%$ & $0.38 \%$ \\
\hline Belgium & $0.22 \%$ & $2.44 \%$ & $0.02 \%$ & $0.63 \%$ & $0.15 \%$ & $0.25 \%$ & $0.04 \%$ & $0.20 \%$ \\
\hline Canada & $0.23 \%$ & $2.88 \%$ & $2.08 \%$ & $3.38 \%$ & $4.63 \%$ & $4.98 \%$ & $3.59 \%$ & $3.59 \%$ \\
\hline Denmark & $0.02 \%$ & $0.97 \%$ & $0.73 \%$ & $0.92 \%$ & $1.80 \%$ & $1.81 \%$ & $0.86 \%$ & $1.11 \%$ \\
\hline Finland & $0.21 \%$ & $1.49 \%$ & $0.86 \%$ & $1.46 \%$ & $1.55 \%$ & $1.61 \%$ & $0.62 \%$ & $0.64 \%$ \\
\hline France & $0.00 \%$ & $1.12 \%$ & $0.72 \%$ & $2.07 \%$ & $1.91 \%$ & $2.39 \%$ & $1.09 \%$ & $1.09 \%$ \\
\hline Germany & $0.02 \%$ & $0.81 \%$ & $0.32 \%$ & $0.97 \%$ & $0.96 \%$ & $1.15 \%$ & $0.15 \%$ & $0.21 \%$ \\
\hline Hong Kong & $0.07 \%$ & $0.12 \%$ & $0.39 \%$ & $0.39 \%$ & $1.09 \%$ & $1.12 \%$ & $0.56 \%$ & $1.06 \%$ \\
\hline Ireland & $0.07 \%$ & $2.53 \%$ & $0.13 \%$ & $1.33 \%$ & $0.31 \%$ & $0.41 \%$ & $0.30 \%$ & $0.33 \%$ \\
\hline Italy & $0.02 \%$ & $0.74 \%$ & $0.64 \%$ & $1.65 \%$ & $1.48 \%$ & $2.10 \%$ & $0.25 \%$ & $0.25 \%$ \\
\hline Japan & $0.13 \%$ & $0.53 \%$ & $0.37 \%$ & $0.63 \%$ & $2.85 \%$ & $2.89 \%$ & $3.33 \%$ & $3.79 \%$ \\
\hline Netherlands & $0.25 \%$ & $0.68 \%$ & $0.07 \%$ & $0.38 \%$ & $0.23 \%$ & $0.47 \%$ & $0.00 \%$ & $0.09 \%$ \\
\hline New Zeland & $0.09 \%$ & $0.66 \%$ & $0.37 \%$ & $0.71 \%$ & $1.78 \%$ & $1.78 \%$ & $0.82 \%$ & $1.66 \%$ \\
\hline Norway & $0.00 \%$ & $2.74 \%$ & $0.36 \%$ & $0.97 \%$ & $1.03 \%$ & $1.08 \%$ & $0.72 \%$ & $0.82 \%$ \\
\hline Portugal & $0.00 \%$ & $0.44 \%$ & $0.23 \%$ & $0.71 \%$ & $0.22 \%$ & $0.28 \%$ & $0.11 \%$ & $0.21 \%$ \\
\hline Singapore & $0.31 \%$ & $0.75 \%$ & $2.36 \%$ & $2.46 \%$ & $4.98 \%$ & $5.01 \%$ & $5.90 \%$ & $6.41 \%$ \\
\hline Spain & $0.20 \%$ & $0.58 \%$ & $1.26 \%$ & $2.00 \%$ & $1.17 \%$ & $1.72 \%$ & $0.00 \%$ & $0.12 \%$ \\
\hline Sweden & $0.40 \%$ & $0.86 \%$ & $2.78 \%$ & $3.03 \%$ & $4.98 \%$ & $4.99 \%$ & $3.87 \%$ & $4.20 \%$ \\
\hline Switzerland & $0.92 \%$ & $1.62 \%$ & $0.06 \%$ & $1.16 \%$ & $0.03 \%$ & $0.97 \%$ & $0.12 \%$ & $0.12 \%$ \\
\hline U.K. & $0.00 \%$ & $1.84 \%$ & $0.69 \%$ & $2.47 \%$ & $1.66 \%$ & $2.43 \%$ & $0.66 \%$ & $0.66 \%$ \\
\hline U.S. & $0.07 \%$ & $2.09 \%$ & $1.33 \%$ & $3.51 \%$ & $2.57 \%$ & $3.25 \%$ & $1.12 \%$ & $1.12 \%$ \\
\hline$\%$ of $\mathrm{M}(1)$ Outperforms & $100 \%$ & & $100 \%$ & & $100 \%$ & & $100 \%$ & \\
\hline
\end{tabular}


Table 6: Model (2), pooled multivariate regression results with DVP and UVP: Estimated coefficients, variance decomposition, and explanatory power

This table reports the pooled multivariate predictability regression results where the predictors are downside and upside variance risk premiums. The table provides coefficient estimates and their paneldata Newey-West standard errors at various horizons (in unit of months). We also report the adjusted $R^{2}$ and the proportion of the $R^{2}$ explained by each predictor (VARC). ${ }^{* * *}\left({ }^{* *},{ }^{*}\right)$ represent significance at the $1 \%(5 \%, 10 \%)$ confidence level.

\begin{tabular}{clllllll}
\hline \hline Horizon & Coef $\left(v p^{D}\right)$ & NW SE & VARC $\left(v p^{D}\right)$ & Coef $\left(v p^{U}\right)$ & NW SE & VARC $\left(v p^{U}\right)$ & $R^{2}$ \\
\hline 1 & -0.1055 & $(0.0720)$ & $4 \%$ & $1.7893^{* * *}$ & $(0.2081)$ & $96 \%$ & $0.88 \%$ \\
2 & $0.147^{* *}$ & $(0.0630)$ & $28 \%$ & $0.8646^{* * *}$ & $(0.1726)$ & $72 \%$ & $0.50 \%$ \\
3 & $0.1828^{* * *}$ & $(0.0588)$ & $29 \%$ & $1.0602^{* * *}$ & $(0.1598)$ & $71 \%$ & $1.12 \%$ \\
4 & $0.1886^{* * *}$ & $(0.0570)$ & $25 \%$ & $1.1948^{* * *}$ & $(0.1644)$ & $75 \%$ & $1.74 \%$ \\
5 & $0.2303^{* * *}$ & $(0.0539)$ & $49 \%$ & $0.8526^{* * *}$ & $(0.1293)$ & $51 \%$ & $1.57 \%$ \\
6 & $0.2676^{* * *}$ & $(0.0524)$ & $76 \%$ & $0.5509^{* * *}$ & $(0.1025)$ & $24 \%$ & $1.61 \%$ \\
7 & $0.2621^{* * *}$ & $(0.0520)$ & $93 \%$ & $0.2705^{* * *}$ & $(0.0994)$ & $7 \%$ & $1.45 \%$ \\
8 & $0.2072^{* * *}$ & $(0.0524)$ & $91 \%$ & $0.2416^{* *}$ & $(0.0980)$ & $9 \%$ & $1.05 \%$ \\
9 & $0.1837^{* * *}$ & $(0.0499)$ & $100 \%$ & 0.0115 & $(0.0950)$ & $0 \%$ & $0.84 \%$ \\
10 & $0.1588^{* * *}$ & $(0.0471)$ & $99 \%$ & -0.0594 & $(0.0905)$ & $1 \%$ & $0.70 \%$ \\
11 & $0.1526^{* * *}$ & $(0.0432)$ & $97 \%$ & -0.1051 & $(0.0880)$ & $3 \%$ & $0.73 \%$ \\
12 & $0.144^{* * *}$ & $(0.0396)$ & $98 \%$ & -0.0809 & $(0.0821)$ & $2 \%$ & $0.71 \%$ \\
\hline
\end{tabular}


Table 7: Model (3), country-level multivariate regression results with DVP, UVP, and other predictors

This table reports the country-level multivariate predictability regression results where the predictors are the following: DVP, UVP, term spread ("tsprd," calculated as the U.S. 10-year yield minus the 3-month yield; source: FRED), and dividend yield ("DY," the dividend yield of the U.S. S\&P 500 stock market index; source: DataStream). The model is a special case of Equation (7) (Section 4):

$$
\begin{aligned}
h^{-1} r_{i, t, t+h} & =a_{i, h}+b_{i, h, D} v p_{t, t+1}^{D}+b_{i, h, U} v p_{t, t+1}^{U} \\
& +c_{i, h, t s p r d} t s p r d_{t}+c_{i, h, D Y} D Y_{t}+\epsilon_{i, t, t+h} .
\end{aligned}
$$

The table presents the coefficient estimates of $v p^{D}$ and $v p^{U}$, their panel-data Newey-West standard errors, and total adjusted $R^{2} \mathrm{~s}$ of the model at selected horizons. The exact coefficient estimates of $v p^{D}$ and $v p^{U}$ for all horizons are shown in Figures 7 and $8 .{ }^{* * *}\left({ }^{* *},{ }^{*}\right)$ represent significance at the $1 \%(5 \%$,

\begin{tabular}{|c|c|c|c|c|c|c|c|c|c|c|c|c|}
\hline Country & $\begin{array}{l}\mathrm{h}=1 \\
v p^{D}\end{array}$ & $v p^{U}$ & $R^{2}$ & $\begin{array}{l}\mathrm{h}=3 \\
v p^{D}\end{array}$ & $v p^{U}$ & $R^{2}$ & $\begin{array}{l}\mathrm{h}=6 \\
v p^{D}\end{array}$ & $v p^{U}$ & $R^{2}$ & $\begin{array}{l}\mathrm{h}=12 \\
v p^{D}\end{array}$ & $v p^{U}$ & $R^{2}$ \\
\hline Australia & $\begin{array}{l}0.2599 \\
(0.3529)\end{array}$ & $\begin{array}{l}2.754^{* * *} \\
(0.9791)\end{array}$ & $1.56 \%$ & $\begin{array}{l}0.4672^{*} \\
(0.2633)\end{array}$ & $\begin{array}{l}1.5562 * * \\
(0.7917)\end{array}$ & $4.45 \%$ & $\begin{array}{l}0.5481^{* * *} \\
(0.2009)\end{array}$ & $\begin{array}{l}0.8867 * * \\
(0.4076)\end{array}$ & $8.04 \%$ & $\begin{array}{l}0.3498 * * \\
(0.1727)\end{array}$ & $\begin{array}{l}0.0013 \\
(0.2723)\end{array}$ & $6.08 \%$ \\
\hline Austria & $\begin{array}{l}-0.3901 \\
(0.4451)\end{array}$ & $\begin{array}{l}2.8256^{* *} \\
(1.1040)\end{array}$ & $0.83 \%$ & $\begin{array}{l}0.1094 \\
(0.3580)\end{array}$ & $\begin{array}{l}1.3066 \\
(0.8170)\end{array}$ & $-0.21 \%$ & $\begin{array}{l}0.3379 \\
(0.3077)\end{array}$ & $\begin{array}{l}0.6158 \\
(0.5994)\end{array}$ & $0.60 \%$ & $\begin{array}{l}0.0688 \\
(0.2488)\end{array}$ & $\begin{array}{l}-0.2603 \\
(0.4254)\end{array}$ & $0.70 \%$ \\
\hline Belgium & $\begin{array}{l}-0.3577 \\
(0.3249)\end{array}$ & $\begin{array}{l}2.5194^{* * *} \\
(0.9308)\end{array}$ & $2.21 \%$ & $\begin{array}{l}0.0282 \\
(0.2247)\end{array}$ & $\begin{array}{l}1.1229^{*} \\
(0.5799)\end{array}$ & $2.23 \%$ & $\begin{array}{l}0.1171 \\
(0.2085)\end{array}$ & $\begin{array}{l}0.6224 \\
(0.3991)\end{array}$ & $4.46 \%$ & $\begin{array}{l}0.0008 \\
(0.1676)\end{array}$ & $\begin{array}{l}-0.0200 \\
(0.3712)\end{array}$ & $5.68 \%$ \\
\hline Canada & $\begin{array}{l}0.0520 \\
(0.3429)\end{array}$ & $\begin{array}{l}3.1244^{* * *} \\
(0.8104)\end{array}$ & $2.19 \%$ & $\begin{array}{l}0.3699 \\
(0.2317)\end{array}$ & $\begin{array}{l}1.7988^{* * *} \\
(0.5695)\end{array}$ & $3.61 \%$ & $\begin{array}{l}0.4557^{* * *} \\
(0.1513)\end{array}$ & $\begin{array}{l}1.0808^{* * *} \\
(0.3308)\end{array}$ & $5.90 \%$ & $\begin{array}{l}0.2834^{*} \\
(0.1469)\end{array}$ & $\begin{array}{l}0.3884 \\
(0.2760)\end{array}$ & $4.62 \%$ \\
\hline Denmark & $\begin{array}{l}-0.1496 \\
(0.3397)\end{array}$ & $\begin{array}{l}1.7164^{* *} \\
(0.8573)\end{array}$ & $0.10 \%$ & $\begin{array}{l}0.2458 \\
(0.2440)\end{array}$ & $\begin{array}{l}0.8076 \\
(0.6310)\end{array}$ & $0.67 \%$ & $\begin{array}{l}0.3155 \\
(0.1927)\end{array}$ & $\begin{array}{l}0.5053 \\
(0.4571)\end{array}$ & $2.17 \%$ & $\begin{array}{l}0.1552 \\
(0.1441)\end{array}$ & $\begin{array}{l}-0.0279 \\
(0.3511)\end{array}$ & $1.51 \%$ \\
\hline Finland & $\begin{array}{l}0.1929 \\
(0.5206)\end{array}$ & $\begin{array}{l}3.2204^{* *} \\
(1.2576)\end{array}$ & $1.20 \%$ & $\begin{array}{l}0.3789 \\
(0.3354)\end{array}$ & $\begin{array}{l}1.717^{* *} \\
(0.8257)\end{array}$ & $2.15 \%$ & $\begin{array}{l}0.421^{* *} \\
(0.2123)\end{array}$ & $\begin{array}{l}0.8418^{*} \\
(0.4847)\end{array}$ & $2.83 \%$ & $\begin{array}{l}0.2038 \\
(0.2270)\end{array}$ & $\begin{array}{l}0.5042 \\
(0.3972)\end{array}$ & $2.49 \%$ \\
\hline France & $\begin{array}{l}-0.0755 \\
(0.3903)\end{array}$ & $\begin{array}{l}2.0552^{*} \\
(1.0596)\end{array}$ & $0.90 \%$ & $\begin{array}{l}0.2203 \\
(0.2348)\end{array}$ & $\begin{array}{l}1.6168 * * * \\
(0.5695)\end{array}$ & $4.51 \%$ & $\begin{array}{l}0.3097^{* *} \\
(0.1354)\end{array}$ & $\begin{array}{l}1.0091^{* * *} \\
(0.3347)\end{array}$ & $7.60 \%$ & $\begin{array}{l}0.1869^{*} \\
(0.1025)\end{array}$ & $\begin{array}{l}0.3018 \\
(0.3108)\end{array}$ & $5.33 \%$ \\
\hline Germany & $\begin{array}{l}-0.1232 \\
(0.4309)\end{array}$ & $\begin{array}{l}1.9562 \\
(1.2554)\end{array}$ & $1.09 \%$ & $\begin{array}{l}0.1946 \\
(0.2532)\end{array}$ & $\begin{array}{l}1.3836^{* *} \\
(0.6816)\end{array}$ & $4.66 \%$ & $\begin{array}{l}0.2759^{*} \\
(0.1536)\end{array}$ & $\begin{array}{l}0.8964 * * \\
(0.4159)\end{array}$ & $9.30 \%$ & $\begin{array}{l}0.1152 \\
(0.1110)\end{array}$ & $\begin{array}{l}0.2065 \\
(0.3826)\end{array}$ & $10.04 \%$ \\
\hline Hong Kong & $\begin{array}{l}0.2017 \\
(0.4163)\end{array}$ & $\begin{array}{l}1.0720 \\
(1.0424)\end{array}$ & $0.78 \%$ & $\begin{array}{l}0.3058 \\
(0.3032)\end{array}$ & $\begin{array}{l}0.6798 \\
(0.8073)\end{array}$ & $4.44 \%$ & $\begin{array}{l}0.3401^{*} \\
(0.1944)\end{array}$ & $\begin{array}{l}0.5155 \\
(0.4441)\end{array}$ & $9.59 \%$ & $\begin{array}{l}0.2070 \\
(0.1684)\end{array}$ & $\begin{array}{l}0.0442 \\
(0.4182)\end{array}$ & $12.76 \%$ \\
\hline Ireland & $\begin{array}{l}-0.2769 \\
(0.4252)\end{array}$ & $\begin{array}{l}2.9342^{* *} \\
(1.1752)\end{array}$ & $2.35 \%$ & $\begin{array}{l}0.0866 \\
(0.2957)\end{array}$ & $\begin{array}{l}1.6152^{*} \\
(0.8940)\end{array}$ & $2.76 \%$ & $\begin{array}{l}0.1672 \\
(0.2064)\end{array}$ & $\begin{array}{l}0.6391 \\
(0.4626)\end{array}$ & $2.08 \%$ & $\begin{array}{l}-0.1043 \\
(0.1508)\end{array}$ & $\begin{array}{l}-0.0510 \\
(0.3259)\end{array}$ & $1.92 \%$ \\
\hline Italy & $\begin{array}{l}0.0136 \\
(0.4935)\end{array}$ & $\begin{array}{l}2.0191^{*} \\
(1.1496)\end{array}$ & $0.07 \%$ & $\begin{array}{l}0.2418 \\
(0.3073)\end{array}$ & $\begin{array}{l}1.5685^{* *} \\
(0.6434)\end{array}$ & $2.28 \%$ & $\begin{array}{l}0.3077 \\
(0.2075)\end{array}$ & $\begin{array}{l}1.1396^{* *} \\
(0.4544)\end{array}$ & $3.72 \%$ & $\begin{array}{l}0.1074 \\
(0.1422)\end{array}$ & $\begin{array}{l}0.1445 \\
(0.3534)\end{array}$ & $-0.10 \%$ \\
\hline Japan & $\begin{array}{l}-0.1051 \\
(0.3449)\end{array}$ & $\begin{array}{l}-1.1404 \\
(0.8621)\end{array}$ & $-0.44 \%$ & $\begin{array}{l}0.2022 \\
(0.2749)\end{array}$ & $\begin{array}{l}-0.2341 \\
(0.6306)\end{array}$ & $0.08 \%$ & $\begin{array}{l}0.36^{* *} \\
(0.1719)\end{array}$ & $\begin{array}{l}0.3609 \\
(0.4068)\end{array}$ & $3.83 \%$ & $\begin{array}{l}0.2793^{*} \\
(0.1655)\end{array}$ & $\begin{array}{l}0.0539 \\
(0.3926)\end{array}$ & $9.00 \%$ \\
\hline Netherlands & $\begin{array}{l}-0.2515 \\
(0.3768)\end{array}$ & $\begin{array}{l}1.2859 \\
(0.9666)\end{array}$ & $1.53 \%$ & $\begin{array}{l}0.1225 \\
(0.2372)\end{array}$ & $\begin{array}{l}1.0505 * * \\
(0.4941)\end{array}$ & $5.87 \%$ & $\begin{array}{l}0.1631 \\
(0.1459)\end{array}$ & $\begin{array}{l}0.8983^{* * *} \\
(0.3386)\end{array}$ & $11.85 \%$ & $\begin{array}{l}0.0525 \\
(0.1103)\end{array}$ & $\begin{array}{l}0.1894 \\
(0.3229)\end{array}$ & $15.93 \%$ \\
\hline New Zeland & $\begin{array}{l}-0.2911 \\
(0.3544)\end{array}$ & $\begin{array}{l}1.5718^{*} \\
(0.9337)\end{array}$ & $1.42 \%$ & $\begin{array}{l}0.1008 \\
(0.2751)\end{array}$ & $\begin{array}{l}1.0914 \\
(0.7512)\end{array}$ & $4.77 \%$ & $\begin{array}{l}0.2624 \\
(0.1857)\end{array}$ & $\begin{array}{l}0.5863 \\
(0.5292)\end{array}$ & $9.96 \%$ & $\begin{array}{l}0.1356 \\
(0.1271)\end{array}$ & $\begin{array}{l}-0.1568 \\
(0.3294)\end{array}$ & $17.54 \%$ \\
\hline Norway & $\begin{array}{l}-0.2178 \\
(0.3686)\end{array}$ & $\begin{array}{l}3.8181^{* * *} \\
(0.9889)\end{array}$ & $1.96 \%$ & $\begin{array}{l}0.1819 \\
(0.2672)\end{array}$ & $\begin{array}{l}1.4815^{* *} \\
(0.7129)\end{array}$ & $0.63 \%$ & $\begin{array}{l}0.2925 \\
(0.2472)\end{array}$ & $\begin{array}{l}0.6855 \\
(0.4815)\end{array}$ & $1.26 \%$ & $\begin{array}{l}0.1645 \\
(0.2205)\end{array}$ & $\begin{array}{l}0.1085 \\
(0.4071)\end{array}$ & $2.81 \%$ \\
\hline
\end{tabular}
$10 \%$ ) confidence level. 
(table continues)

\begin{tabular}{|c|c|c|c|c|c|c|c|c|c|c|c|c|}
\hline \multirow[b]{2}{*}{ Country } & \multicolumn{3}{|l|}{$\overline{\mathrm{h}=1}$} & \multicolumn{3}{|l|}{$\mathrm{h}=3$} & \multicolumn{3}{|l|}{$\overline{\mathrm{h}=6}$} & \multicolumn{3}{|l|}{$\overline{\mathrm{h}=12}$} \\
\hline & $v p^{D}$ & $v p^{U}$ & $R^{2}$ & $v p^{D}$ & $v p^{U}$ & $R^{2}$ & $v p^{D}$ & $v p^{U}$ & $R^{2}$ & $v p^{D}$ & $v p^{U}$ & $R^{2}$ \\
\hline Portugal & $\begin{array}{l}-0.0248 \\
(0.3472)\end{array}$ & $\begin{array}{l}1.5182 \\
(1.0054)\end{array}$ & $0.29 \%$ & $\begin{array}{l}0.1767 \\
(0.2549)\end{array}$ & $\begin{array}{l}1.2418^{* *} \\
(0.6234)\end{array}$ & $2.55 \%$ & $\begin{array}{l}0.1692 \\
(0.2637)\end{array}$ & $\begin{array}{l}0.5928 \\
(0.5557)\end{array}$ & $3.65 \%$ & $\begin{array}{l}-0.0023 \\
(0.1855)\end{array}$ & $\begin{array}{l}-0.0463 \\
(0.5362)\end{array}$ & $4.53 \%$ \\
\hline Singapore & $\begin{array}{l}0.2336 \\
(0.4731)\end{array}$ & $\begin{array}{l}1.9504 \\
(1.1986)\end{array}$ & $0.26 \%$ & $\begin{array}{l}0.5350 \\
(0.3696)\end{array}$ & $\begin{array}{l}1.2114 \\
(0.7867)\end{array}$ & $3.15 \%$ & $\begin{array}{l}0.6099^{* *} \\
(0.2557)\end{array}$ & $\begin{array}{l}0.6895 \\
(0.5570)\end{array}$ & $7.23 \%$ & $\begin{array}{c}0.4913^{* *} \\
(0.2026)\end{array}$ & $\begin{array}{l}0.1954 \\
(0.4520)\end{array}$ & $9.99 \%$ \\
\hline Spain & $\begin{array}{l}0.2549 \\
(0.4367)\end{array}$ & $\begin{array}{l}1.7865 \\
(1.2652)\end{array}$ & $0.88 \%$ & $\begin{array}{l}0.3805 \\
(0.2755)\end{array}$ & $\begin{array}{l}1.6269 * * * \\
(0.5389)\end{array}$ & $5.17 \%$ & $\begin{array}{l}0.2894 \\
(0.2390)\end{array}$ & $\begin{array}{l}1.1391^{* *} \\
(0.5754)\end{array}$ & $7.41 \%$ & $\begin{array}{l}0.0701 \\
(0.1585)\end{array}$ & $\begin{array}{l}-0.0017 \\
(0.4508)\end{array}$ & $4.54 \%$ \\
\hline Sweden & $\begin{array}{l}0.3117 \\
(0.4148)\end{array}$ & $\begin{array}{l}2.1688^{* *} \\
(1.0647)\end{array}$ & $0.94 \%$ & $\begin{array}{l}0.5778^{* *} \\
(0.2704)\end{array}$ & $\begin{array}{l}1.5517^{* *} \\
(0.7561)\end{array}$ & $5.22 \%$ & $\begin{array}{l}0.6413^{* * *} \\
(0.1802)\end{array}$ & $\begin{array}{l}0.8234^{*} \\
(0.4213)\end{array}$ & $9.36 \%$ & $\begin{array}{l}0.4213^{* * *} \\
(0.1600)\end{array}$ & $\begin{array}{l}0.3085 \\
(0.3697)\end{array}$ & $12.16 \%$ \\
\hline Switzerland & $\begin{array}{l}-0.4303 \\
(0.3271)\end{array}$ & $\begin{array}{l}1.0875 \\
(0.8887)\end{array}$ & $1.77 \%$ & $\begin{array}{l}-0.0807 \\
(0.2186)\end{array}$ & $\begin{array}{l}1.1068^{* *} \\
(0.5130)\end{array}$ & $4.58 \%$ & $\begin{array}{l}0.0268 \\
(0.1209)\end{array}$ & $\begin{array}{l}0.9511^{* * *} \\
(0.2934)\end{array}$ & $10.53 \%$ & $\begin{array}{l}-0.0258 \\
(0.0830)\end{array}$ & $\begin{array}{l}0.2541 \\
(0.2564)\end{array}$ & $18.63 \%$ \\
\hline U.K. & $\begin{array}{l}-0.0710 \\
(0.3346)\end{array}$ & $\begin{array}{l}2.1448^{* * *} \\
(0.7099)\end{array}$ & $2.19 \%$ & $\begin{array}{l}0.1619 \\
(0.2293)\end{array}$ & $\begin{array}{l}1.5679^{* * *} \\
(0.5407)\end{array}$ & $5.82 \%$ & $\begin{array}{l}0.2325^{*} \\
(0.1279)\end{array}$ & $\begin{array}{l}1.0478^{* * *} \\
(0.2974)\end{array}$ & $8.66 \%$ & $\begin{array}{l}0.1249 \\
(0.0983)\end{array}$ & $\begin{array}{l}0.3347 \\
(0.2385)\end{array}$ & $9.44 \%$ \\
\hline U.S. & $\begin{array}{l}0.0199 \\
(0.3392)\end{array}$ & $\begin{array}{l}2.1218^{* * *} \\
(0.7726)\end{array}$ & $3.39 \%$ & $\begin{array}{l}0.2121 \\
(0.2351)\end{array}$ & $\begin{array}{l}1.5707^{* * *} \\
(0.5410)\end{array}$ & $9.76 \%$ & $\begin{array}{l}0.2612^{* *} \\
(0.1177)\end{array}$ & $\begin{array}{l}0.9631^{* * *} \\
(0.2791)\end{array}$ & $13.90 \%$ & $\begin{array}{l}0.1473^{*} \\
(0.0861)\end{array}$ & $\begin{array}{l}0.3607^{*} \\
(0.1865)\end{array}$ & $15.60 \%$ \\
\hline
\end{tabular}


Table 8: Model (4), pooled multivariate regression results with DVP, UVP, and other predictors: Estimated coefficients, variance decomposition, and explanatory power

This table reports the pooled multivariate predictability regression results where the predictors are the following: DVP, UVP, term spread ("tsprd," calculated as the U.S. 10-year yield minus the 3-month yield; source: FRED), and dividend yield ("DY," the dividend yield of the U.S. S\&P 500 stock market index; source: DataStream). The model is a special case of Equation (8) (Section 44,

$$
\begin{aligned}
h^{-1} r_{i, t, t+h} & =a_{h}+b_{h, D} v p_{t, t+1}^{D}+b_{h, U} v p_{t, t+1}^{U} \\
& +c_{h, t s p r d} \operatorname{sprd}_{t}+c_{h, D Y} D Y_{t}+\epsilon_{i, t, t+h} .
\end{aligned}
$$

For each predictor, the first column presents the coefficient estimates and their significance level using the Newey-West standard errors reported in the second column. The third column reports the variance decomposition (VARC), $\widehat{b_{x}} \frac{\operatorname{cov}(\text { Fitted }, x)}{\text { var(Fitted) }}$, where $x$ is any of the predictors. By design, all VARCs add up to 1 . Column " $R^{2}$ " reports the adjusted $R^{2}$ of the model. The table also reports an $\mathrm{F}$ test comparing Model (4) with Model (2), which is a nested model. ${ }^{* * *}\left({ }^{* *},{ }^{*}\right)$ represent significance at the $1 \%$ (5\%,

\begin{tabular}{|c|c|c|c|c|c|c|c|c|c|c|}
\hline Horizon & $\operatorname{Coef}\left(v p^{D}\right)$ & NW SE & $\operatorname{VARC}\left(v p^{D}\right)$ & $\operatorname{Coef}\left(v p^{U}\right)$ & NW SE & $\operatorname{VARC}\left(v p^{U}\right)$ & & & & \\
\hline 1 & -0.0557 & $(0.0089)$ & $1 \%$ & $2.0232^{* * *}$ & $(0.0208)$ & $57 \%$ & & & & \\
\hline 2 & $0.2016^{* * *}$ & $(0.0069)$ & $10 \%$ & $1.0899 * * *$ & $(0.0099)$ & $23 \%$ & & & & \\
\hline 3 & $0.2372^{* * *}$ & $(0.0053)$ & $12 \%$ & $1.2927^{* * *}$ & $(0.0077)$ & $29 \%$ & & & & \\
\hline 4 & $0.2426^{* * *}$ & $(0.0051)$ & $12 \%$ & $1.4402^{* * *}$ & $(0.0069)$ & $33 \%$ & & & & \\
\hline 5 & $0.2802^{* * *}$ & $(0.0049)$ & $19 \%$ & $1.0987^{* * *}$ & $(0.0069)$ & $20 \%$ & & & & \\
\hline 6 & $0.3138^{* * *}$ & $(0.0043)$ & $26 \%$ & $0.795^{* * *}$ & $(0.0074)$ & $10 \%$ & & & & \\
\hline 7 & $0.3045^{* * *}$ & $(0.0041)$ & $29 \%$ & $0.5057^{* * *}$ & $(0.0060)$ & $4 \%$ & & & & \\
\hline 8 & $0.2431^{* * *}$ & $(0.0042)$ & $22 \%$ & $0.4731^{* * *}$ & $(0.0063)$ & $4 \%$ & & & & \\
\hline 9 & $0.2131^{* * *}$ & $(0.0038)$ & $20 \%$ & $0.2342^{* * *}$ & $(0.0062)$ & $0 \%$ & & & & \\
\hline 10 & $0.1818^{* * *}$ & $(0.0035)$ & $16 \%$ & $0.1579^{*}$ & $(0.0064)$ & $0 \%$ & & & & \\
\hline 11 & $0.17^{* * *}$ & $(0.0032)$ & $16 \%$ & 0.1067 & $(0.0059)$ & $-1 \%$ & & & & \\
\hline 12 & $0.156^{* * *}$ & $(0.0031)$ & $14 \%$ & $0.1287^{*}$ & $(0.0059)$ & $-1 \%$ & & & & \\
\hline Horizon & Coef(tsprd) & NW SE & VARC(tsprd) & Coef(DY) & NW SE & VARC(DY) & $\operatorname{VARC}\left(v p^{D}+v p^{U}\right)$ & $R^{2}$ & $\mathrm{~F}(\mathrm{H} 0: \mathrm{M}(2))$ & p-value \\
\hline 1 & $-4.1804^{* * *}$ & $(0.0032)$ & $8 \%$ & $66.654^{* * *}$ & $(0.854)$ & $33 \%$ & $58 \%$ & $1.65 \%$ & 56.17 & $0 \%$ \\
\hline 2 & $-4.692^{* * *}$ & $(0.0024)$ & $14 \%$ & $66.4107^{* * *}$ & $(0.831)$ & $53 \%$ & $33 \%$ & $1.98 \%$ & 107.01 & $0 \%$ \\
\hline 3 & $-4.6515^{* * *}$ & $(0.0019)$ & $11 \%$ & $67.9058^{* * *}$ & $(0.795)$ & $47 \%$ & $41 \%$ & $3.38 \%$ & 165.14 & $0 \%$ \\
\hline 4 & $-4.5658 * * *$ & $(0.0018)$ & $9 \%$ & $70.5776^{* * *}$ & $(0.775)$ & $47 \%$ & $44 \%$ & $4.80 \%$ & 226.18 & $0 \%$ \\
\hline 5 & $-4.159 * * *$ & $(0.0016)$ & $5 \%$ & $69.4541^{* * *}$ & $(0.758)$ & $56 \%$ & $39 \%$ & $5.07 \%$ & 258.32 & $0 \%$ \\
\hline 6 & $-3.7997 * * *$ & $(0.0014)$ & $2 \%$ & $67.8702^{* * *}$ & $(0.739)$ & $61 \%$ & $36 \%$ & $5.47 \%$ & 285.34 & $0 \%$ \\
\hline 7 & $-3.464^{* * *}$ & $(0.0012)$ & $1 \%$ & $64.8069^{* * *}$ & $(0.714)$ & $67 \%$ & $32 \%$ & $5.47 \%$ & 296.01 & $0 \%$ \\
\hline 8 & $-2.8051^{* * *}$ & $(0.0012)$ & $-3 \%$ & $61.8148^{* * *}$ & $(0.686)$ & $77 \%$ & $25 \%$ & $5.20 \%$ & 303.63 & $0 \%$ \\
\hline 9 & $-2.1529 * * *$ & $(0.0011)$ & $-6 \%$ & $57.6357^{* * *}$ & $(0.668)$ & $86 \%$ & $20 \%$ & $4.93 \%$ & 297.71 & $0 \%$ \\
\hline 10 & $-1.5013^{* *}$ & $(0.0011)$ & $-7 \%$ & $54.1682^{* * *}$ & $(0.649)$ & $91 \%$ & $16 \%$ & $4.85 \%$ & 300.96 & $0 \%$ \\
\hline 11 & -0.9088 & $(0.0010)$ & $-6 \%$ & $50.8702^{* * *}$ & $(0.635)$ & $91 \%$ & $15 \%$ & $4.99 \%$ & 308.55 & $0 \%$ \\
\hline 12 & -0.3350 & $(0.0010)$ & $-3 \%$ & $48.3424^{* * *}$ & $(0.627)$ & $89 \%$ & $14 \%$ & $5.30 \%$ & 332.88 & $0 \%$ \\
\hline
\end{tabular}
$10 \%)$ confidence level. 
Table 9: Estimation results of real upside and downside uncertainties

This table reports estimation results of real upside and downside economic uncertainties extracted from the log change in the monthly U.S. industrial production index. Growth is denoted by $\theta$ and follows the process

$$
\begin{aligned}
\theta_{t+1} & =\theta_{0}+\rho_{\theta \theta} \theta_{t}+\rho_{\theta \theta p}\left(\theta p_{t}-\overline{\theta p}\right)+\rho_{\theta \theta n}\left(\theta n_{t}-\overline{\theta n}\right)+u_{\theta, t+1}, \\
u_{\theta, t+1} & =\delta_{\theta \theta p} \omega_{\theta p, t+1}-\delta_{\theta \theta n} \omega_{\theta n, t+1},
\end{aligned}
$$

where

$$
\begin{aligned}
\omega_{\theta p, t+1} & \sim \Gamma\left(\theta p_{t}, 1\right)-\theta p_{t}, \\
\omega_{\theta n, t+1} & \sim \Gamma\left(\theta n_{t}, 1\right)-\theta n_{t}, \\
\theta p_{t+1} & =\overline{\theta p}+\rho_{\theta p}\left(\theta p_{t}-\overline{\theta p}\right)+\delta_{\theta p} \omega_{\theta p, t+1}, \\
\theta n_{t+1} & =\overline{\theta n}+\rho_{\theta n}\left(\theta n_{t}-\overline{\theta n}\right)+\delta_{\theta n} \omega_{\theta n, t+1} .
\end{aligned}
$$

\begin{tabular}{|c|c|c|c|c|c|}
\hline \multicolumn{6}{|c|}{ A. Estimation results } \\
\hline \multicolumn{2}{|r|}{$\theta_{t}$} & \multicolumn{3}{|c|}{$\theta p_{t}$} & $\theta n_{t}$ \\
\hline \multirow[t]{2}{*}{$\theta_{0}$} & $0.0015^{* * *}$ & $\overline{\theta p}$ & 500 (fix) & $\overline{\theta n}$ & $10.3362^{* * *}$ \\
\hline & $(0.0003)$ & & & & $(2.0747)$ \\
\hline \multirow[t]{2}{*}{$\rho_{\theta \theta}$} & $0.3818^{* * *}$ & $\rho_{\theta p}$ & $0.9979^{* * *}$ & $\rho_{\theta n}$ & $0.9525^{* * *}$ \\
\hline & $(0.0316)$ & & $(0.0171)$ & & $(0.0096)$ \\
\hline \multirow[t]{2}{*}{$\rho_{\theta \theta p}$} & 0.0000 & & & & \\
\hline & $(0.0002)$ & & & & \\
\hline \multirow[t]{2}{*}{$\rho_{\theta \theta n}$} & -0.0001 & & & & \\
\hline & $(0.0012)$ & & & & \\
\hline \multirow[t]{2}{*}{$\delta_{\theta \theta p}$} & $0.0001^{* * *}$ & $\delta_{\theta p}$ & $0.3739 * * *$ & & \\
\hline & $(0.0000)$ & & $(0.0173)$ & & \\
\hline \multirow[t]{2}{*}{$\delta_{\theta \theta n}$} & $0.0028^{* * *}$ & & & $\delta_{\theta p}$ & $2.2996^{* * *}$ \\
\hline & $(0.0003)$ & & & & $(0.1907)$ \\
\hline \multicolumn{3}{|c|}{ B. Moment match } & \multicolumn{3}{|c|}{ C. Cyclicality } \\
\hline & Data & Model & & $\theta p_{t}$ & $\theta n_{t}$ \\
\hline \multirow[t]{2}{*}{ Mean } & $0.0022^{* * *}$ & 0.0024 & $\rho(N B E R)$ & -0.0201 & $0.6012^{* * *}$ \\
\hline & $(0.0003)$ & & & $(0.0512)$ & $(0.0409)$ \\
\hline Variance & $\begin{array}{l}5.8 \mathrm{E}-5^{* * *} \\
(7.7 \mathrm{E}-6)\end{array}$ & $6.7 \mathrm{E}-5$ & & & \\
\hline
\end{tabular}

The estimation is conducted using the AML in Bates $(2006) .{ }^{* * *}\left({ }^{* *},{ }^{*}\right)$ represent significance at the $1 \%$ $(5 \%, 10 \%)$ confidence level. Panel B shows moment matching. In this panel, values under "Model" are in bold if the model-implied moments are within the $95 \%$ confidence interval of data point estimates. Panel $\mathrm{C}$ provides a cyclicality test and shows the correlations of the estimates of $\theta p$ and $\theta n$ with the NBER recession indicator. 
Table 10: Estimation results of risk aversion right- and left-tail state variables

This table reports estimation results of risk aversion right- and left-tail state variables, $q p_{t}$ and $q n_{t}$, respectively, extracted from a monthly risk aversion index estimated from a variant of the habit-formation dynamic asset pricing model and using a wide information set of economic variables and risky asset prices in Bekaert, Engstrom, and $\mathrm{Xu}(2017)$. The risk aversion state variable is denoted by $q$ and follows the process

$$
\begin{aligned}
q_{t+1} & =q_{0}+\rho_{q q} q_{t}+\rho_{q \theta p}\left(\theta p_{t}-\overline{\theta p}\right)+\rho_{q \theta n}\left(\theta n_{t}-\overline{\theta n}\right)+\rho_{q q p}\left(q p_{t}-\overline{q p}\right)+\rho_{q q n}\left(q n_{t}-\overline{q n}\right)+u_{q, t+1}, \\
u_{q, t+1} & =\delta_{q \theta p} \omega_{\theta p, t+1}+\delta_{q \theta n} \omega_{\theta n, t+1}+\delta_{q q p} \omega_{q p, t+1}-\delta_{q q n} \omega_{q n, t+1},
\end{aligned}
$$

where

$$
\begin{aligned}
\omega_{q p, t+1} & \sim \Gamma\left(q p_{t}, 1\right)-q p_{t}, \\
\omega_{q n, t+1} & \sim \Gamma\left(q n_{t}, 1\right)-q n_{t}, \\
q p_{t+1} & =\overline{q p}+\rho_{q p}\left(q p_{t}-\overline{q p}\right)+\delta_{q p} \omega_{q p, t+1}, \\
q n_{t+1} & =\overline{q n}+\rho_{q n}\left(q n_{t}-\overline{q n}\right)+\delta_{q n} \omega_{q n, t+1} .
\end{aligned}
$$

The estimation is conducted in two stages; first, we project $q_{t+1}$ onto $\left\{q_{t}, \theta p_{t}, \theta n_{t}, \omega_{\theta p, t+1}, \omega_{\theta n, t+1}\right\}$; then,

\begin{tabular}{|c|c|c|c|c|c|}
\hline \multicolumn{6}{|c|}{ A. Estimation Results } \\
\hline & $q_{t}$ & & $q p_{t}$ & & $q n_{t}$ \\
\hline$q_{0}$ & $\begin{array}{l}0.1298^{* * *} \\
(0.0239)\end{array}$ & $\overline{q p}$ & $\begin{array}{l}14.5891^{* * *} \\
(0.9812)\end{array}$ & $\overline{q n}$ & $\begin{array}{l}\text { 612.3177*** } \\
(44.1574)\end{array}$ \\
\hline$\rho_{q q}$ & $\begin{array}{l}0.7142^{* * *} \\
(0.0367)\end{array}$ & $\rho_{q p}$ & $\begin{array}{l}0.6352^{* * *} \\
(0.0229)\end{array}$ & $\rho_{q n}$ & $\begin{array}{l}0.9999^{* * *} \\
(0.0315)\end{array}$ \\
\hline$\rho_{q \theta p}$ & $\begin{array}{l}0.0003 \\
(0.0003)\end{array}$ & & & & \\
\hline$\rho_{q \theta n}$ & $\begin{array}{l}0.0036^{* * *} \\
(0.0010)\end{array}$ & & & & \\
\hline$\rho_{q q p}$ & $\begin{array}{l}0.0000 \\
(0.0016)\end{array}$ & & & & \\
\hline$\rho_{q q n}$ & $\begin{array}{l}-0.0001^{*} \\
(0.0001)\end{array}$ & & & & \\
\hline$\delta_{q \theta p}$ & $\begin{array}{l}0.0007^{*} \\
(0.0004)\end{array}$ & $\delta_{q p}$ & $\begin{array}{l}3.291^{* * *} \\
(0.2166)\end{array}$ & & \\
\hline$\delta_{q \theta n}$ & $\begin{array}{l}0.0195^{* * *} \\
(0.0039)\end{array}$ & & & $\delta_{q p}$ & $\begin{array}{l}0.0044 \\
(0.0140)\end{array}$ \\
\hline$\delta_{q q p}$ & $\begin{array}{l}0.0209^{* * *} \\
(0.0041)\end{array}$ & & & & \\
\hline$\delta_{q q n}$ & $\begin{array}{l}0.0008 \\
(0.0011)\end{array}$ & & & & \\
\hline & Ioment Mat & & & C. Cyclicalit & \\
\hline & Data & Model & & $q p_{t}$ & $q n_{t}$ \\
\hline Mean & $\begin{array}{l}0.3068^{* * *} \\
(0.0084)\end{array}$ & 0.3102 & $\rho(N B E R)$ & $\begin{array}{l}0.2546^{* * *} \\
(0.0495)\end{array}$ & $\begin{array}{l}-0.1118^{* *} \\
(0.0508)\end{array}$ \\
\hline Variance & $\begin{array}{l}0.0084^{*} \\
(0.0045)\end{array}$ & 0.0094 & & & \\
\hline
\end{tabular}
we estimate latent processes using AML in Bates $(2006) .{ }^{* * *}\left({ }^{* *},{ }^{*}\right)$ represent significance at the $1 \%$ $(5 \%, 10 \%)$ confidence level. Panel B shows moment matching. In this panel, values under "Model" are in bold if the model-implied moments are within the $95 \%$ confidence interval of data point estimates. Panel C provides a cyclicality test and shows the correlations of the estimates of $q p$ and $q n$ with the NBER recession indicator. 
Table 11: Variance risk premium components, moment matching

This table presents moment matching results for the Generalized Method of Moments (GMM). The GMM system estimates the loadings of downside and upside variance premiums on second-moment state variables as implied in the theoretical model with time-varying loadings. The model implies the following closed-form solution for the time-varying global (U.S.) variance premium:

$$
\begin{aligned}
V_{t}^{Q}\left(r_{t+1}\right)-V_{t}^{P}\left(r_{t+1}\right) & =\left(\boldsymbol{\xi}_{\mathbf{2}} \boldsymbol{\Sigma}\right)^{\circ 2}\left[\left(\mathbf{1}-\boldsymbol{m}_{\mathbf{2}} \boldsymbol{\Sigma}\right)^{\circ-2}-\mathbf{1}\right]\left(\boldsymbol{\Omega} \boldsymbol{Y}_{\boldsymbol{t}}+\boldsymbol{e}\right) \\
& \equiv D V P+U V P
\end{aligned}
$$

where there are only four relevant state variables (although we use the most general state variable representation here, $\left.\boldsymbol{Y}_{\boldsymbol{t}}\right),\left\{c p_{t}, c n_{t}, q p_{t}, q n_{t}\right\} . c p_{t}$ and $c n_{t}$ represent the upside and downside uncertainties, respectively, and are proxied by $\widehat{\theta p}_{t}$ and $\widehat{\theta n}_{t}$ (see Table 9 . $q p_{t}\left(q n_{t}\right)$ represents the second moment of swings in right-tail (left-tail) risk aversion after controlling for macroeconomic uncertainties (see Table 10). Our estimation strategy is as follows. First, we denote the empirical benchmarks as $\widetilde{v p^{D}}$ and $v p^{U}$. Then, for each iteration, we compute the downside and upside VP candidates:

$$
\begin{aligned}
\widehat{v p}_{t}^{D} & =w_{\theta p, t}^{D} \widehat{\theta p}_{t}+w_{\theta n, t}^{D} \widehat{\theta n}_{t}+w_{q p, t}^{D} \widehat{q p}_{t}+w_{q n, t}^{D} \widehat{q n}_{t}, \\
\widehat{v p}_{t}^{U} & =w_{\theta p, t}^{U} \widehat{\theta p}_{t}+w_{\theta n, t}^{U} \widehat{\theta n}_{t}+w_{q p, t}^{U} \widehat{q p}_{t}+w_{q n, t}^{U} \widehat{q n}_{t}, \\
w_{x, t}^{D} & =w_{x, 0}^{D}+w_{x, 1}^{D} z_{t}, \\
w_{x, t}^{U} & =w_{x, 0}^{U}+w_{x, 1}^{U} z_{t}, \forall x \in\{\theta p, \theta n, q p, q n\},
\end{aligned}
$$

where $z_{t}$ is proxied by $u_{\theta, t}^{2}$ to capture environments with different shock realizations that could introduce non-linearity, and thus $\boldsymbol{w}=\left\{w_{\theta p, 0}^{D}, w_{\theta n, 0}^{D}, w_{q p, 0}^{D}, w_{q n, 0}^{D}, w_{\theta p, 0}^{U}, w_{\theta n, 0}^{U}, w_{q p, 0}^{U}, w_{q n, 0}^{U}\right.$, $\left.w_{\theta p, 1}^{D}, w_{\theta n, 1}^{D}, w_{q p, 1}^{D}, w_{q n, 1}^{D}, w_{\theta p, 1}^{U}, w_{\theta n, 1}^{U}, w_{q p, 1}^{U}, w_{q n, 1}^{U}\right\}$ are 16 unknown parameters. The raw moment conditions of interest are the following:

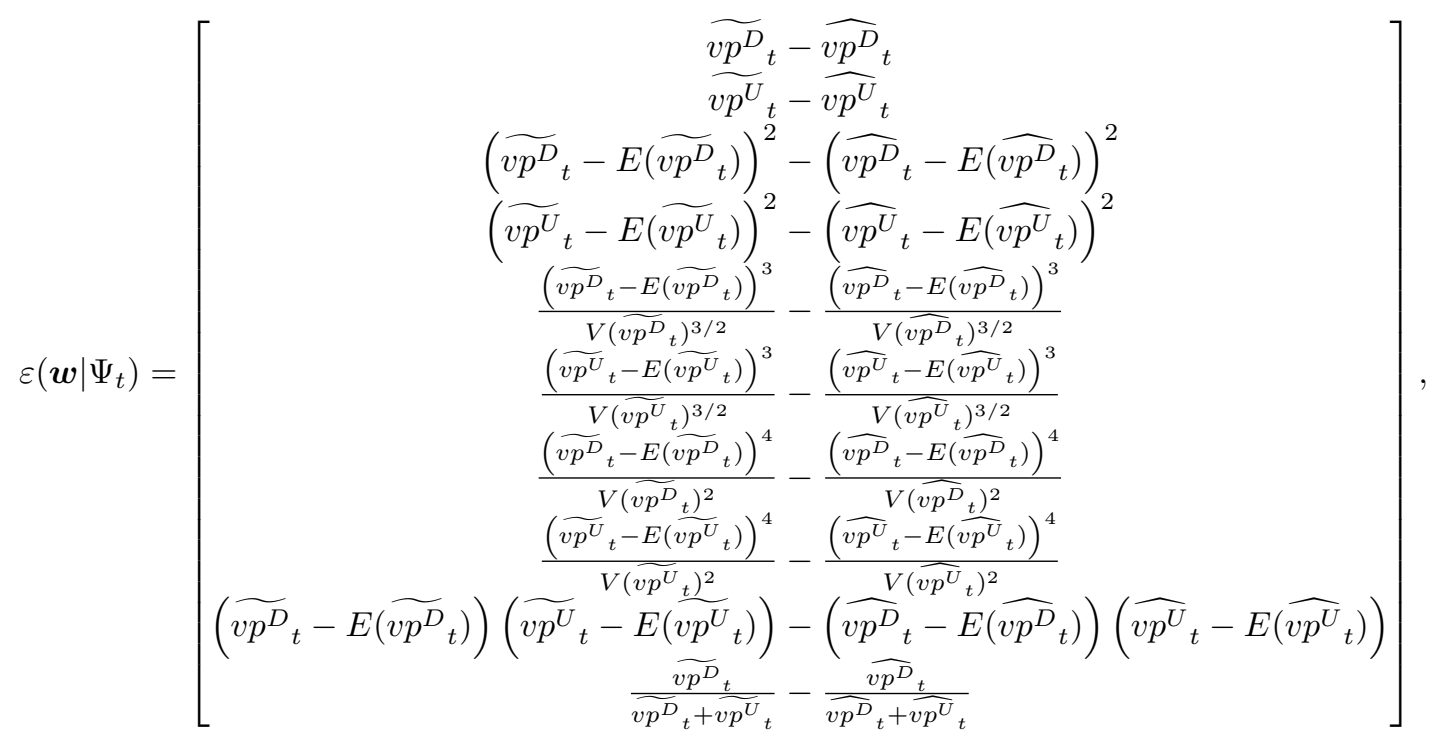

where $\Psi_{t}$ represents the information set, which includes $\left\{\widehat{\theta p}_{t}, \widehat{\theta n}_{t}, \widehat{q p}_{t}, \widehat{q n}_{t}, \widehat{v p}_{t}\right.$ and $\left.\widehat{v p}_{t}\right\}$, and model-implied VP components $\left(\widehat{v p D}_{t}\right.$ and $\left.\widehat{v p^{U}}{ }_{t}\right)$ contain $\boldsymbol{w}$. Each raw moment condition is then multiplied with a set of instruments $\left\{1, \widehat{\theta p}_{t}, \widehat{\theta n}_{t}, \widehat{q p}_{t}, \widehat{q n}_{t}, \theta_{t-1}, q_{t-1}, u_{\theta, t}, u_{q, t}\right\}$. The GMM system has 90 moments and 16 unknowns and is estimated using iterative GMM. "****" indicates that the model estimate is within the $90 \%$ confidence interval of the empirical point estimate in the same row. 


\begin{tabular}{lllll}
\hline \hline \multicolumn{5}{c}{ Panel A. Moment Matching } \\
\hline & Moment & Empirical & Boot. SE & Model \\
\hline 1 & $v p^{D}$ & 13.471 & $(0.747)$ & $13.65^{* * *}$ \\
2 & $v p^{U}$ & 0.568 & $(0.214)$ & $0.574^{* * *}$ \\
3 & $\left(v p^{D}-E\left(v p^{D}\right)\right)^{2}$ & 194.360 & $(37.047)$ & $195.184^{* * *}$ \\
4 & $\left(v p^{U}-E\left(v p^{U}\right)\right)^{2}$ & 14.496 & $(5.723)$ & $14.541^{* * *}$ \\
5 & $\left(v p^{D}-E\left(v p^{D}\right)\right)^{3} /\left(S D\left(v p^{D}\right)^{3}\right)$ & 2.683 & $(1.010)$ & $2.61^{* * *}$ \\
6 & $\left(v p^{U}-E\left(v p^{U}\right)\right)^{3} /\left(S D\left(v p^{U}\right)^{3}\right)$ & -4.782 & $(4.110)$ & $-4.319^{* * *}$ \\
7 & $\left(v p^{D}-E\left(v p^{D}\right)\right)^{4} /\left(S D\left(v p^{D}\right)^{4}\right)$ & 12.821 & $(5.734)$ & $12.849^{* * *}$ \\
8 & $\left(v p^{U}-E\left(v p^{U}\right)\right)^{4} /\left(S D\left(v p^{U}\right)^{4}\right)$ & 50.316 & $(43.864)$ & $50.057^{* * *}$ \\
9 & $\left(v p^{D}-E\left(v p^{D}\right)\right) *\left(v p^{U}-E\left(v p^{U}\right)\right)$ & 0.130 & $(12.160)$ & $0.469^{* * *}$ \\
10 & $v p^{D} /\left(v p^{D}+v p^{U}\right)$ & 1.019 & $(0.047)$ & $1.022^{* * *}$ \\
\hline \multicolumn{5}{c}{ Panel B. Overidentification test } \\
\hline \multicolumn{4}{c}{}
\end{tabular}

GMM J Statistics: 53.44

Hansen's J test p-value: 0.965 (Over-identifying restrictions are valid) 
Table 12: Economic determinants of variance risk premium components

This table presents loading estimates of the VP, in Panel A, and relative economic magnitudes of each determinant, in Panel B, for the system of equations in Table 11. In Panel A, the constant estimate corresponds to $w_{x, 0}^{D}$, and the time-varying estimate corresponds to $w_{x, 1}^{D}$. Standard errors are shown in parentheses and variance decomposition results are shown in the third row ("VARC"). Panel B calculates exact loading magnitudes at various levels of current uncertainty realizations $z_{t}$ (full-sample average, $90 \%, 95 \%$, and $99 \%$ percentiles). For the purpose of interpretation, the loadings are rescaled to reflect changes in variance risk premiums given $1 \mathrm{SD}$ changes in a determinant.

\begin{tabular}{|c|c|c|c|c|c|}
\hline \multicolumn{6}{|c|}{ A. Estimation results } \\
\hline & & $\theta p_{t}$ & $\theta n_{t}$ & $q p_{t}$ & $q n_{t}$ \\
\hline \multirow[t]{6}{*}{ DVP } & Constant & $-0.226^{* * *}$ & $1.257^{* * *}$ & $0.502^{* * *}$ & $0.168^{* * *}$ \\
\hline & SE & $(0.004)$ & $(0.012)$ & $(0.003)$ & $(0.003)$ \\
\hline & VARC & $14.87 \%$ & $33.63 \%$ & $39.97 \%$ & $-0.89 \%$ \\
\hline & Time-varying & 109.414 & $-8622.124^{* * *}$ & $159.673^{* * *}$ & 33.529 \\
\hline & & (128.197) & $(98.369)$ & $(61.178)$ & $(93.603)$ \\
\hline & & $17.93 \%$ & $-14.56 \%$ & $1.40 \%$ & $7.66 \%$ \\
\hline \multirow{6}{*}{ UVP } & Constant & $0.005^{*}$ & $0.089 * * *$ & $-0.037^{* * *}$ & -0.002 \\
\hline & & $(0.003)$ & $(0.006)$ & $(0.001)$ & $(0.002)$ \\
\hline & & $0.06 \%$ & $-6.23 \%$ & $2.37 \%$ & $-0.01 \%$ \\
\hline & Time-varying & $-561.812^{* * *}$ & $-9009.524^{* * *}$ & $2870.665^{* * *}$ & $364.519^{* * *}$ \\
\hline & & $(28.314)$ & $(34.107)$ & $(12.830)$ & $(20.702)$ \\
\hline & & $-81.10 \%$ & $106.16 \%$ & $4.78 \%$ & $73.98 \%$ \\
\hline \multicolumn{6}{|c|}{ B. Economic magnitudes of loadings at various $z_{t}$ values } \\
\hline & $z_{t}$ values & $\theta p_{t} / S D\left(\theta p_{t}\right)$ & $\theta n_{t} / S D\left(\theta n_{t}\right)$ & $q p_{t} / S D\left(q p_{t}\right)$ & $q n_{t} / S D\left(q n_{t}\right)$ \\
\hline \multirow[t]{4}{*}{ DVP } & $\operatorname{Mean}\left(z_{t}\right)$ & -4.3395 & 5.9953 & 8.5446 & 0.8143 \\
\hline & $90 \operatorname{th}\left(z_{t}\right)$ & -4.2625 & 3.9625 & 8.6409 & 0.8201 \\
\hline & $95 \operatorname{th}\left(z_{t}\right)$ & -4.1278 & 0.4083 & 8.8093 & 0.8302 \\
\hline & $99 \operatorname{th}\left(z_{t}\right)$ & -3.3540 & -20.0111 & 9.7766 & 0.8884 \\
\hline \multirow[t]{4}{*}{ UVP } & $\operatorname{Mean}\left(z_{t}\right)$ & -0.3395 & -1.7736 & 1.2947 & 0.0623 \\
\hline & $90 \operatorname{th}\left(z_{t}\right)$ & -0.7350 & -3.8977 & 3.0260 & 0.1253 \\
\hline & $95 \operatorname{th}\left(z_{t}\right)$ & -1.4266 & -7.6117 & 6.0530 & 0.2355 \\
\hline & $99 \operatorname{th}\left(z_{t}\right)$ & -5.3997 & -28.9485 & 23.4435 & 0.8682 \\
\hline
\end{tabular}


Table 13: U.S. predictive coefficients, moment matching

This table provides moment matches of model-implied and empirical predictive coefficients of variance risk premium components at various horizons. Our model suggests that international equity risk premiums can be written as a linear combination of real uncertainty and risk aversion state variables. Here, the four empirical proxies are $\widehat{\theta p}_{t}, \widehat{\theta n}_{t}, \widehat{q p}_{t}$, and $\widehat{q n}_{t}$ (see Tables 9 and 10 :

$$
\widehat{E R P}_{h, t}^{i}=v_{\theta p, h, t}^{i} \widehat{\theta p}_{t}+v_{\theta n, h, t}^{i} \widehat{\theta n}_{t}+v_{q p, h, t}^{i} \widehat{q p}_{t}+v_{q n, h, t}^{i} \widehat{q n}_{t}+\text { Idiosyncratic }
$$

where $\widehat{E R P}_{h, t}^{i}$ is the $h$-month equity risk premium estimate for country i at time $\mathrm{t}$ and the coefficients are assumed to follow

$$
\begin{aligned}
& v_{\theta p, h, t}^{i}=v_{\theta p, h, 0}+\boldsymbol{v}_{\boldsymbol{\theta p}, \boldsymbol{h}, \mathbf{1}}{ }^{\prime} \boldsymbol{x}^{\boldsymbol{i}}+v_{\theta p, h, 2} z_{t}, \\
& v_{\theta n, h, t}^{i}=v_{\theta n, h, 0}+\boldsymbol{v}_{\boldsymbol{\theta n}, \boldsymbol{h}, \mathbf{1}}{ }^{\prime} \boldsymbol{x}^{\boldsymbol{i}}+v_{\theta n, h, 2} z_{t}, \\
& v_{q p, h, t}^{i}=v_{q p, h, 0}+\boldsymbol{v}_{\boldsymbol{q p}, \boldsymbol{h}, \mathbf{1}}{ }^{\prime} \boldsymbol{x}^{\boldsymbol{i}}+v_{q p, h, 2} z_{t}, \\
& v_{q n, h, t}^{i}=v_{q n, h, 0}+\boldsymbol{v}_{\boldsymbol{q n}, \boldsymbol{h}, \mathbf{1}}{ }^{\prime} \boldsymbol{x}^{\boldsymbol{i}}+v_{q n, h, 2} z_{t},
\end{aligned}
$$

where $\boldsymbol{x}$ is a chosen set of country-specific variables that are informative about financial development (proxied by standardized credit-to-GDP ratios; source: DataStream) and economic integration (proxied by standardized trade-to-GDP ratios; source: World Bank). $z_{t}$ is proxied by $u_{\theta, t}^{2}$ to capture environments with different shock realizations that could introduce non-linearity. There are 16 unknown parameters:

$\boldsymbol{v}=\left\{v_{\theta p, h, 0}, v_{\theta n, h, 0}, v_{q p, h, 0}, v_{q n, h, 0}, \boldsymbol{v}_{\boldsymbol{\theta p}, \boldsymbol{h}, \mathbf{1}}, \boldsymbol{v}_{\boldsymbol{\theta} \boldsymbol{n , h , \mathbf { 1 }}}, \boldsymbol{v}_{\boldsymbol{q p} \boldsymbol{h , \boldsymbol { h }} \mathbf{1}}, \boldsymbol{v}_{\boldsymbol{q n}, \boldsymbol{h}, \mathbf{1}}, v_{\theta p, h, 2}, v_{\theta n, h, 2}, v_{q p, h, 2}, v_{q n, h, 2}\right\}$. The model-implied predictive coefficient is

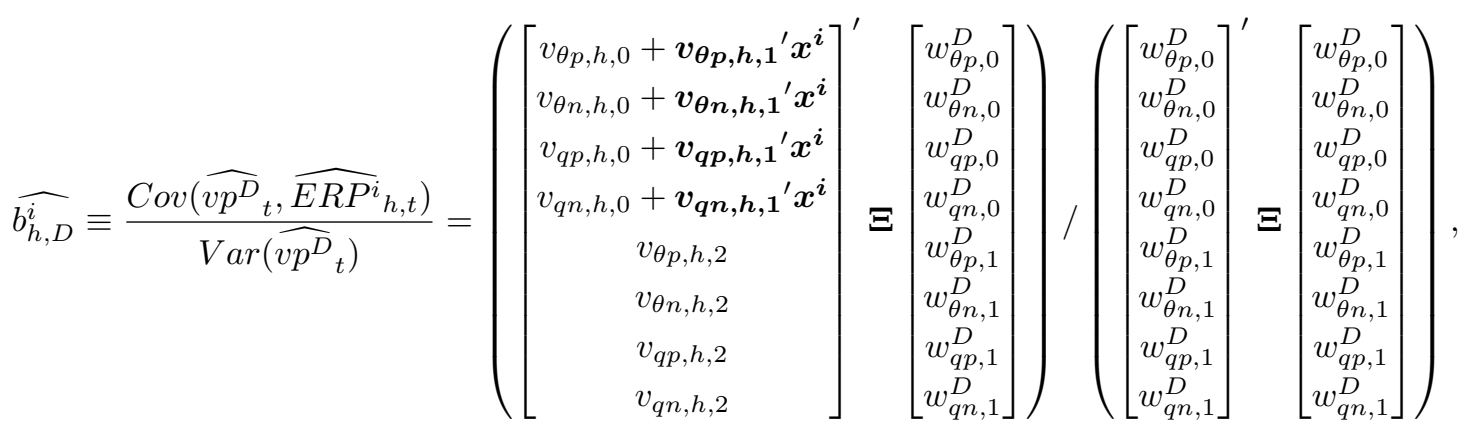

where $\boldsymbol{\Xi}$ is the covariance-variance matrix of $\left[\theta p_{t}, \theta n_{t}, q p_{t}, q n_{t}, \theta p_{t} z_{t}, \theta n_{t} z_{t}, q p_{t} z_{t}, q n_{t} z_{t}\right]$. A similar calculation applies to the UVP predictive coefficients $\widehat{b_{h, U}^{i}}$. For each horizon $h$, the estimation is conducted by minimizing the sum of standardized residual-squared of $22 \widehat{b_{h, D}^{i}}, 22 \widehat{b_{h, U}^{i}}$, and the equity risk premium of the U.S.. " ****" indicates that the model estimate is within the $90 \%$ confidence interval of the empirical point estimate in the same row.

\begin{tabular}{llllllllll}
\hline \hline & \multicolumn{3}{c}{$b_{U S, h, D}$} & & & $b_{U S, h, U}$ & & \multicolumn{3}{c}{$E R P_{U S, h}$} \\
\hline Horizon & Empirical & SE & Model & Empirical & SE & Model & Empirical & SE & Model \\
\hline 1 & -0.0414 & $(0.1942)$ & $-0.0864^{* * *}$ & 1.8530 & $(0.7119)$ & $1.9058^{* * *}$ & 9.3108 & $(2.7320)$ & $9.3108^{* * *}$ \\
2 & 0.1270 & $(0.1406)$ & $0.1528^{* * *}$ & 1.1123 & $(0.5153)$ & $1.0129^{* * *}$ & 9.3090 & $(1.9763)$ & $9.3091^{* * *}$ \\
3 & 0.1485 & $(0.1136)$ & $0.1774^{* * *}$ & 1.3055 & $(0.4164)$ & $1.2383^{* * *}$ & 9.4330 & $(1.6141)$ & $9.433^{* * *}$ \\
4 & 0.1513 & $(0.1000)$ & $0.182^{* * *}$ & 1.3367 & $(0.3661)$ & $1.3916^{* * *}$ & 9.4152 & $(1.4301)$ & $9.4152^{* * *}$ \\
5 & 0.1771 & $(0.0920)$ & $0.2268^{* * *}$ & 1.0113 & $(0.3368)$ & $1.0139^{* * *}$ & 9.3903 & $(1.3122)$ & $9.3903^{* * *}$ \\
6 & 0.2075 & $(0.0864)$ & $0.2616^{* * *}$ & 0.6927 & $(0.3162)$ & $0.6973^{* * *}$ & 9.3751 & $(1.2294)$ & $9.3748^{* * *}$ \\
7 & 0.1918 & $(0.0810)$ & $0.2515^{* * *}$ & 0.5431 & $(0.2960)$ & $0.4132^{* * *}$ & 9.3529 & $(1.1497)$ & $9.3529^{* * *}$ \\
8 & 0.1568 & $(0.0769)$ & $0.2019^{* * *}$ & 0.4251 & $(0.2810)$ & $0.362^{* * *}$ & 9.3534 & $(1.0886)$ & $9.3534^{* * *}$ \\
9 & 0.1448 & $(0.0739)$ & $0.1817^{* * *}$ & 0.2212 & $(0.2698)$ & $0.1084^{* * *}$ & 9.3132 & $(1.0434)$ & $9.3131^{* * *}$ \\
10 & 0.1332 & $(0.0710)$ & $0.1588^{* * *}$ & 0.1613 & $(0.2591)$ & $0.0296^{* * *}$ & 9.2862 & $(1.0027)$ & $9.2861^{* * *}$ \\
11 & 0.1272 & $(0.0683)$ & $0.1504^{* * *}$ & 0.1125 & $(0.2494)$ & $-0.0329^{* * *}$ & 9.2627 & $(0.9660)$ & $9.2627^{* * *}$ \\
12 & 0.1209 & $(0.0662)$ & $0.1404^{* * *}$ & 0.1020 & $(0.2414)$ & $-0.0052^{* * *}$ & 9.2498 & $(0.9357)$ & $9.2498^{* * *}$ \\
\hline
\end{tabular}


Table 14: Panel-data predictive coefficients, moment matching

This table continues Table 13 and provides moment matches of model-implied and empirical predictive coefficients of variance risk premium components at various horizons.

\begin{tabular}{lllllll}
\hline \hline & \multicolumn{3}{c}{ Mean of $b_{i, h, D}$} & \multicolumn{3}{c}{ Mean of $b_{i, h, U}$} \\
\hline Horizon & Empirical & SE & Model & Empirical & SE & Model \\
\hline 1 & -0.1055 & $(0.0463)$ & $-0.1183^{* * *}$ & 1.7893 & $(0.2162)$ & $1.748^{* * *}$ \\
2 & 0.1470 & $(0.0397)$ & $0.1311^{* * *}$ & 0.8646 & $(0.1564)$ & $0.8389^{* * *}$ \\
3 & 0.1828 & $(0.0341)$ & $0.1687^{* * *}$ & 1.0602 & $(0.0988)$ & $1.0506^{* * *}$ \\
4 & 0.1886 & $(0.0330)$ & $0.1746^{* * *}$ & 1.1948 & $(0.0887)$ & $1.1879^{* * *}$ \\
5 & 0.2303 & $(0.0336)$ & $0.2152^{* * *}$ & 0.8526 & $(0.0691)$ & $0.852^{* * *}$ \\
6 & 0.2676 & $(0.0340)$ & $0.2539^{* * *}$ & 0.5509 & $(0.0512)$ & $0.5637^{* * *}$ \\
7 & 0.2621 & $(0.0333)$ & $0.2511^{* * *}$ & 0.2705 & $(0.0454)$ & $0.2931^{* * *}$ \\
8 & 0.2072 & $(0.0324)$ & $0.2004^{* * *}$ & 0.2416 & $(0.0465)$ & $0.2521^{* * *}$ \\
9 & 0.1837 & $(0.0321)$ & $0.1789^{* * *}$ & 0.0115 & $(0.0390)$ & $0.0253^{* * *}$ \\
10 & 0.1588 & $(0.0324)$ & $0.1557^{* * *}$ & -0.0594 & $(0.0415)$ & $-0.0429^{* * *}$ \\
11 & 0.1526 & $(0.0323)$ & $0.1503^{* * *}$ & -0.1051 & $(0.0422)$ & $-0.0885^{* * *}$ \\
12 & 0.1440 & $(0.0321)$ & $0.1418^{* * *}$ & -0.0809 & $(0.0390)$ & $-0.0698^{* * *}$ \\
\hline
\end{tabular}


Table 15: Relative changes in predictive coefficients when deleting one channel

This table demonstrates the relative contributions of the four premium state variables in explaining the positive predictive coefficients of downside and upside variance premiums of three hypothetical countries at various horizons (Table 13). Panel A calibrates an "average" global country (i.e., $\boldsymbol{x}^{i}=0$ ); Panel B calibrates a country with the same level of the trade-to-GDP ratio as the U.S. and an average country's credit-to-GDP ratio; Panel $\mathrm{C}$ calibrates a country with the same level of the credit-to-GDP ratio as the U.S. and an average country's trade-to-GDP ratio. "Deleting" one channel means that we first impose the $v$ loadings associated with a state variable to be 0 , then, we obtain $\widehat{b_{h, D}}$ using Equation 70 , and then, we calculate the relative change $=\frac{\widehat{\widehat{b_{h, D}}}-\widehat{b_{h, D}}}{\widehat{b_{h, D}}}$. The more negative the changes, the more positive contributions the state variables carry; negative values are highlighted.

\begin{tabular}{lcllllllll}
\hline \hline & \multicolumn{3}{c}{$\Delta$ DVP Predictability } & \multicolumn{5}{c}{$\Delta$ UVP Predictability } \\
\hline Horizon & $\theta p$ & $\theta n$ & $q p$ & $q n$ & $\theta p$ & $\theta n$ & $q p$ & $q n$ \\
\hline 1 & 2.40 & -6.66 & 4.29 & -1.04 & 0.02 & -1.18 & 0.23 & -0.07 \\
2 & -0.27 & 3.78 & -4.96 & 0.45 & 0.00 & -1.54 & 0.62 & -0.08 \\
3 & -1.82 & 3.16 & -2.89 & 0.56 & 0.04 & -1.32 & 0.37 & -0.09 \\
4 & 0.06 & 4.07 & -5.87 & 0.73 & -0.01 & -1.56 & 0.69 & -0.12 \\
5 & 1.27 & 3.01 & -5.48 & 0.21 & -0.06 & -1.98 & 1.10 & -0.06 \\
6 & 0.77 & 1.93 & -3.61 & -0.09 & -0.06 & -2.27 & 1.29 & 0.03 \\
7 & -0.33 & 0.87 & -1.90 & 0.36 & 0.01 & -1.95 & 1.30 & -0.35 \\
8 & -0.89 & 0.77 & -1.14 & 0.26 & 0.11 & -1.61 & 0.72 & -0.22 \\
9 & -1.17 & 0.01 & -0.58 & 0.74 & 1.38 & -0.22 & 3.27 & -5.43 \\
10 & -0.77 & -0.07 & -0.56 & 0.41 & -0.41 & -0.70 & -1.62 & 1.73 \\
11 & -0.52 & -0.11 & -0.55 & 0.18 & -0.13 & -0.48 & -0.74 & 0.35 \\
12 & -0.68 & -0.20 & -0.57 & 0.45 & -0.18 & -1.08 & -0.92 & 1.18 \\
\hline Mean & -0.16 & 0.88 & -1.98 & 0.27 & 0.06 & -1.33 & 0.53 & -0.26 \\
Mean(1 3) & 0.10 & 0.09 & -1.19 & -0.01 & 0.02 & -1.35 & 0.41 & -0.08 \\
Mean(4 6) & 0.70 & 3.00 & -4.99 & 0.28 & -0.04 & -1.94 & 1.03 & -0.05 \\
Mean(7 12) & -0.73 & 0.21 & -0.88 & 0.40 & 0.13 & -1.01 & 0.33 & -0.46 \\
\hline & & & & & & & &
\end{tabular}




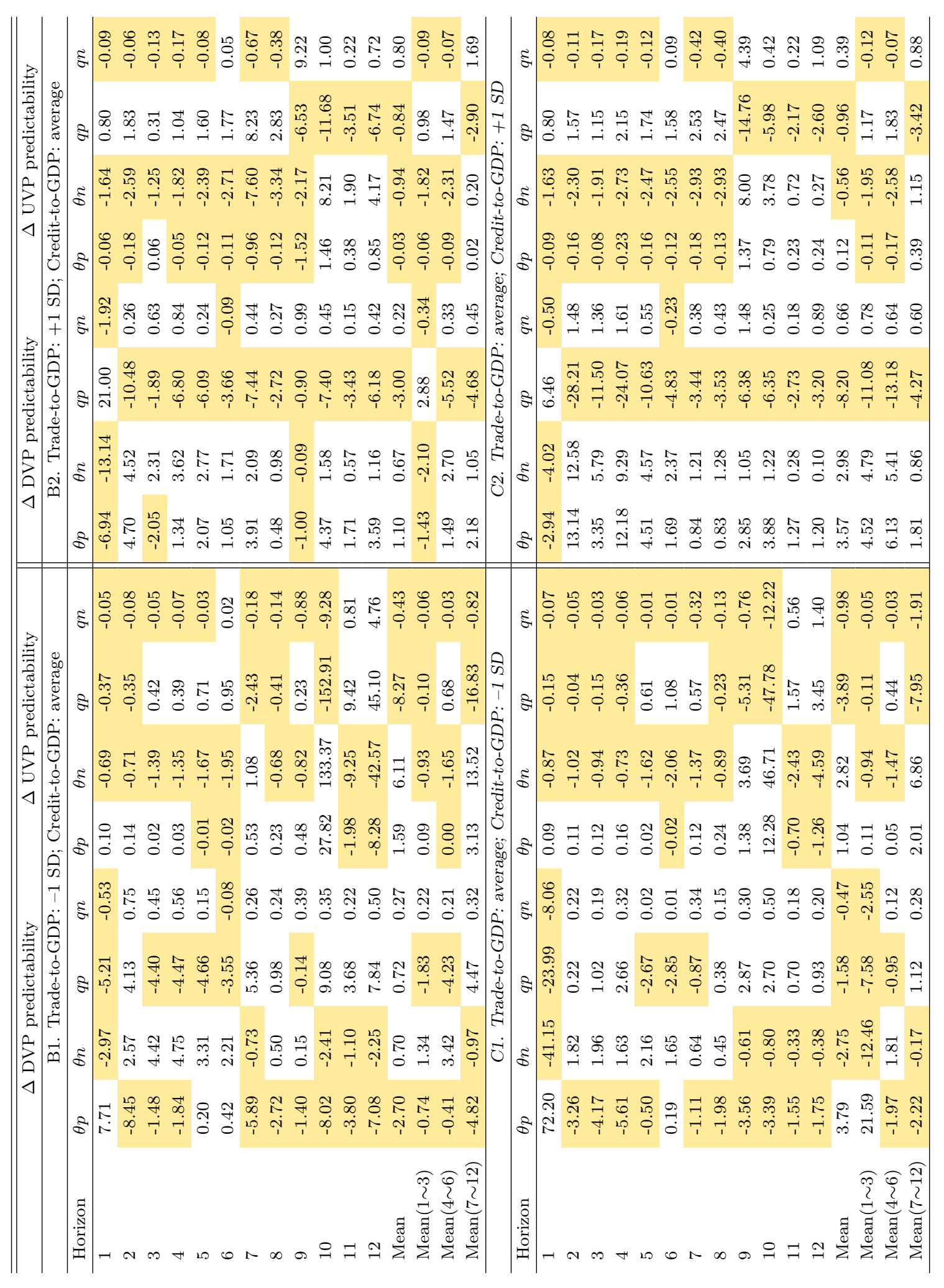


Table 16: Relative economic importance of real and financial integration in international stock return predictability

This table demonstrates the relative contribution of the four variance premium determinants on international stock return predictability at different types of market integration. We consider two integration channels: (1) the real channel, which is proxied by the standardized level of the trade-to-GDP ratio; (2) the financial channel, which is proxied by the the standardized level of the credit-to-GDP ratio. Thus, an average country has a combination of (trade-to-GDP, credit-to-GDP) of $(0,0)$. The combination $(1,0)((-1,0))$ indicates a country with a trade-to-GDP value that is 1 standard deviation above (below) the average, and $(0,1)((0,-1))$ a country with a credit-to-GDP ratio that is 1 standard deviation above (below) average. Panels A and B report average changes in the predictability after deleting one channel over horizons between two and seven months. Panel A (B) reports the results for the strengthening (weakening) of a channel - that is, a one standard deviation increase (decrease) in the average characteristic. In rows "Diff — Positive contributors," we calculate the difference between $(0,0)$ and an alternative calibration with various levels of the trade-to-GDP and credit-to-GDP ratios for positive contributors; bold columns indicate columns of the key variance premium determinants according to Table 12 .

\begin{tabular}{lllllllll}
\hline \hline & \multicolumn{3}{c}{$\Delta$ DVP predictability } & \multicolumn{1}{c}{$\Delta$ UVP predictability } \\
\hline \multicolumn{3}{c}{ A. Horizons $[2,7] ;$ strengthening } \\
\hline (Trade-to-GDP, credit-to-GDP) & $\theta p$ & $\theta n$ & $\boldsymbol{q} \boldsymbol{p}$ & $q n$ & $\theta p$ & $\boldsymbol{\theta n}$ & $q p$ & $q n$ \\
\hline$(0,0)$ & -0.05 & 2.80 & $\mathbf{- 4 . 1 2}$ & 0.37 & -0.01 & $\mathbf{- 1 . 7 7}$ & 0.89 & -0.11 \\
$(1,0)$ & 1.84 & 2.84 & $\mathbf{- 6 . 0 6}$ & 0.39 & -0.22 & $\mathbf{- 3 . 0 6}$ & 2.46 & -0.18 \\
Diff — Positive contributors & -1.89 & & $\mathbf{1 . 9 4}$ & & 0.21 & $\mathbf{1 . 2 9}$ & & 0.07 \\
$(0,1)$ & 5.95 & 5.97 & $\mathbf{- 1 3 . 7 8}$ & 0.86 & -0.15 & $\mathbf{- 2 . 4 8}$ & 1.79 & -0.15 \\
Diff — Positive contributors & -6.01 & & $\mathbf{9 . 6 6}$ & & 0.14 & $\mathbf{0 . 7 1}$ & & 0.04 \\
\hline & B. Horizons $[2,7] ;$ weakening & & & & \\
\hline (Trade-to-GDP, credit-to-GDP) & $\theta p$ & $\theta n$ & $\mathbf{q} \boldsymbol{p}$ & $q n$ & $\theta p$ & $\boldsymbol{\theta n}$ & $q p$ & $q n$ \\
\hline$(0,0)$ & -0.05 & 2.80 & $\mathbf{- 4 . 1 2}$ & 0.37 & -0.01 & $\mathbf{- 1 . 7 7}$ & 0.89 & -0.11 \\
$(-1,0)$ & -2.84 & 2.76 & $\mathbf{- 1 . 2 7}$ & 0.35 & 0.11 & $\mathbf{- 1 . 0 0}$ & -0.05 & -0.07 \\
Diff - Positive contributors & 2.79 & & $\mathbf{- 2 . 8 5}$ & & -0.13 & $\mathbf{- 0 . 7 7}$ & & -0.04 \\
$(0,-1)$ & -2.41 & 1.64 & $\mathbf{- 0 . 4 2}$ & 0.18 & 0.09 & $\mathbf{- 1 . 2 9}$ & 0.29 & -0.08 \\
Diff - Positive contributors & 2.36 & & $\mathbf{- 3 . 7 0}$ & & -0.10 & $\mathbf{- 0 . 4 8}$ & & -0.03 \\
\hline
\end{tabular}


Total Implied Variance

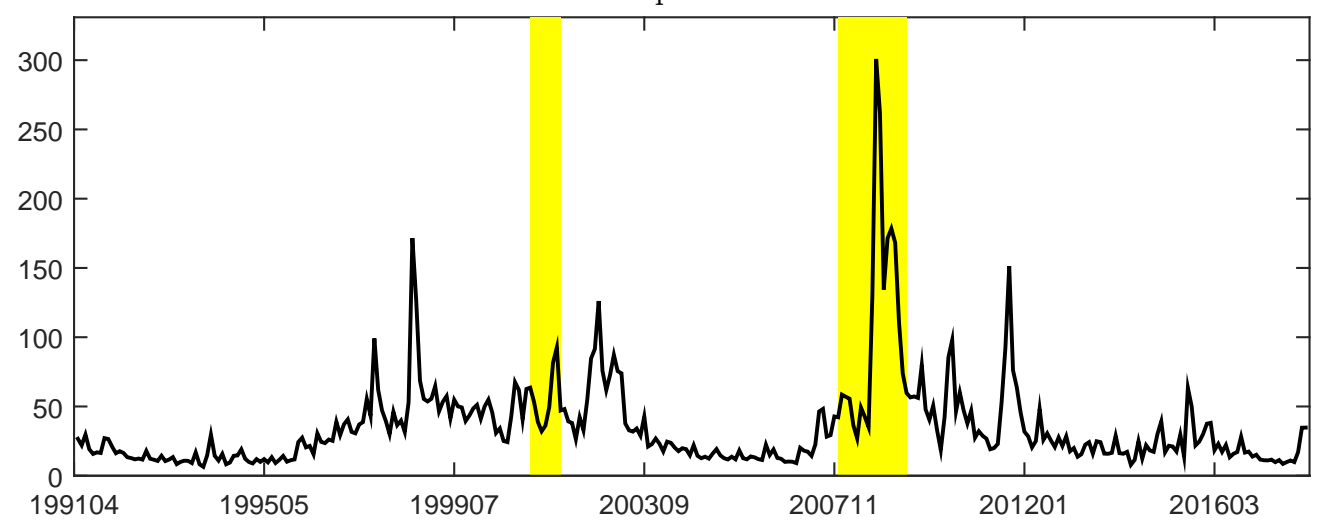

Implied Variance Components

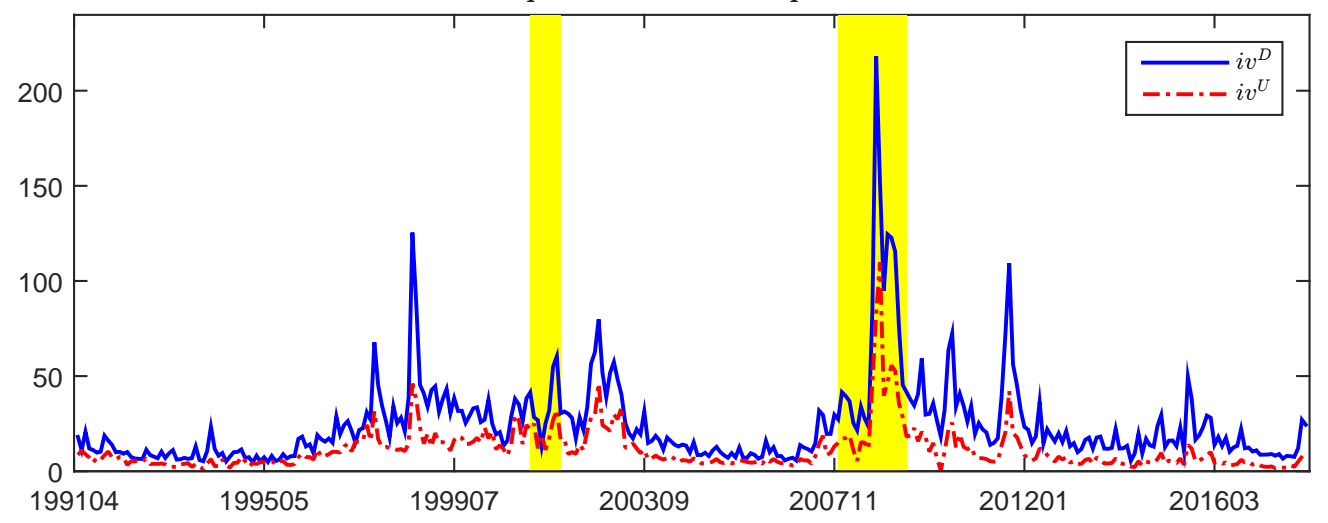

Figure 1: Option-implied variance and its downside and upside components

This figure shows the time series of total option-implied variance (upper panel) and its downside and upside components (lower panel). The construction details for option-implied variances are shown in Section 3. Measures are in units of variance-i.e., in percentage squared divided by 12 . 
Total Variance Risk Premium

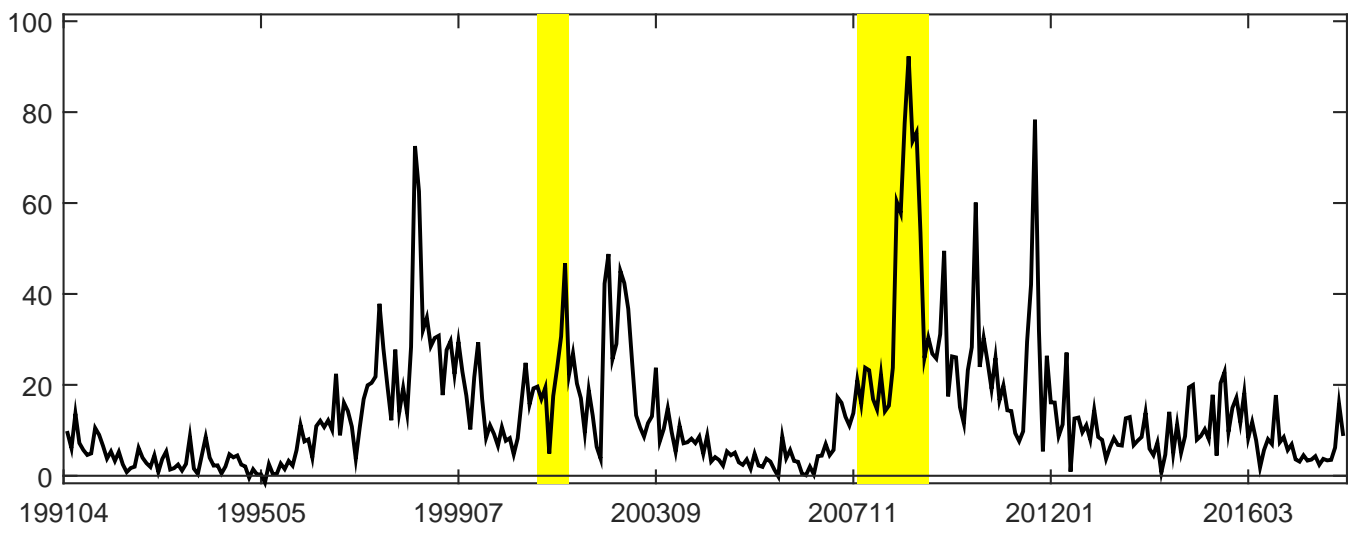

Variance Risk Premium Components

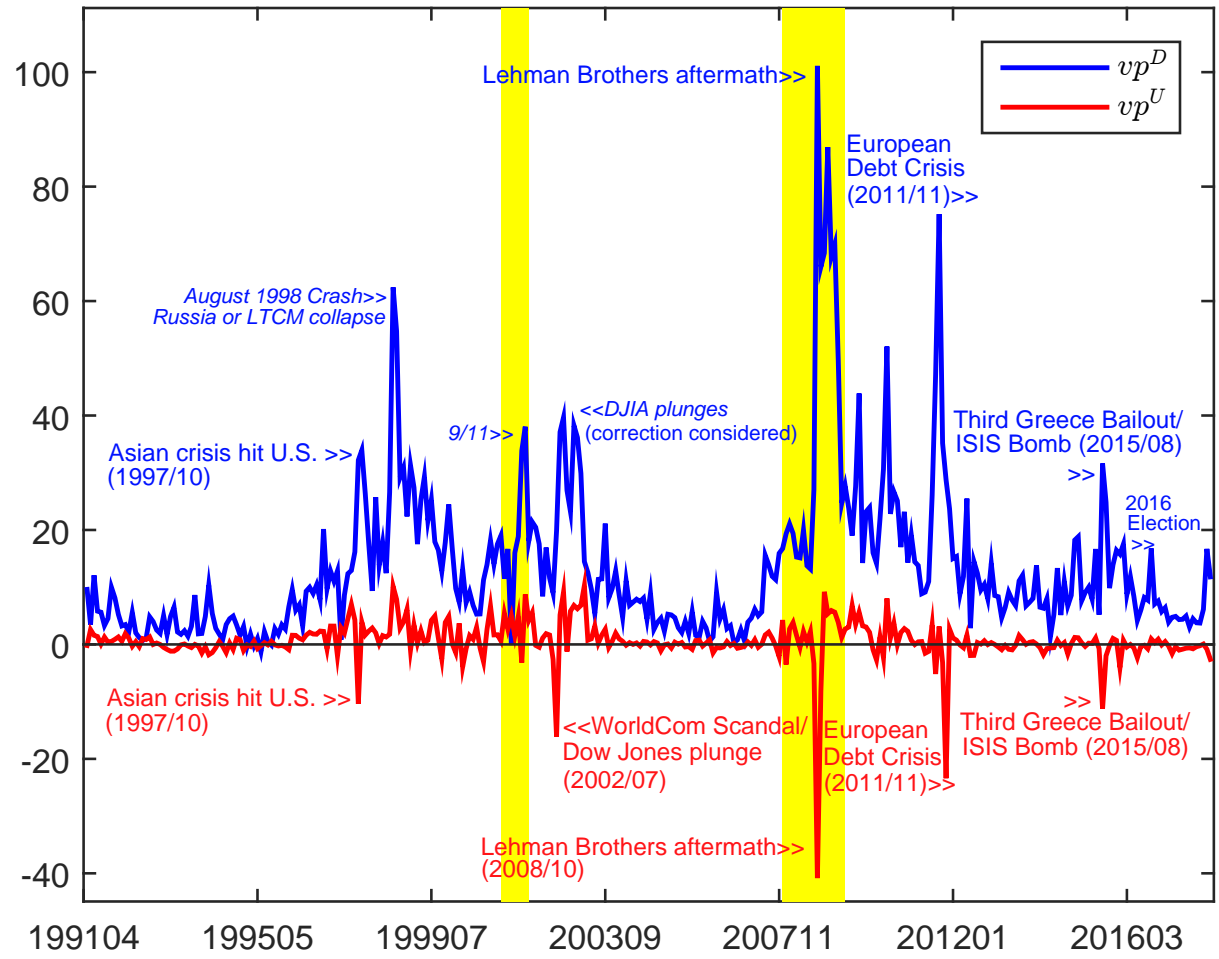

Figure 2: Variance risk premium and its downside and upside components

This figure shows the time series of the total variance risk premium (upper panel) and its downside and upside components (lower panel). The construction details of variance risk premiums are shown in Section 3 The downside (upside) variance risk premium is calculated as the difference between the option-implied downside (upside) variance and the expected downside (upside) realized semivariance. We use the "chosen" forecasts of the downside and upside realized semivariances from Table 1. Measures are in units of monthly variance -i.e., in annual percentage squared divided by 12 . 

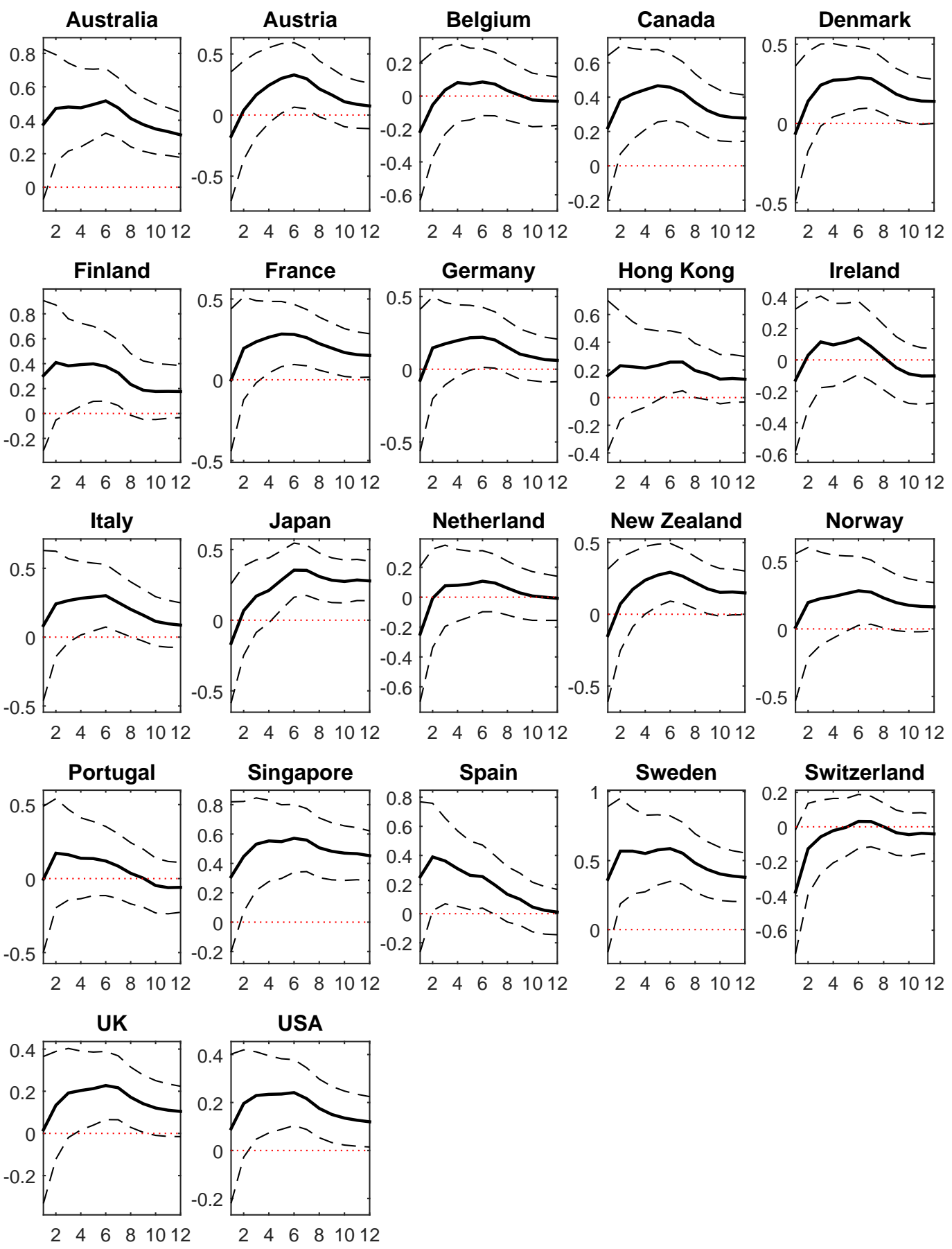

Figure 3: Total VP coefficients, null model

This figure shows the estimate of the coefficient associated with total VP (the solid lines) and its confidence interval given NW standard errors (the dashed lines) from the country-specific null model for all within-one-year horizons. The table corresponding to this plot is Table 4. 

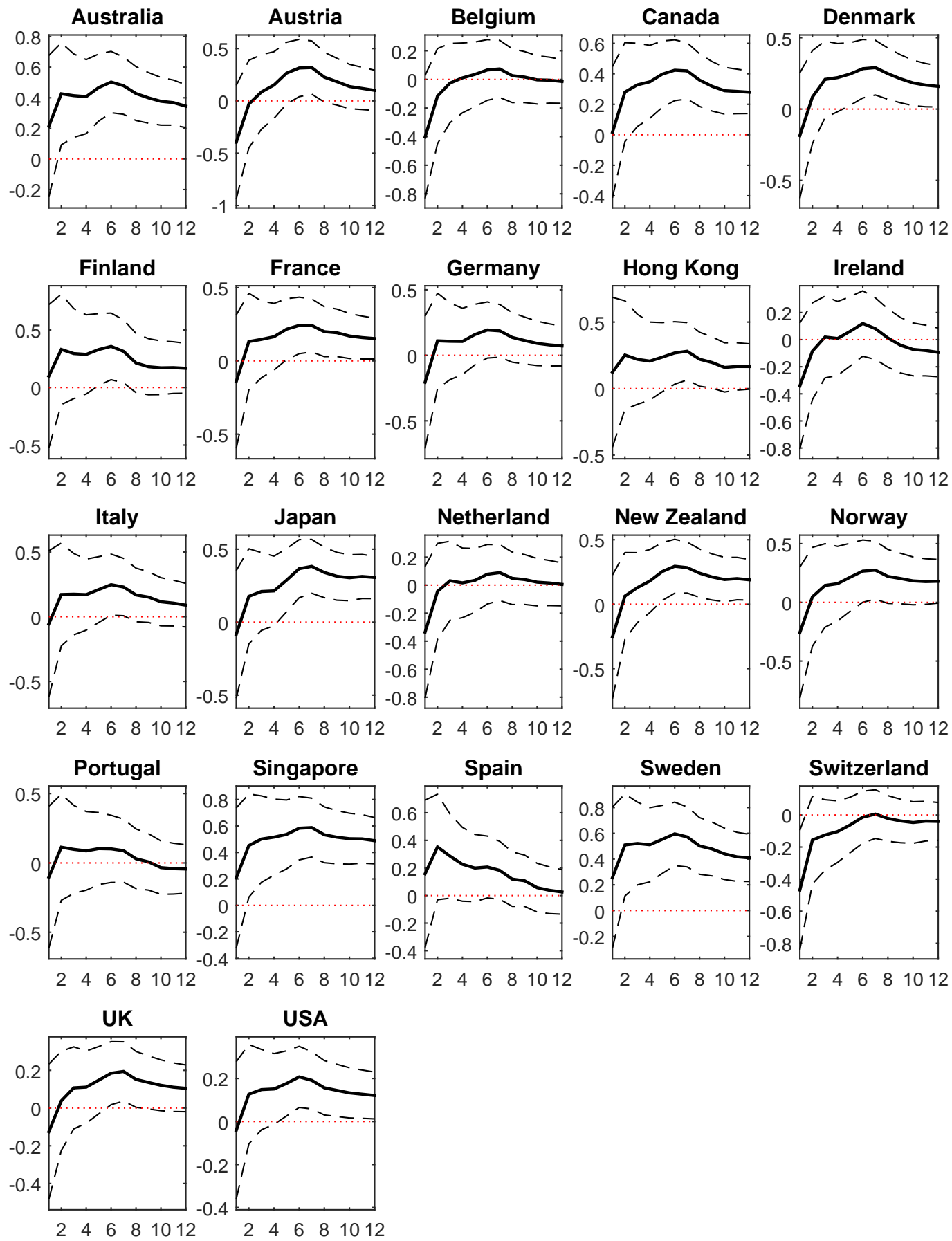

Figure 4: DVP predictive coefficients, model (1)

This figure shows the estimate of the coefficient associated with DVP (the solid lines) and its confidence interval given NW standard errors (the dashed lines) from the country-specific model, model (1), for all within-one-year horizons. The table corresponding to this plot is Table 5 . The model is introduced in Section 4 . 

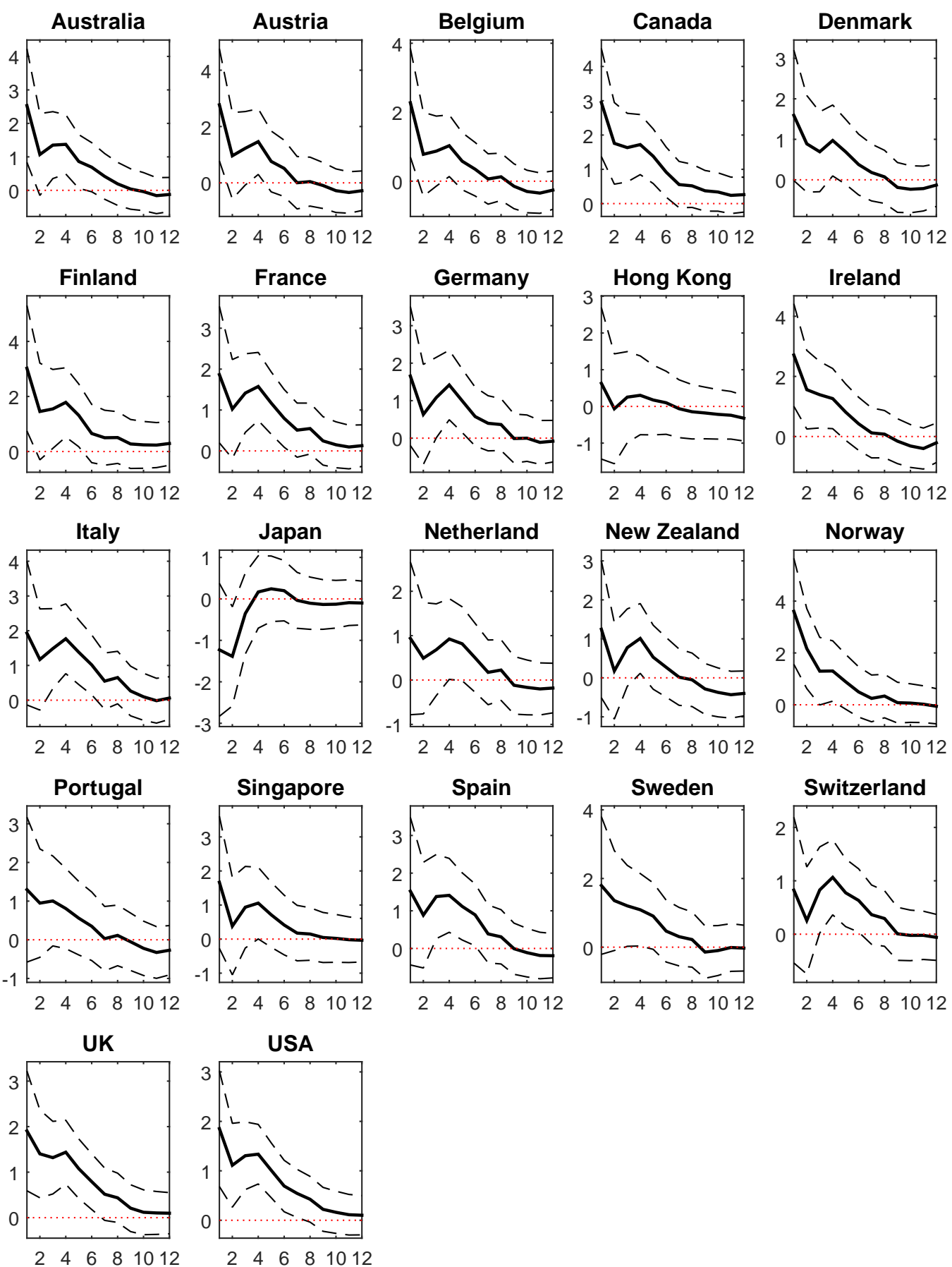

Figure 5: UVP predictive coefficients, model (1)

This figure shows the estimate of the coefficient associated with UVP (the solid lines) and its confidence interval given NW standard errors (the dashed lines) from the country-specific model, model (1), for all within-one-year horizons. The table corresponding to this plot is Table 5 The model is introduced in Section 4 . 

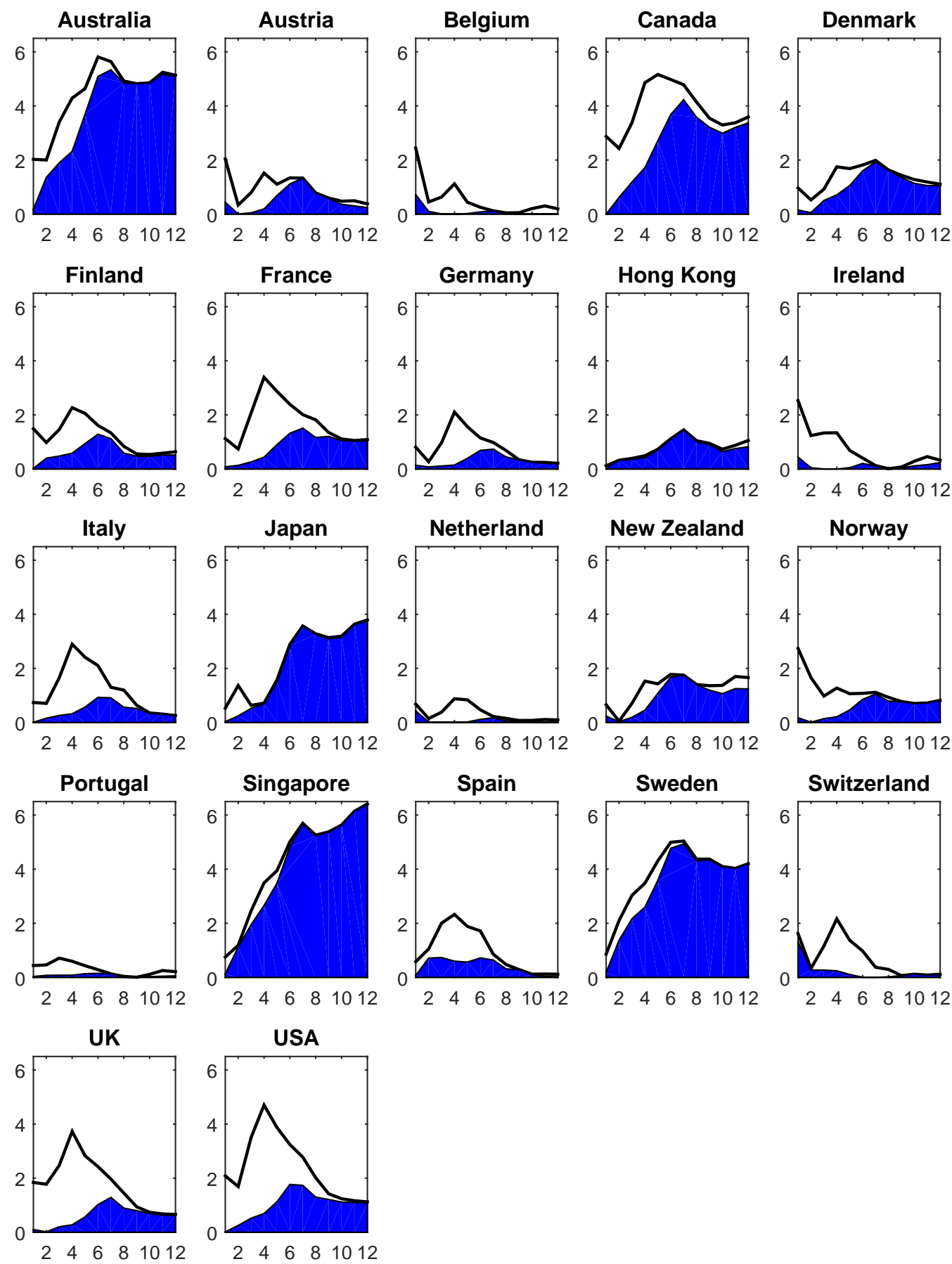

Figure 6: Explanatory power of DVP and UVP, model (1)

The figure shows the portion of the total $R^{2}$ explained by DVP and UVP in the country-specific model (model (1)). The solid line represents the total adjusted $R^{2}$ at the country level. The blue region represents the part that is explained by DVP and the remaining area denotes the total variance explained by UVP. The table corresponding to this plot is Table 5 

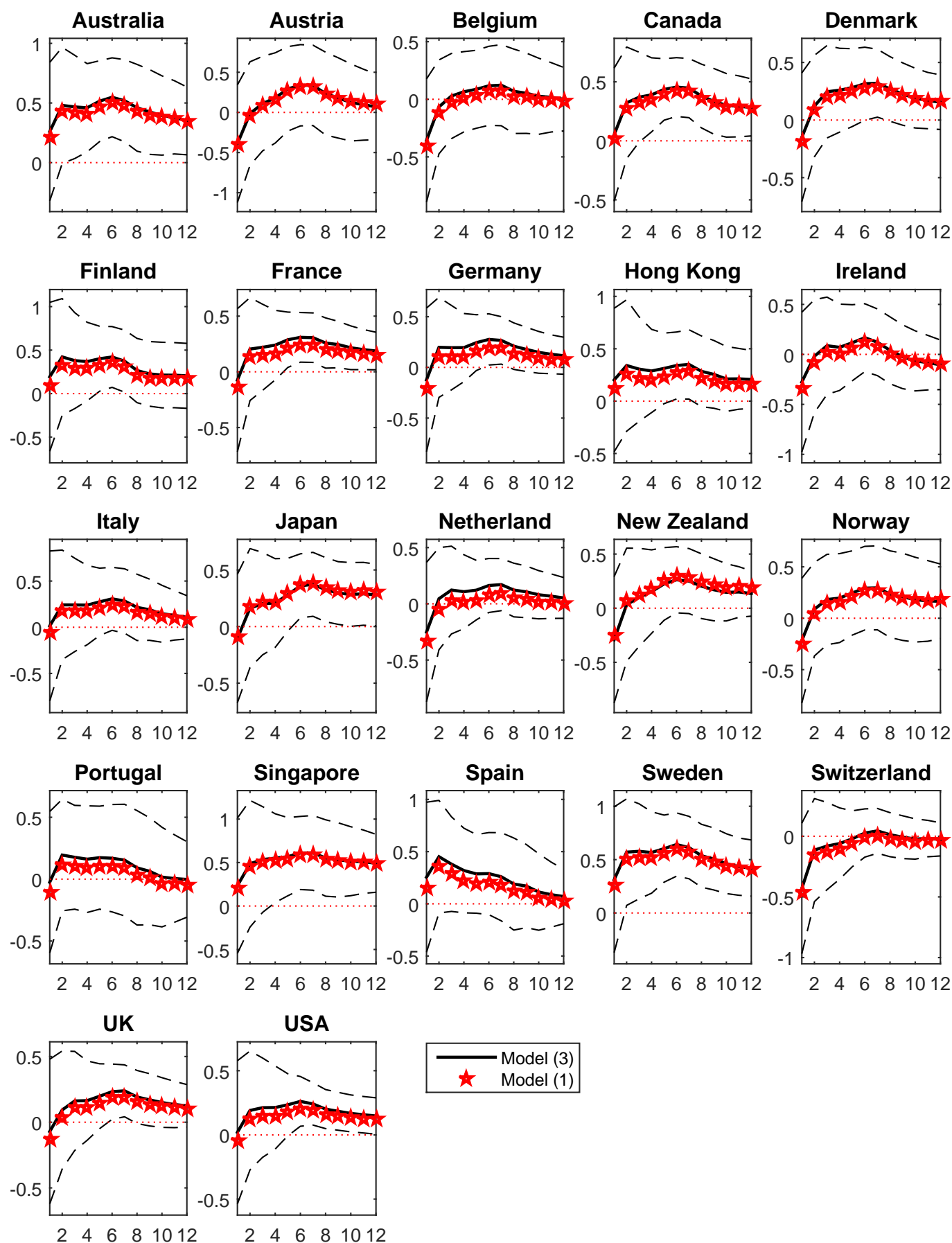

Figure 7: DVP coefficient estimates, model (3)

The figure compares the coefficient estimates of DVP in model (3) (the solid lines) with those of model (1) (the stars). The dashed lines correspond to the $90 \%$ confidence intervals given NW standard errors. Model (3) is a country-specific model with other predictors (term spread and dividend yield). The model is introduced in Section 4 

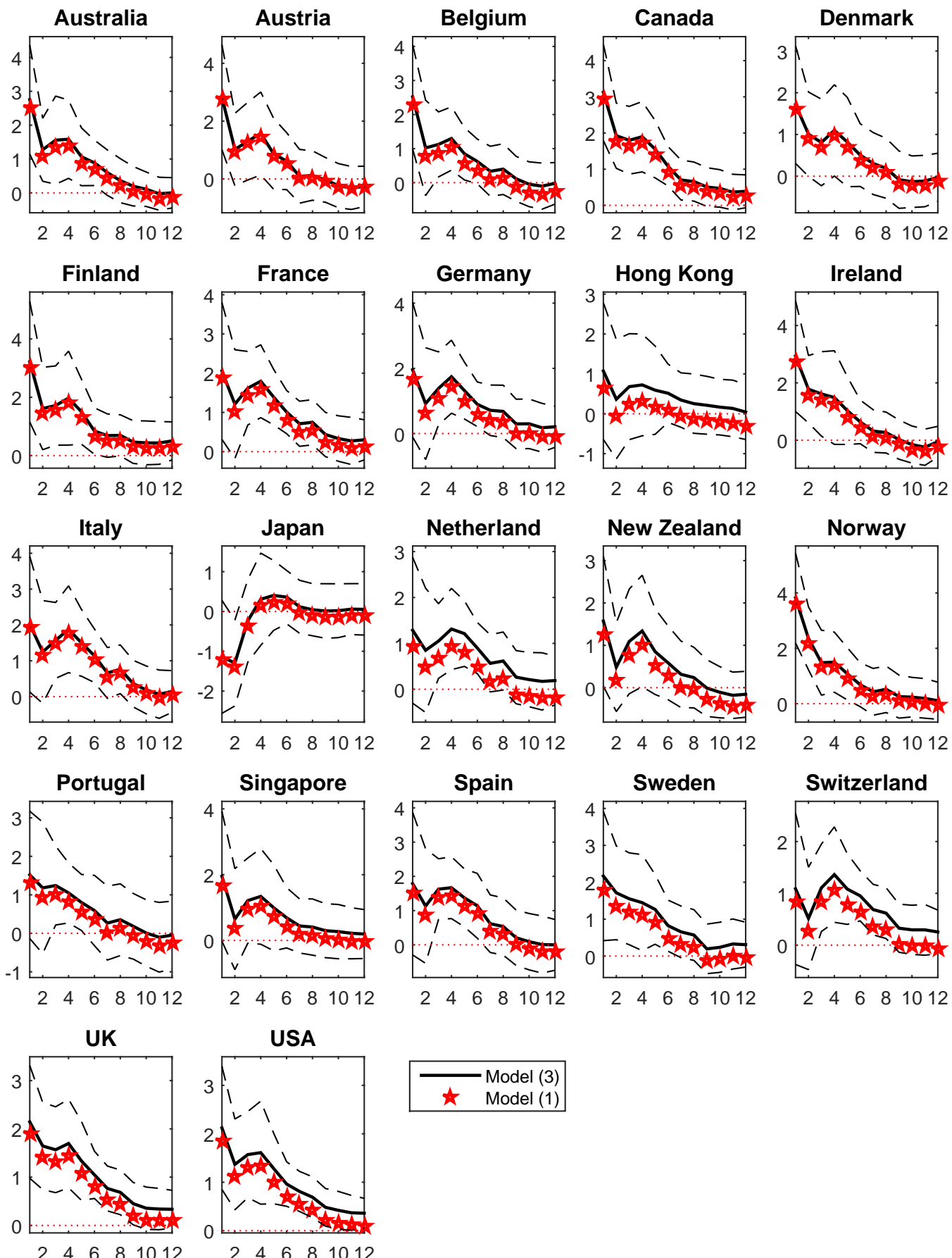

Figure 8: UVP coefficient estimates, model (3)

The figure compares the coefficient estimates of UVP in model (3) (the solid lines) with those of model (1) (the stars). The dashed lines correspond to the $90 \%$ confidence intervals given NW standard errors. Model (3) is a country-specific model with other predictors (term spread and dividend yield). The model is introduced in Section 4 

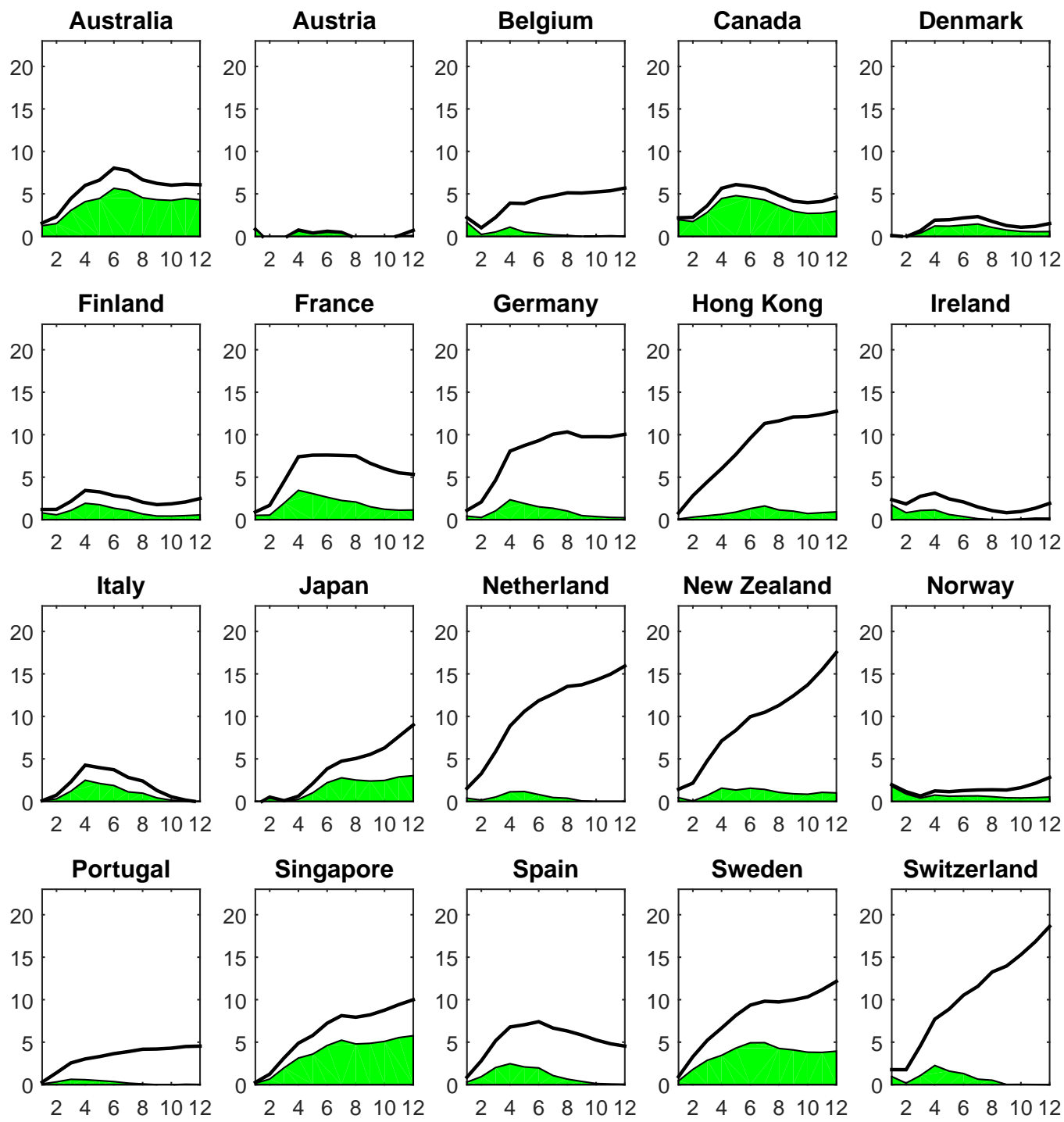

Switzerland
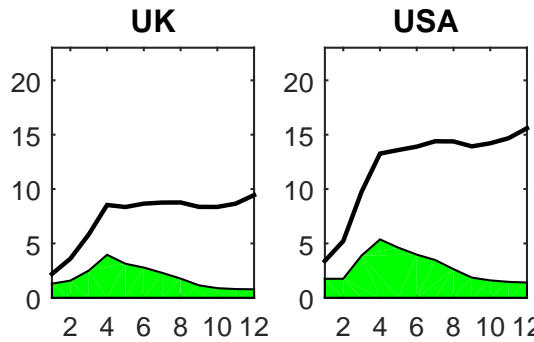

Figure 9: Explanatory power of DVP and UVP in model (3)

The solid line represents the total adjusted $R^{2}$ for model (3), the country-level model in which we control for the term spread and the dividend yield. The green region represents the portion of $R^{2}$ that is explained by both upside and downside variance premiums. The model is introduced in Section 4 . 

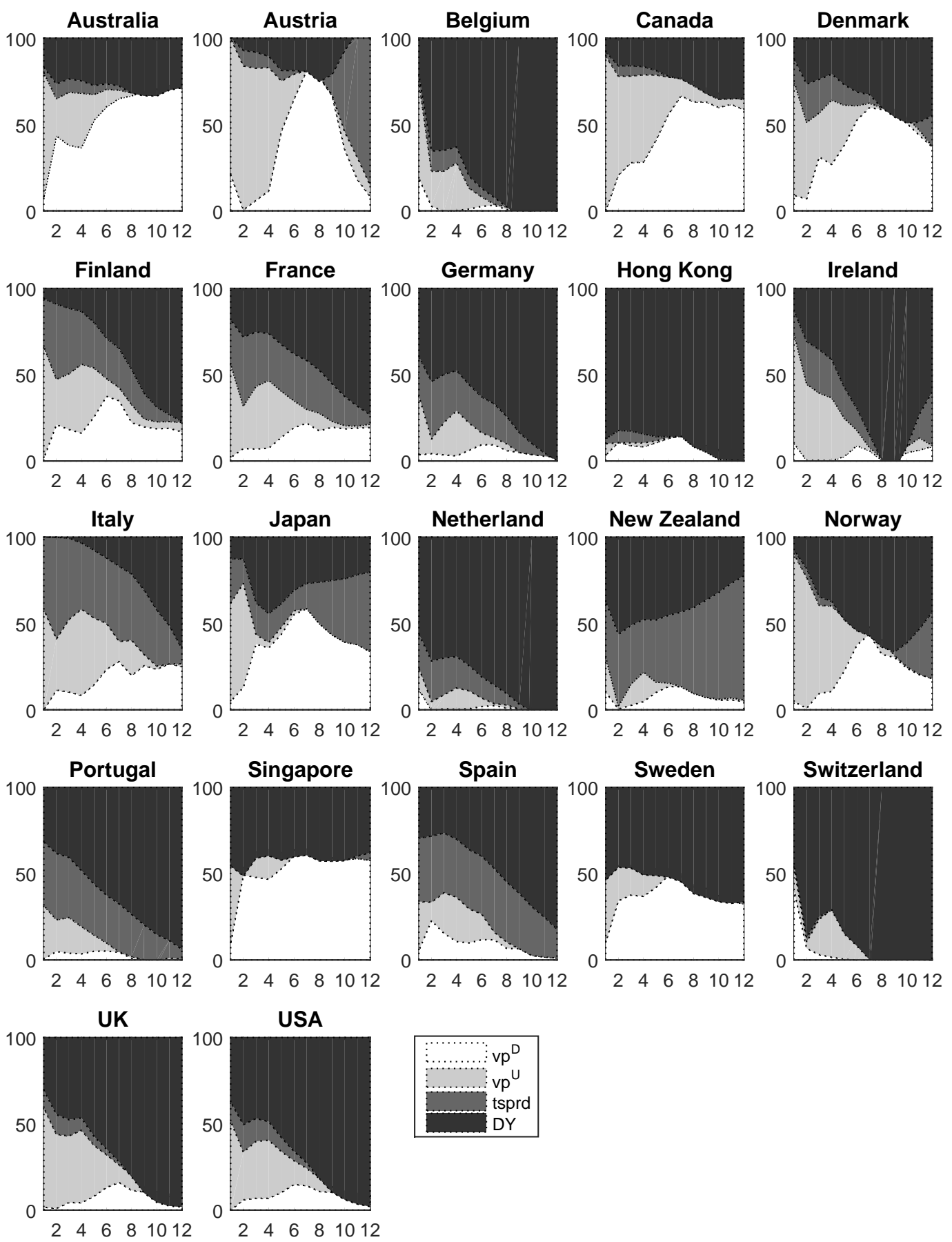

Figure 10: Variance decomposition among the four predictors in model (3)

The figure shows the proportion of $R^{2}$ explained by each of the predictors in model (3), the country-level model with DVP $\left(v p^{D}\right)$, UVP $\left(v p^{U}\right)$, the term spread $(t s p r)$, and the dividend yield $(D Y)$. The model is introduced in Section 4 . 


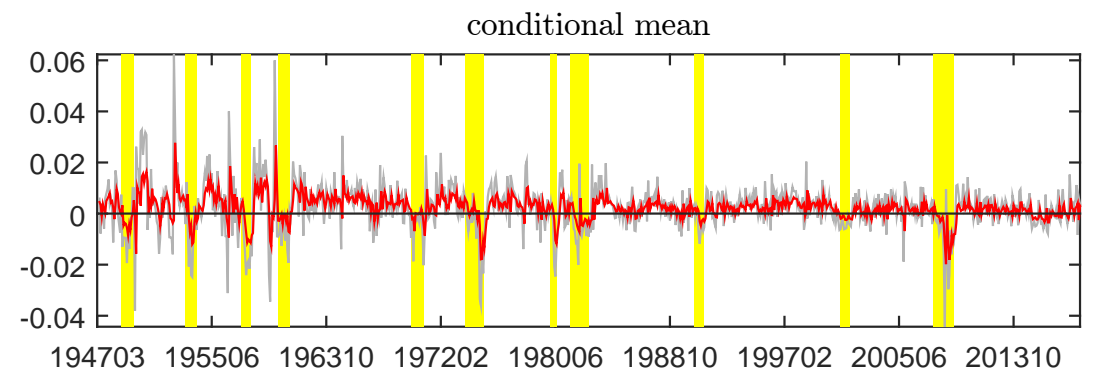

Real economic upside uncertainty

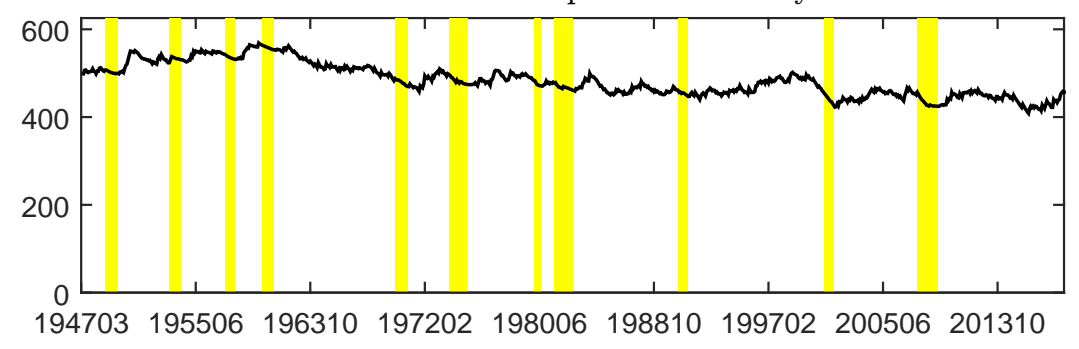

Real economic downside uncertainty

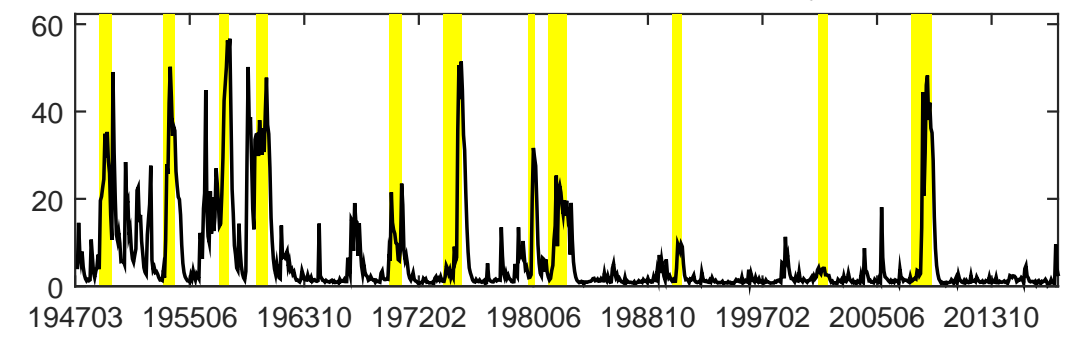

Figure 11: Conditional mean of real growth and real economic upside and downside uncertainties

This figure shows the time series of the estimate of the conditional mean of real economic growth $\left(\theta_{t}\right)$ and the upside and downside real economic uncertainty $\left(\theta p_{t}\right.$ and $\left.\theta n_{t}\right)$ as shown in Table 9 . Shaded regions indicate NBER recessions. 

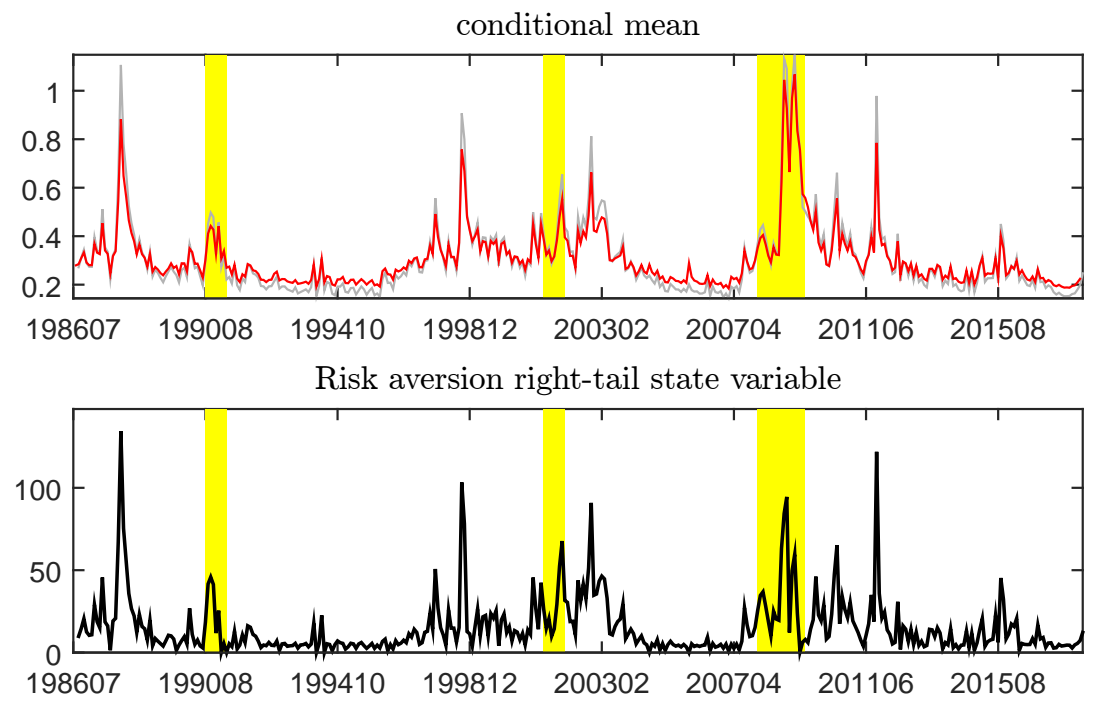

Risk aversion left-tail state variable

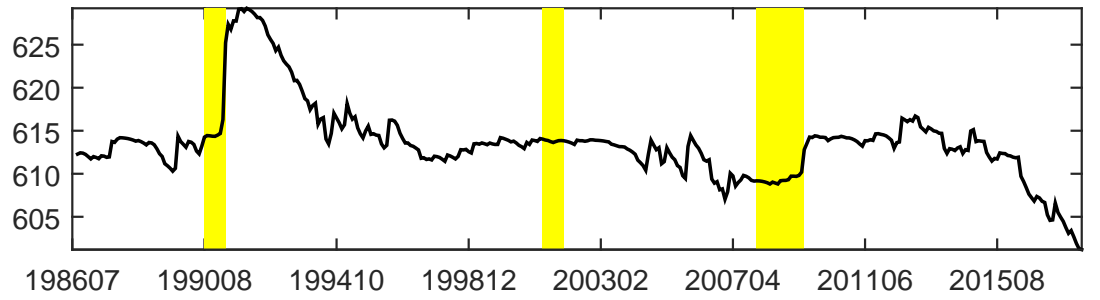

Figure 12: Conditional mean of risk aversion and right- and left-tail risk aversion state variables

This figure shows the time series of the estimate of the conditional mean of risk aversion $\left(q_{t}\right)$ and the right- and left-tail risk aversion state variables $\left(q p_{t}\right.$ and $\left.q n_{t}\right)$ as shown in Table 10 . Shaded regions indicate NBER recessions. 

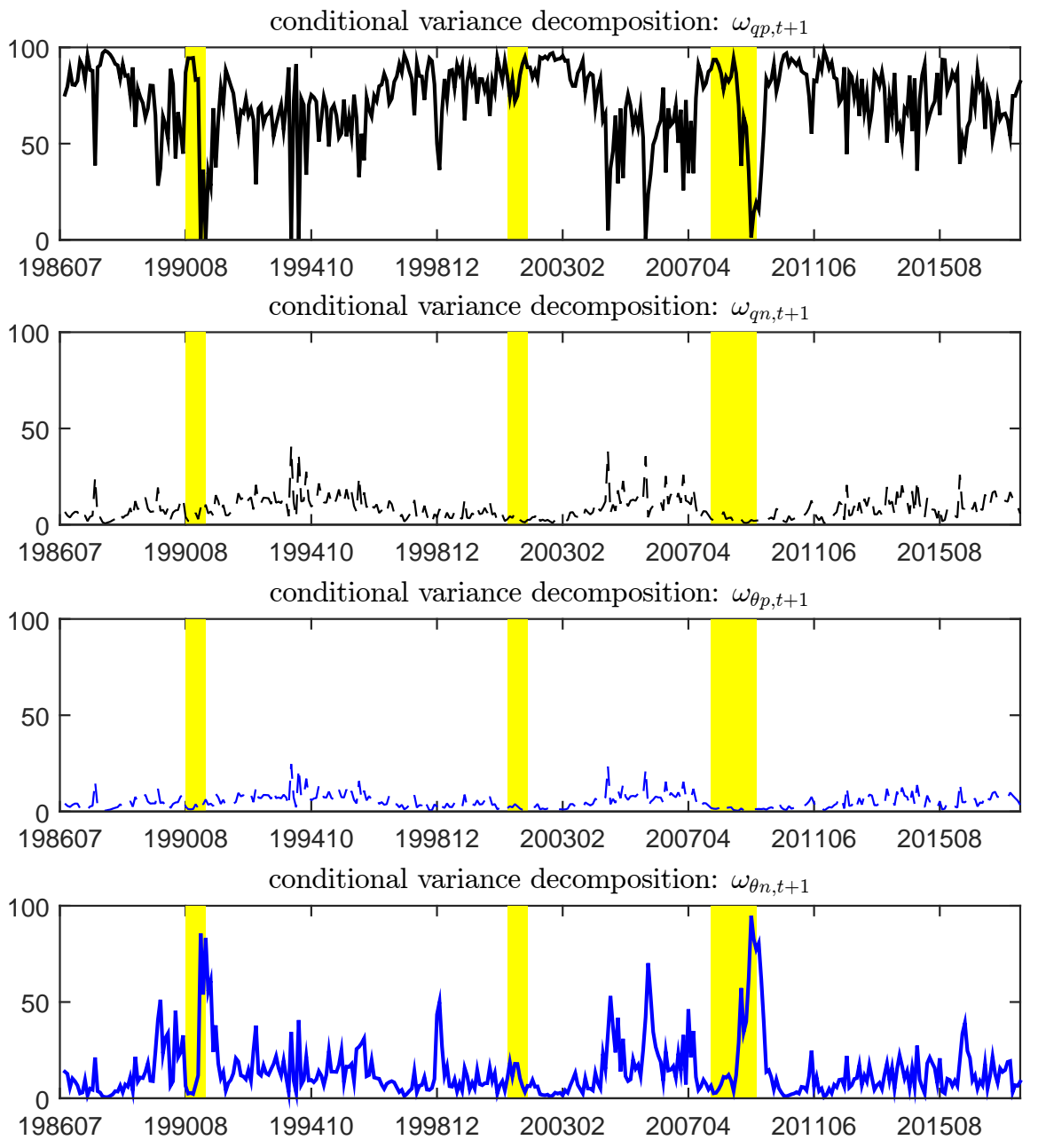

Figure 13: Variance decomposition of the conditional variance of total risk aversion $q_{t+1}$ Shaded regions indicate NBER recessions. 

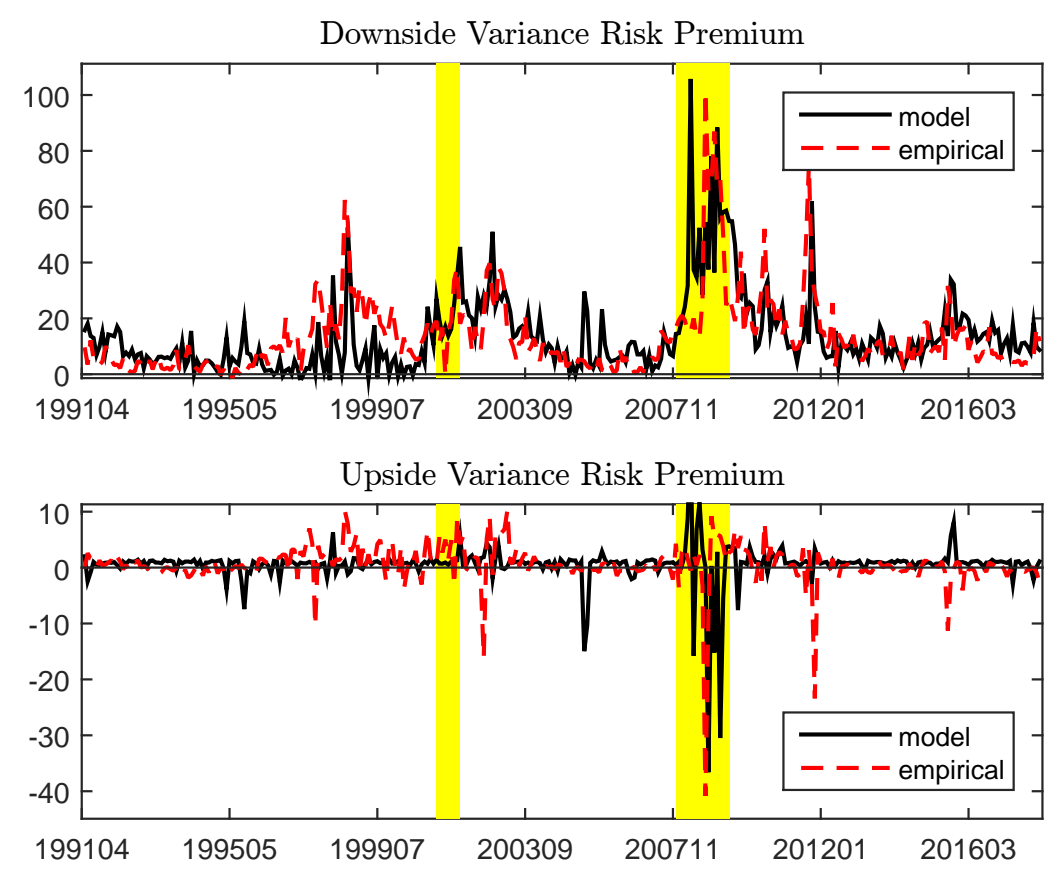

Figure 14: Model-implied and empirical variance risk premium components under a timevarying loading model

Shaded regions indicate NBER recessions. 
Total Variance Risk Premium: time-varying loadings

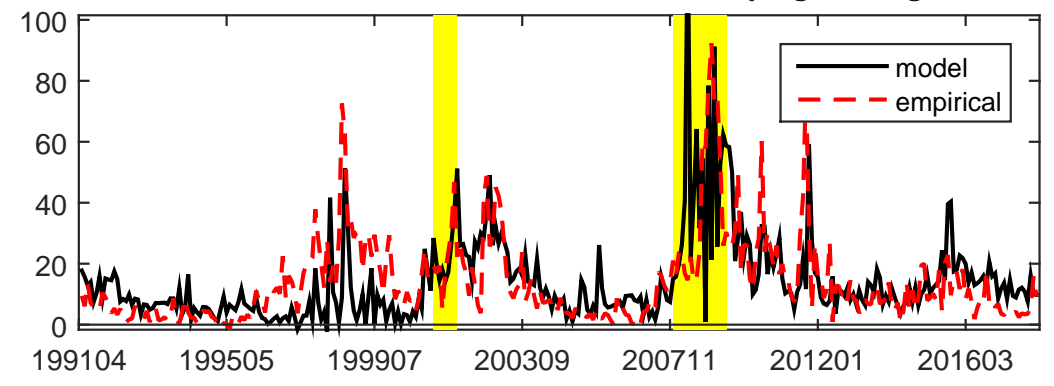

Figure 15: Model-implied and empirical total variance risk premium under the timevarying loading model

The correlation between the two lines is $47.10 \%$. Shaded regions indicate NBER recessions. 

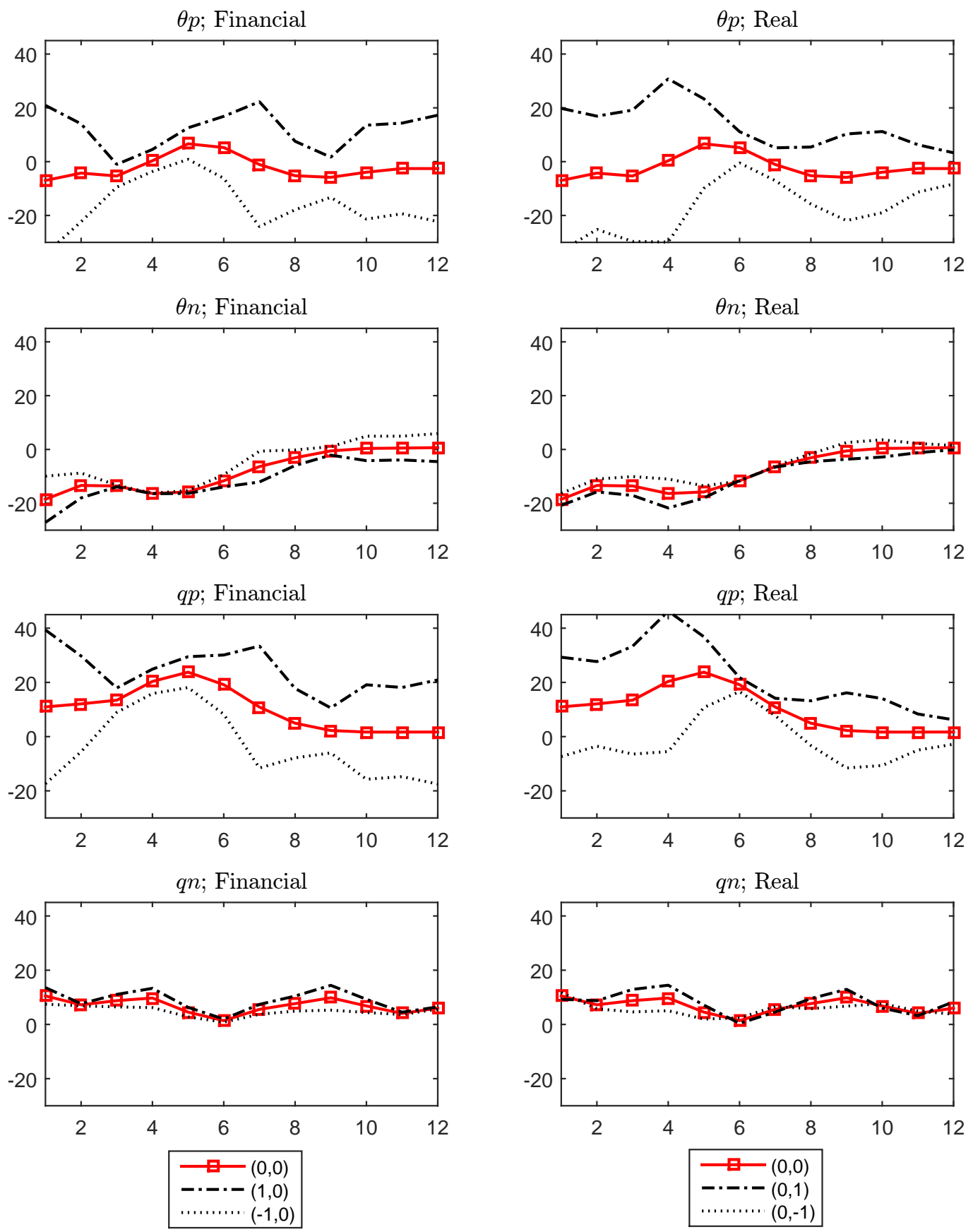

Figure 16: Relative economic magnitudes of equity risk premium loadings on premium state variables

This figure shows the relative economic magnitudes of the loadings of the premium state variables on the equity premium at different horizons for countries with different integration characteristics. In particular, we show the loadings for an average country $(0,0)$ (the red lines with squares, which are the same for the panels to the right and to the left). We show the effect on loadings of changes in the financial channel proxied by $\pm 1 \mathrm{SD}$ of the trade-to-GDP ratio (left panels) and the effect of changes in the real channel proxied by $\pm 1 \mathrm{SD}$ of the credit-to-GDP ratio (right panels). As an example, the relative magnitude of the $q p$ loading is $\left[v_{q p, h, 0}+v_{q p, h, 2} E\left(z_{t}\right)\right] \times S D\left(q p_{t}\right)$ at $(0,0)$,

$\left[v_{q p, h, 0}+v_{q p, h, 1, \text { Trade }}+v_{q p, h, 2} E\left(z_{t}\right)\right] \times S D\left(q p_{t}\right)$ at $(1,0)$, and

$\left[v_{q p, h, 0}+v_{q p, h, 1, C r e d i t}+v_{q p, h, 2} * E\left(z_{t}\right)\right] \times S D\left(q p_{t}\right)$ at $(0,1)$. Using $\max \left(z_{t}\right) \operatorname{ormin}\left(z_{t}\right)$ instead of $E\left(z_{t}\right)$ does not affect the curve values until the second decimal point. 
ERP loadings on two countercyclical state variabels, $\theta_{n}$ and $q_{p}$

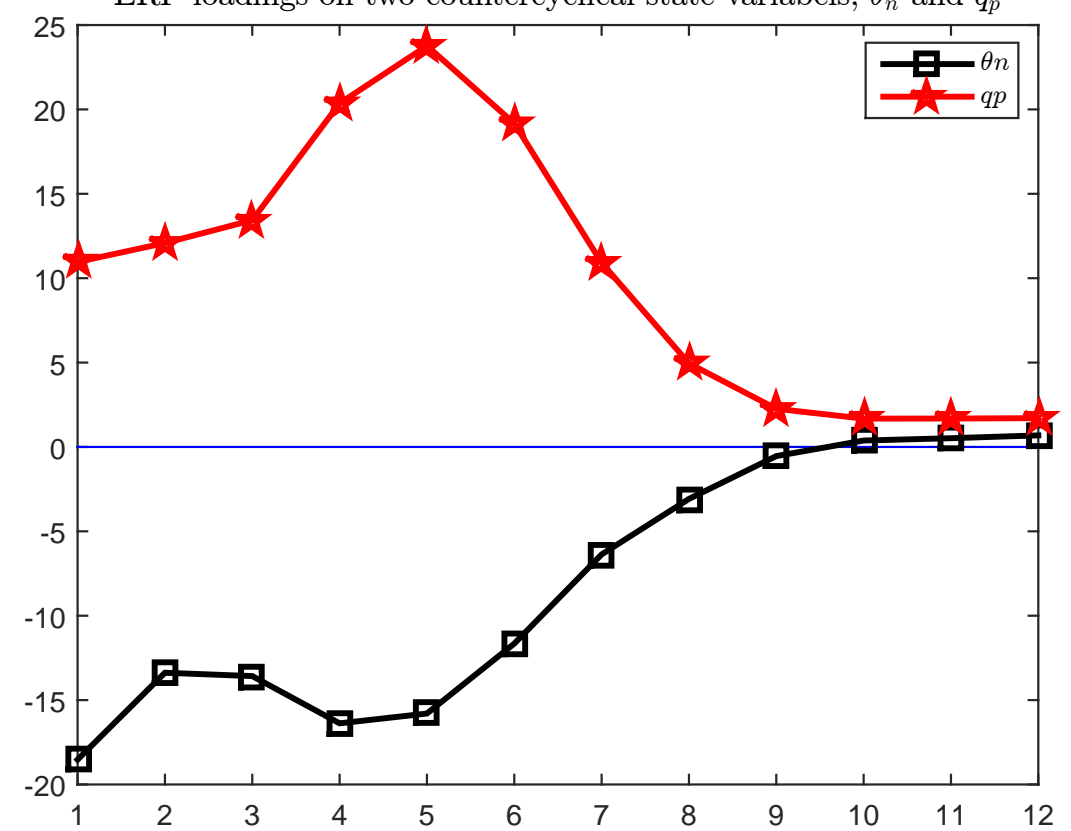

Figure 17: Economic magnitudes of equity risk premium loadings on two countercyclical state variables

The figure shows the loadings of the real economic uncertainty and total risk aversion state variables on the equity risk premium of an "average" country $(0,0)$ at all within-one-year horizons. 